University of Tennessee Health Science Center

UTHSC Digital Commons

\title{
Preclinical Study of Potential Antiglioma Novel Tetrahydroisoquinoline Analogs: Pharmacokinetics and Mechanism of Action
}

Fei Ma

University of Tennessee Health Science Center

Follow this and additional works at: https://dc.uthsc.edu/dissertations

Part of the Medicinal and Pharmaceutical Chemistry Commons, and the Pharmaceutics and Drug Design Commons

\section{Recommended Citation}

Ma, Fei , "Preclinical Study of Potential Antiglioma Novel Tetrahydroisoquinoline Analogs:

Pharmacokinetics and Mechanism of Action" (2012). Theses and Dissertations (ETD). Paper 362.

http://dx.doi.org/10.21007/etd.cghs.2012.0191.

This Dissertation is brought to you for free and open access by the College of Graduate Health Sciences at UTHSC Digital Commons. It has been accepted for inclusion in Theses and Dissertations (ETD) by an authorized administrator of UTHSC Digital Commons. For more information, please contact jwelch30@uthsc.edu. 


\title{
Preclinical Study of Potential Antiglioma Novel Tetrahydroisoquinoline Analogs: Pharmacokinetics and Mechanism of Action
}

\begin{abstract}
Gliomas, the tumors of glial cells, account for $80 \%$ of primary malignant brain tumors. In 2011 , there were about 18,300 new cases of maligant gliomas in the United States alone. Patients with glioblastoma multiforme or anaplastic astrocytoma, the two major types of malignant gliomas, have a median survival of 14 months or 2 to 3 years, respectively. Therefore novel treatments for malignant glioma are urgently needed.

A novel series of tetrahydroisoquinoline derivatives with antiglioma activity has been undergoing drug metabolism/pharmacokinetics (DMPK)-guided lead optimization. EDL-291 was result from structure modification of last generation compound EDL-155. Its preclinical pharmacokinetics were characterized in this dissertation project. In male Sprague Daley (SD) rats, after $10 \mathrm{mg} / \mathrm{kg}$ intravenous injection, total body clearance (CL) of EDL-291 was $209 \mathrm{~mL} / \mathrm{min} / \mathrm{kg}$ (CV 23.7\%), 39\% lower than EDL-155 but still much higher than rat liver blood flow. 1.2\% of dosed EDL-291 was found in urine (fe) over the $24 \mathrm{hr}$ post-dose period. EDL-291 is stable in whole blood, not accumulated in red blood cells, but susceptible to pulmonary microsomal metabolism. Thus, extensive lung metabolism is the major contributor of the high $\mathrm{CL}$ value. The volume of distribution of EDL-291 at steady state (Vdss) in SD rats was $32.5 \mathrm{~L} / \mathrm{kg}$ (CV $46.6 \%)$. The ratio of the EDL-291 brain area under concentration curve (AUC) to plasma AUC between 20 - 180 min after intravenous injection was 14.0. The brain/plasma AUC ratio at $10-180 \mathrm{~min}$ after $50 \mathrm{mg} / \mathrm{kg}$ subcutaneous injection to C57BL/6J mice was 4.07. The bioavailability (F) of EDL-291 after $40 \mathrm{mg} / \mathrm{kg}$ oral gavage in SD rats was $40.4 \%$. Attempts to reduce pulmonary metabolism led to the discovery of EDL-323, which had a dramatically reduced clearance compared to EDL-291. However, the brain penetration of EDL-323 was significantly lower than EDL-291. Thus, further structural modifications are required to achieve both reduced clearance and enhanced brain penetration.

Antigloma activity of EDL compounds was discovered in phenotype screening. A preliminary evaluation of the effect of EDL-291 on human glioma cell apoptosis machinery was conducted as part of the effort to elucidate its mechanism of action. After EDL-291 treatment, active caspase-3 and the amount of cleaved PARP were increased in both U87MG and U-251 cells. In addition, the antiproliferative effect of EDL-291 was partially reversed by a caspase-3/7 inhibitor. However, neither the caspase-8 inhibitor nor caspase-9 inhibitor reversed the apoptotic effect of EDL-291. Decylubiquinone (dUb) can enhance caspase-3 activation as well as antiproliferative effect caused by EDL-291 treatment. Therefore, dUb could be a candidate companion drug of EDL-291 analogs in treating glioma.
\end{abstract}

\section{Document Type}

Dissertation

\section{Degree Name}

Doctor of Philosophy (PhD)

\section{Program}

Pharmaceutical Sciences

\section{Research Advisor}

Charles Ryan Yates, Pharm. D., Ph.D. 


\section{Keywords}

Apoptosis, Decylubiquinone, EDL-291, Glioma, Pharmacokinetics, Tetrahydroisoquinoline

\section{Subject Categories}

Medicinal and Pharmaceutical Chemistry | Medicine and Health Sciences | Pharmaceutics and Drug Design | Pharmacy and Pharmaceutical Sciences

\section{Comments}

Two year embargo expired May 2014 


\title{
Preclinical Study of Potential Antiglioma Novel Tetrahydroisoquinoline Analogs: Pharmacokinetics and Mechanism of Action
}

\author{
A Dissertation \\ Presented for \\ The Graduate Studies Council \\ The University of Tennessee \\ Health Science Center
}

\author{
In Partial Fulfillment \\ Of the Requirements for the Degree \\ Doctor of Philosophy \\ From The University of Tennessee
}

By

Fei Ma

May 2012 
Copyright (C) 2012 by Fei Ma. All rights reserved. 


\section{DEDICATION}

I dedicate this dissertation to my parents,

Zheng Ma and Shuxiang Lei, and to my wife and son,

Fan Zhang and Alexander Zhang Ma. 


\section{ACKNOWLEDGEMENTS}

I would like to acknowledge all those who supported and helped me during my Ph.D. training. First and foremost, I would like to express my deepest gratitude to my advisor, Dr. Charles Ryan Yates, for giving me the opportunity to develop my Ph.D. project in his lab, for his constant guidance, support, and encouragement. I sincerely appreciate Dr. Yates for all the knowledge I gained from him and all the help he gave me during my graduate studies.

I would also like to express gratitude to my other committee members: Dr. Bernd Meibohm, Dr. Duane D. Miller, Dr. Eldon E. Geisert, and Dr. Leonard Lothstein for serving on my committee and providing excellent suggestions and guidance throughout the projects.

In addition, I would like to thank Drs. Renukadevi Patil, Shivaputra A. Patil, and Igor Rakov in Dr. Miller's group for providing the compounds used in this study. Thanks go to Drs. Xiangdi Wang, Suchareeta Mitra, Mohamed A. Nassr, Xiaofei Wang, and Mr. William E. Orr in Dr. Geisert's group for their helps in imaging and some animal experiments. Thanks Drs. Nageshwar Budha, Lisa Tang, Yi Zhang, Hari Desu, Kui Zeng, Wen Qu, Chaoju Xiao, and Jin Xu for various assistances I received from them.

Further, I want to thank each member and friend in the Yates' laboratory - both previous and current lab members - Drs. Pengfei Song, Shen Li, Suma Ramagir, Leslie Stuart, Karin Thompson, Hari Kosanam, and Ms. Lizhi Sun for their friendship and help.

Finally, I extend deep thanks to my parents, my wife, and my parents-in-law for their love and support.

Thank you to all of those who helped me throughout my project whose name may not be listed here.

This research was financially supported by The University of Tennessee College of Pharmacy and ED Laboratories, Inc. 


\begin{abstract}
Gliomas, the tumors of glial cells, account for $80 \%$ of primary malignant brain tumors. In 2011, there were about 18,300 new cases of maligant gliomas in the United States alone. Patients with glioblastoma multiforme or anaplastic astrocytoma, the two major types of malignant gliomas, have a median survival of 14 months or 2 to 3 years, respectively. Therefore novel treatments for malignant glioma are urgently needed.

A novel series of tetrahydroisoquinoline derivatives with antiglioma activity has been undergoing drug metabolism/pharmacokinetics (DMPK)-guided lead optimization. EDL-291 was result from structure modification of last generation compound EDL-155. Its preclinical pharmacokinetics were characterized in this dissertation project. In male Sprague Daley (SD) rats, after $10 \mathrm{mg} / \mathrm{kg}$ intravenous injection, total body clearance (CL) of EDL-291 was $209 \mathrm{~mL} / \mathrm{min} / \mathrm{kg}$ (CV 23.7\%), 39\% lower than EDL-155 but still much higher than rat liver blood flow. 1.2\% of dosed EDL-291 was found in urine $\left(\mathrm{f}_{\mathrm{e}}\right)$ over the $24 \mathrm{hr}$ post-dose period. EDL-291 is stable in whole blood, not accumulated in red blood cells, but susceptible to pulmonary microsomal metabolism. Thus, extensive lung metabolism is the major contributor of the high CL value. The volume of distribution of EDL-291 at steady state $\left(\mathrm{Vd}_{\mathrm{ss}}\right)$ in $\mathrm{SD}$ rats was $32.5 \mathrm{~L} / \mathrm{kg}(\mathrm{CV} 46.6 \%)$. The ratio of the EDL-291 brain area under concentration curve (AUC) to plasma AUC between 20 - 180 min after intravenous injection was 14.0. The brain/plasma AUC ratio at $10-180 \mathrm{~min}$ after $50 \mathrm{mg} / \mathrm{kg}$ subcutaneous injection to $\mathrm{C} 57 \mathrm{BL} / 6 \mathrm{~J}$ mice was 4.07 . The bioavailability (F) of EDL-291 after $40 \mathrm{mg} / \mathrm{kg}$ oral gavage in SD rats was $40.4 \%$. Attempts to reduce pulmonary metabolism led to the discovery of EDL-323, which had a dramatically reduced clearance compared to EDL-291. However, the brain penetration of EDL-323 was significantly lower than EDL-291. Thus, further structural modifications are required to achieve both reduced clearance and enhanced brain penetration.

Antigloma activity of EDL compounds was discovered in phenotype screening. A preliminary evaluation of the effect of EDL-291 on human glioma cell apoptosis machinery was conducted as part of the effort to elucidate its mechanism of action. After EDL-291 treatment, active caspase-3 and the amount of cleaved PARP were increased in both U87MG and U-251 cells. In addition, the antiproliferative effect of EDL-291 was partially reversed by a caspase-3/7 inhibitor. However, neither the caspase- 8 inhibitor nor caspase-9 inhibitor reversed the apoptotic effect of EDL-291. Decylubiquinone (dUb) can enhance caspase-3 activation as well as antiproliferative effect caused by EDL-291 treatment. Therefore, dUb could be a candidate companion drug of EDL-291 analogs in treating glioma.
\end{abstract}




\section{TABLE OF CONTENTS}

CHAPTER 1. INTRODUCTION .....................................................................................

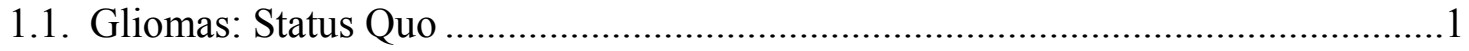

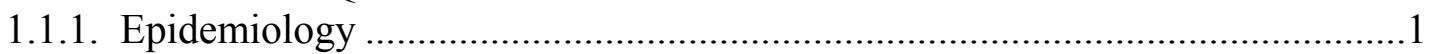

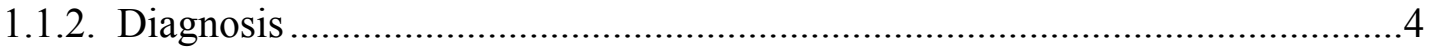

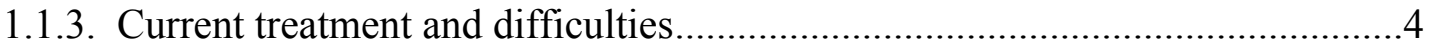

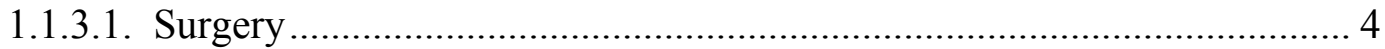

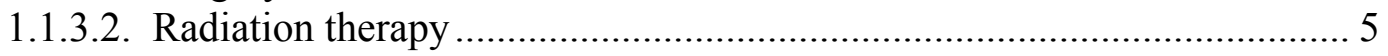

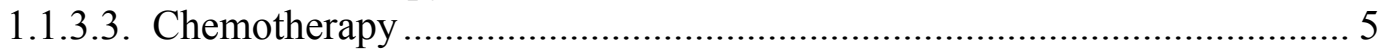

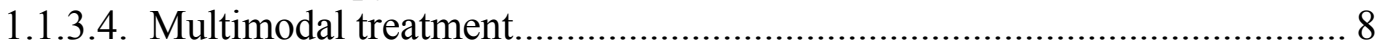

1.2. Pharmacokinetics Considerations in Antiglioma Drug Discovery and

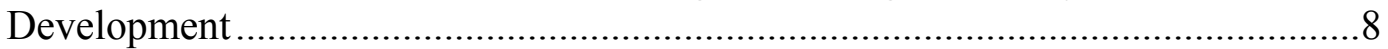

1.2.1. Role of pharmacokinetics in drug discovery and development ...................... 8

1.2.2. A major challenge for antiglioma chemotherapy: the blood-brain barrier........8

1.2.3. Strategies for enhancing brain penetration of antiglioma drugs.....................11

1.2.3.1. Circumventing BBB by local administration....................................... 11

1.2.3.1.1. Intracerebroventricular or intracavitary injection. ....................... 11

1.2.3.1.2. Impregnated polymer implantation........................................... 12

1.2.3.1.3. Convention-enhanced delivery. ................................................. 12

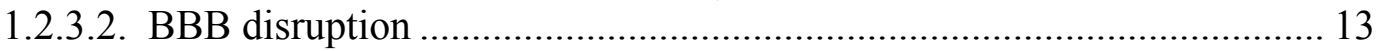

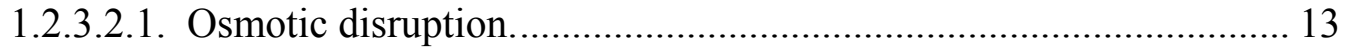

1.2.3.2.2. MRI-guided ultrasound disruption............................................ 14

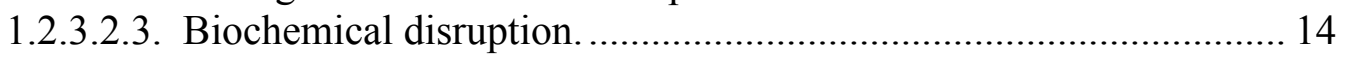

1.2.3.3. Inhibition of drug efflux transporters.............................................. 14

1.2.3.4. Taking advantage of BBB carriers and transporters ........................... 15

1.2.3.5. Passive diffusion enhancement by drug structure modification ............. 15

1.2.4. Physiochemical characteristics of successful CNS drugs .............................16

1.2.5. Overview of DMPK of last generation of EDL compounds ........................17

1.3. Background for Mechanism of Action Study ..................................................19

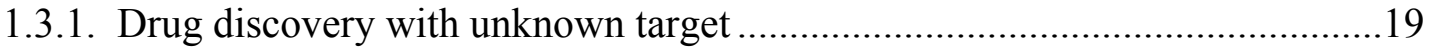

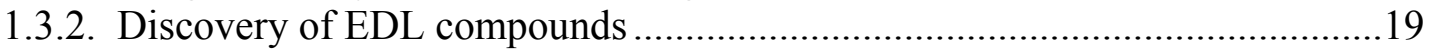

1.3.3. Cell death pathways induced by chemotherapy .......................................20

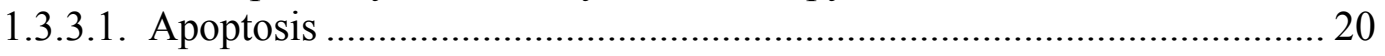

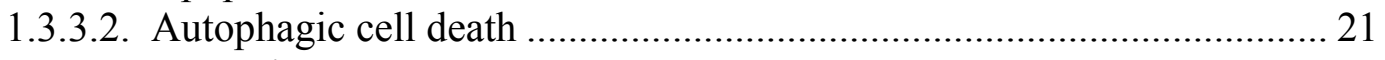

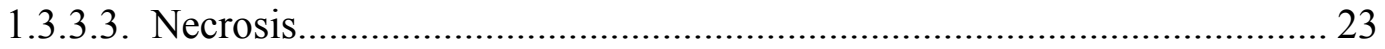

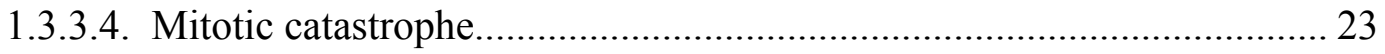

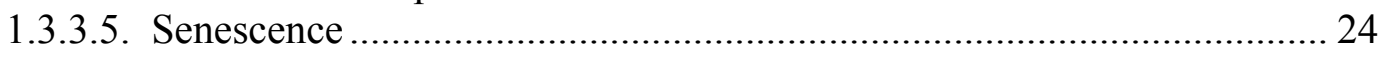

CHAPTER 2. PHARMACOKINETICS OF EDL-291 .........................................25

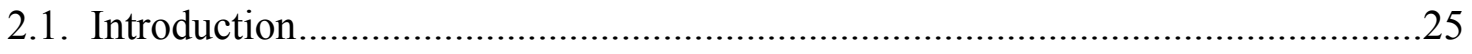

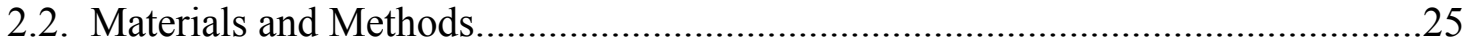

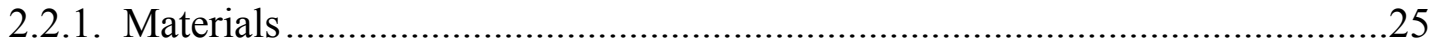

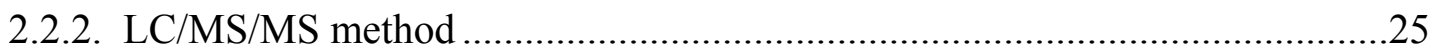

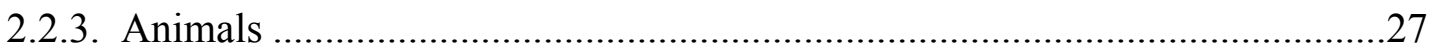




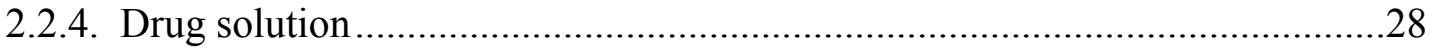

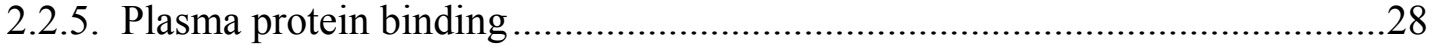

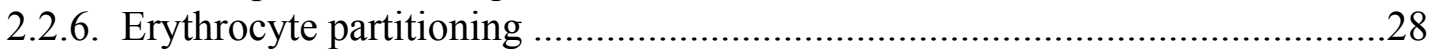

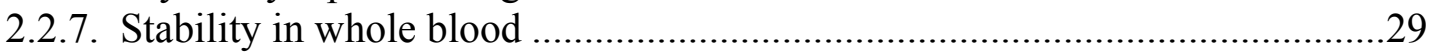

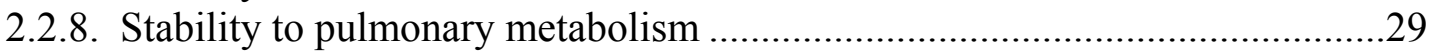

2.2.9. Pharmacokinetic sampling and processing ..................................................30

2.2.9.1. Peripheral pharmacokinetics .............................................................. 30

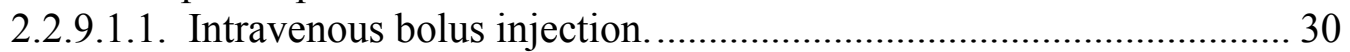

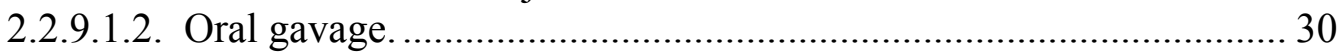

2.2.9.2. CNS pharmacokinetics........................................................................ 30

2.2.9.2.1. Rat intravenous bolus injection.................................................... 30

2.2.9.2.2. Mouse subcutaneous injection .......................................................... 30

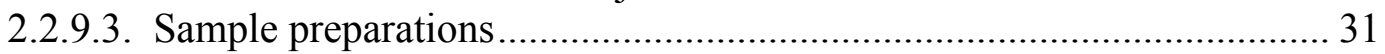

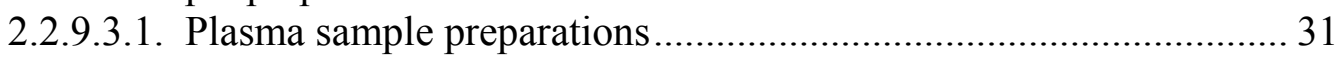

2.2.9.3.2. Feces sample preparations …………………………................... 31

2.2.9.3.3. Urine sample preparations …………………………………..... 31

2.2.9.3.4. Brain sample preparations ………………….............................. 31

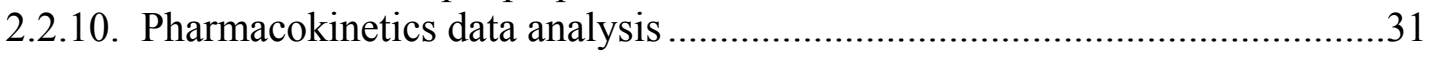

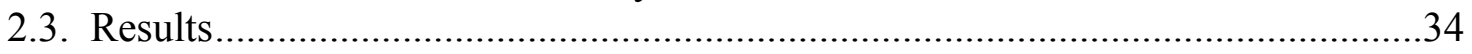

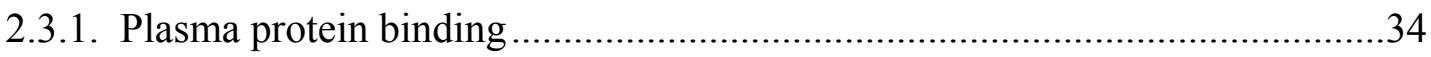

2.3.2. Erythrocyte partitioning ……………………..........................................34

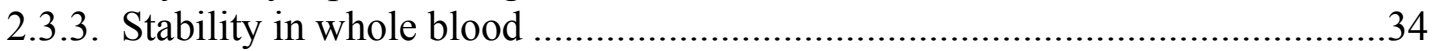

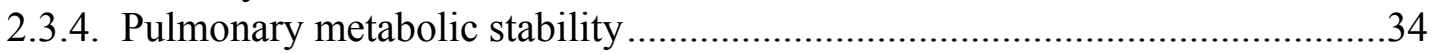

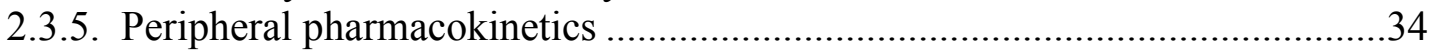

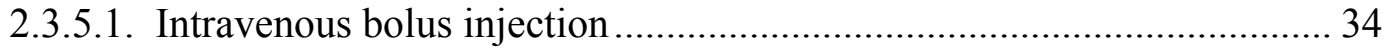

2.3.5.2. Oral gavage ..................................................................................... 39

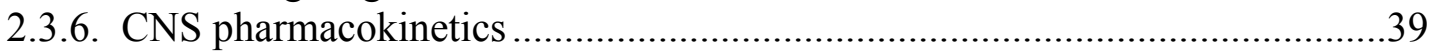

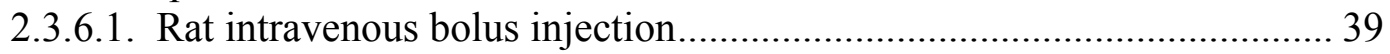

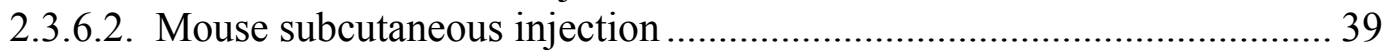

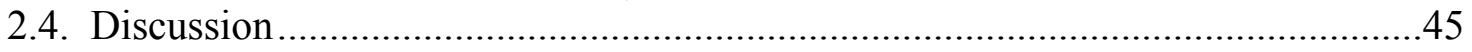

CHAPTER 3. PHARMACOKINETICS OF EDL-323 ....................................................48

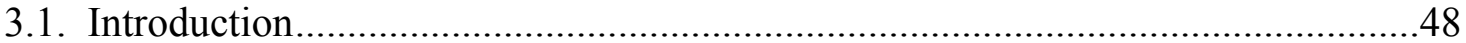

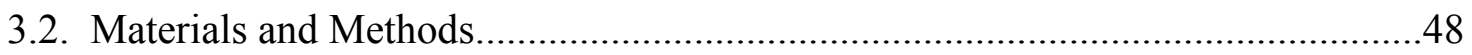

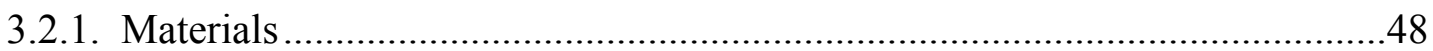

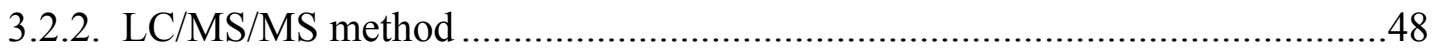

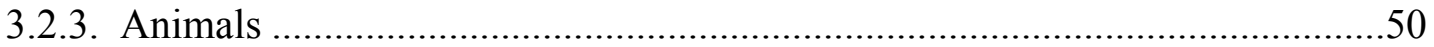

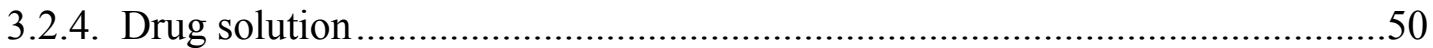

3.2.5. Pharmacokinetic sampling and processing ....................................................50

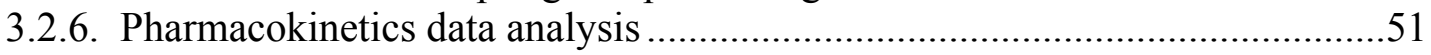

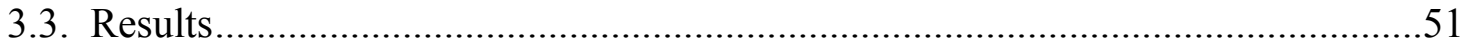

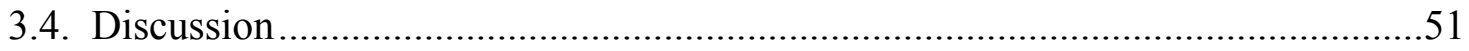

CHAPTER 4. MECHANISM OF ACTION STUDY OF EDL-291 ..............................53

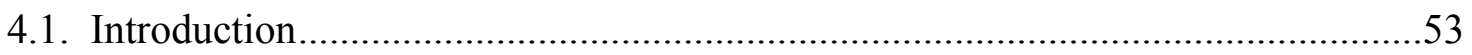

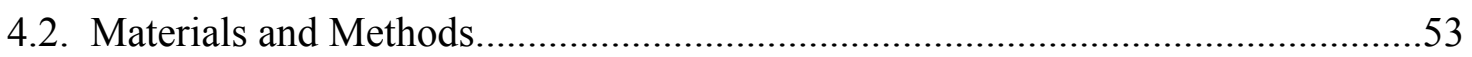


4.2.1. Cell cultures

4.2.2. Cell proliferation assay with caspase inhibitors or mitochondrial permeability transition (MPT) inhibitors

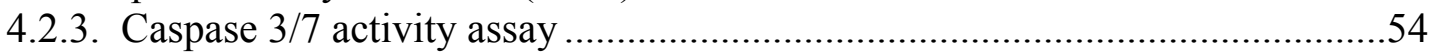

4.2.4. Luminex assay of activated caspase-3 and poly (ADP-ribose) polymerase (PARP)

4.2.5. Phase contrast and fluorescence microscopy ………....................................55

4.2.6. Terminal deoxynucleotidyl transferase dUTP nick end labeling (TUNEL)

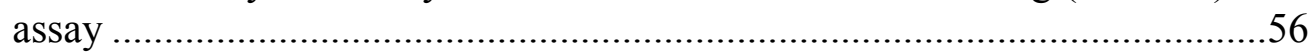

4.3. Results

4.3.1. Effect of caspase inhibitor

4.3.2. Effector caspase activation.

4.3.3. Cell and nucleus morphology ………………..........................................56

4.3.4. DNA fragmentation............................................................................64

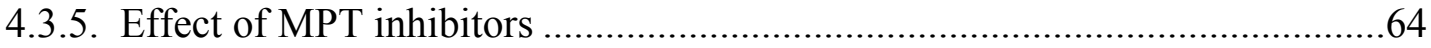

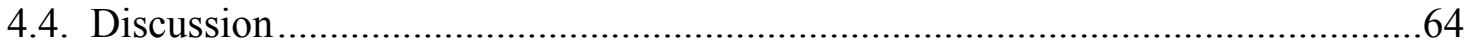

CHAPTER 5. SUMMARY.................................................................................................72

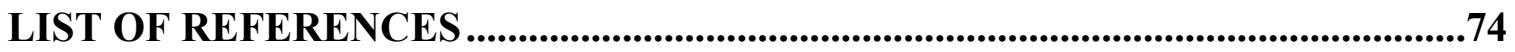

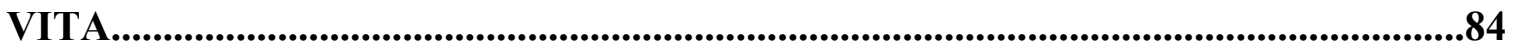




\section{LIST OF TABLES}

Table 1-1. Primary malignant brain and CNS tumor incidence and mortality rates in 2008 (age-standardized, per 100,000 person-years) ...................................2

Table 1-2. Guideline for the management of newly diagnosed glioblastoma .................9

Table 2-1. Percentage of parent compounds remaining after $2 \mathrm{hr}$ incubation with rat pulmonary microsomes ........................................................................36

Table 2-2. Pharmacokinetic parameters of EDL-291 in male SD rats after intravenous bolus injection.

Table 2-3. Pharmacokinetic parameters of EDL-291 in male SD rats after oral gavage

Table 3-1. Pharmacokinetic parameters of EDL-323 in male SD rats after intravenous bolus injection. 


\section{LIST OF FIGURES}

Figure 1-1. Distribution of gliomas by histology subtypes ............................................

Figure 1-2. Structure and selected physiochemical properties of EDL-155 ....................18

Figure 2-1. Structure and selected physiochemical properties of EDL-291 ....................26

Figure 2-2. Three-compartment user-defined model for simultaneous fitting of plasma and brain concentration of EDL-291 after intravenous bolus injection

Figure 2-3. WinNonlin codes for the three-compartment user-defined model in

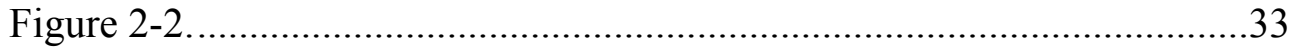

Figure 2-4. Erythrocyte partitioning of EDL-291 and EDL-155 .....................................35

Figure 2-5. Stability of EDL-291 and EDL-155 in whole rat blood ................................35

Figure 2-6. Plasma concentration-time profile in SD rats after $10 \mathrm{mg} / \mathrm{kg}$ intravenous bolus injection or $40 \mathrm{mg} / \mathrm{kg}$ oral gavage of EDL-291 ................................37

Figure 2-7. Metabolites of EDL-291 in rat plasma and feces...........................................40

Figure 2-8. Brain and plasma concentration-time profile after $10 \mathrm{mg} / \mathrm{kg}$ intravenous bolus injection to SD rats

Figure 2-9. Simultaneous fitting of rat brain and plasma concentration after 10 $\mathrm{mg} / \mathrm{kg}$ intravenous bolus injection to the three-compartment user-defined model

Figure 2-10. Brain and plasma concentration-time profile after $50 \mathrm{mg} / \mathrm{kg}$ subcutaneous injection to mice

Figure 2-11. The usual relationship between total body clearance (CL), hepatic clearance $\left(\mathrm{CL}_{h}\right)$, renal clearance $\left(\mathrm{CL}_{\mathrm{r}}\right)$, and liver blood flow $\left(\mathrm{Q}_{\mathrm{h}}\right)$.....

Figure 3-1. Structure and selected physiochemical properties of EDL-323

Figure 3-2. Plasma concentration-time profile after $10 \mathrm{mg} / \mathrm{kg}$ intravenous bolus injection of EDL-323

Figure 4-1. Antiproliferative effect of EDL-291 can be partially reversed by pan-caspase inhibitor (panel A) and caspase-3/7 inhibitor (panel B), but not by caspase- 8 and 9 inhibitors (panel C)

Figure 4-2. EDL-291 can increase caspase-3/7 activity in human glioblastoma cells ....60 
Figure 4-3. Increase of activated caspase-3 and its product, cleaved poly (ADP-ribose) polymerase (PARP) after EDL-291 treatment as measured by Luminex multiplex immunoassay

Figure 4-4. Cell morphology checked by phase contrast microscopy.............................62

Figure 4-5. Nucleus morphology checked by florescent microscopy after Hoescht staining

Figure 4-6. DNA fragmentation assay results from flow cytometric TUNEL .65

Figure 4-7. Antiproliferative effect of EDL-291 and caspase 3/7 activation can be enhanced, rather than reversed by decylubiquinone (dUb). .66

Figure 4-8. Apoptosis pathways and proposed model of EDL-291's effect in glioma

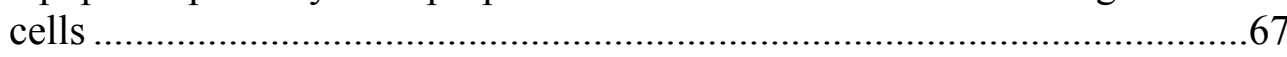

Figure 4-9. Chemical structures of decylubiquinone and embelin .69 


\section{CHAPTER 1. INTRODUCTION}

In 2011, there were more than 248,000 new cases of primary malignant brain tumors around the world [1], while about 22,000 new cases were in the United States [2]. About 182,000 people [1], including 13,000 Americans [2], died from primary malignant brain tumors each year. $80 \%$ of these tumors are gliomas, while glioblastoma (World Health Organization [WHO] grade IV) is the most common (Figure 1-1) and also the most malignant glioma [3]. Under the current standard of care, glioblastoma patients only have a 14 month life expectancy after diagnosis [4]. For patients with anaplastic astrocytoma (WHO grade III), another major type of malignant glioma, the life expectancy is somewhat longer (2-3 years) [5]. New treatment options for malignant gliomas are urgently needed.

\subsection{Gliomas: Status Quo}

\subsubsection{Epidemiology}

According to most recent CBTRUS (Central Brain Tumor Registry of the United States) report, incidence rate of primary brain tumors was 19.89 per 100,000 personyears in the USA (2004 - 2008) [3]. According to Surveillance, Epidemiology, and End Results (SEER) Cancer Statistics Review, the incidence rate of primary malignant brain tumors is 6.5 per 100,000 person-years in the USA, which suggests that about 22,340 new cases developed in 2011 [2]. The total number of primary malignant brain tumor deaths for the USA in 2011 is estimated to be 13,110 [2]. As shown in Table 1-1, both incidence and mortality rates of primary brain tumors in the USA are higher than the average world rates.

Gliomas (International Classification of Diseases for Oncology, 3rd Edition [ICD-O-3]: 9380-9384, 9391-9460, 9480) are tumors (Figure 1-1) that arise from different types of glial cells [3]. As a broad category, gliomas represent $80 \%$ of primary malignant brain tumors in the USA. Gliomas also account for 30\% of all primary brain tumors, which is only slightly less than meningioma (35\%). However, only $2 \%$ of meningioma is malignant, while $97 \%$ of gliomas are malignant [3]. Incidence rate of gliomas is 6.04 (5.87 for malignant gliomas) per 100,000 person-years in the USA, which suggest about 19,000 new cases in 2011 [3].

Based histology and presumed cell of origin, gliomas can be subdivided into glioblastoma, astrocytoma, oligodendroglioma, ependymoma, and a few more rare tumors [3]. When these subtypes are counted separately, glioblastoma is the second most common primary brain tumors, the most common primary malignant brain tumor, and also most common glioma subtype (53.9\%) [3]. Incidence rate of glioblastoma was 3.20 per 100,000 person-years in the USA, which suggests about 10,000 new cases in 2011. 


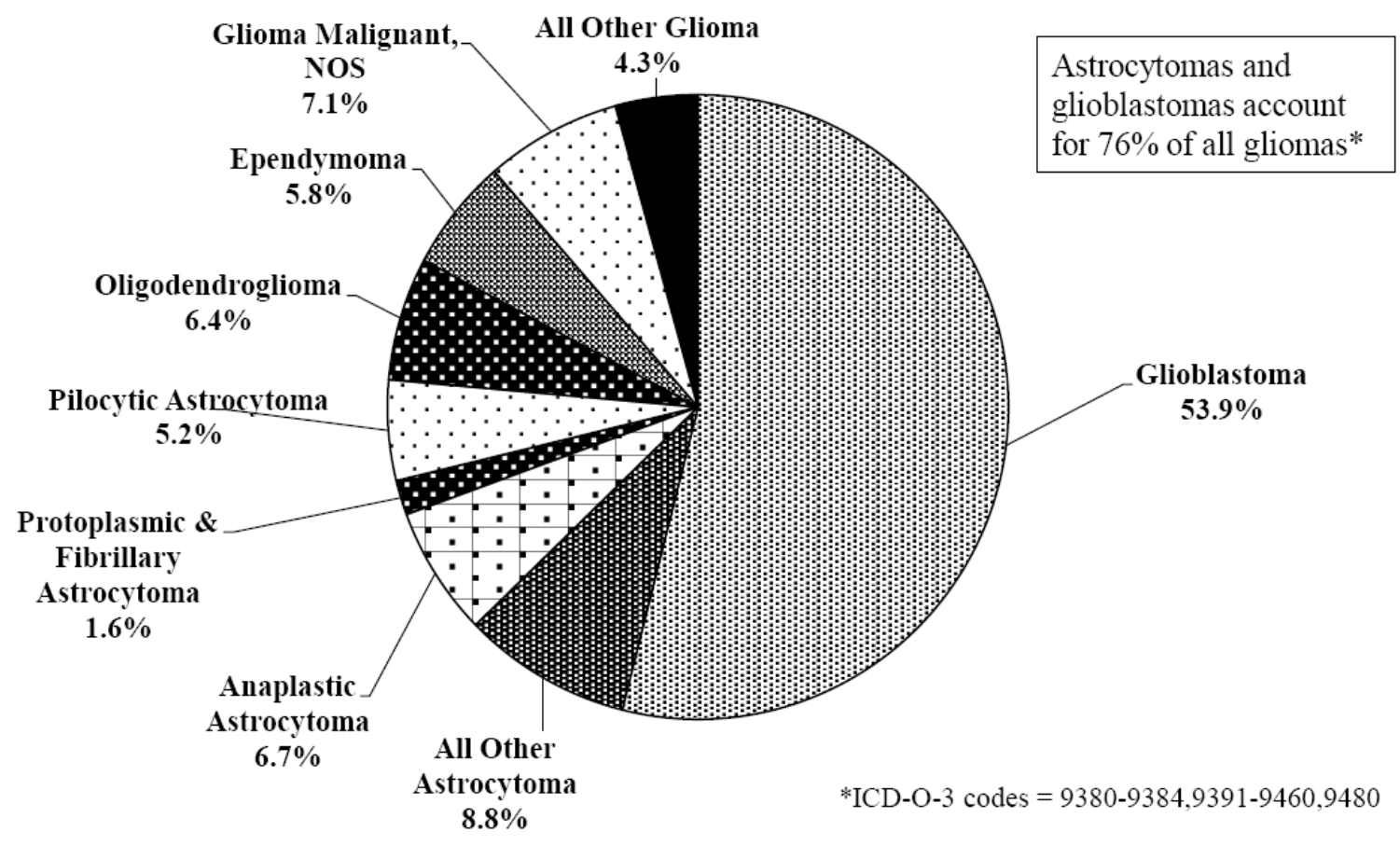

Figure 1-1. Distribution of gliomas by histology subtypes

Reprinted from "CBTRUS Statistical Report: Primary Brain and Central Nervous System Tumors Diagnosed in the United States in 2004-2008." Source: Central Brain Tumor Registry of the United States (Hinsdale, IL). Available from: http://www.cbtrus.org/ reports/reports.html [accessed March 12, 2012]. (No permission needed.)

Table 1-1. Primary malignant brain and CNS tumor incidence and mortality rates in 2008 (age-standardized, per 100,000 person-years)

\begin{tabular}{cccccc}
\hline \multirow{2}{*}{ Gender } & \multicolumn{2}{c}{ Incidence rates } & & \multicolumn{2}{c}{ Mortality rates } \\
\cline { 2 - 3 } \cline { 5 - 6 } & World & USA & & World & USA \\
\hline Male & 3.8 & 7.6 & & 2.9 & 5.3 \\
Female & 3.1 & 5.2 & & 2.2 & 3.5 \\
Both & 3.5 & 6.3 & & 2.5 & 4.3 \\
\hline
\end{tabular}

Sources: Ferlay J, et al., GLOBOCAN 2008 v2.0, cancer incidence and mortality worldwide: IARC CancerBase No. 10 [Internet]. Lyon (France): International Agency for Research on Cancer, 2010. Available from: http://globocan.iarc.fr [accessed Janary 1, 2012]. And Howlader N, et al., SEER cancer statistics review, 1975-2008 [Internet]. Bethesda (MD): National Cancer Institute (USA), 2011. Available from: http://seer.cancer.gov/csr/1975_2008/[accessed Janary 1, 2012]. 
When combined together, astrocytomas and glioblastoma account for $76 \%$ of gliomas [3].

A wide variety of factors have been reported to be associated with elevated glioma risk [6]. According to the 2008 consensus from the epidemiologists in Brain Tumor Epidemiology Consortium (BTEC) [7], most well-established glioma risk factors include aging, ionizing radiation exposure and certain rare hereditary syndromes. The incidence rates of adult glioma increase with older age until age 80 [8]. Data compiled by CBTRUS shows the incidence rates of glioma in different age groups in the USA during 2004 - 2008 are 2.4 (age 0 - 19), 2.7 (age 20 - 34), 4.1 (age 35 - 44), 6.7 (age 45 - 54), 11.6 (age 55 - 64), 17.3 (age 65 - 74), $19.0(75$ - 84), $11.3(85+$ ) per 100,000 person-years [3]. Ionizing radiation exposure is the only established environmental risk factor for glioma $[6,9,10]$. Multiple studies show a linear dose-response relationship between ionizing radiation exposure and glioma risk. A recent study indicates that for survivors of various childhood cancer in the USA and Canada, exposure to radiotherapy was associated with significantly increased risks for the development of subsequent glioma (odds ratio $=6.78$ ), especially when the dose is higher than 30 Gy [11]. An earlier Israeli study shows that patients who received low dose X-ray therapy (1-6 Gy) in childhood for tinea capitis (ringworm of the scalp) also have a 2.6-fold increase of risk for glioma [12]. Another study shows that Japanese atomic bomb survivors have statistically significant increased risk of glioma (excess relative risk $=0.6$ per Sv) [13]. Rare genetic syndromes, such as neurofibromatosis types 1 and 2 (germ-line mutations in tumor suppressor genes NF1 or NF2), tuberous sclerosis (germ-line mutations in tumor suppressor gene TSC1 or TSC2), the Li-Fraumeni syndrome (germ-line p53 mutations), and Turcot syndrome type 1 (biallelic germ-line mutations in DNA mismatch repair genes hPMS2, hMSH2, or hMLH1), are associated with gliomas [6, 7].

Other established glioma risk factors are male gender, Caucasian race, and epilepsy/seizures/convulsions [7]. The incidence rate of gliomas is higher in males (7.17 per 100,000 person-years in the USA) than in females (5.08 per 100,000 person-years in the USA) [3]. When different races/ethnics in the USA are compared, whites have the highest incidence rate of gliomas (6.2 per 100,000 person-years), followed by Hispanic and American Indians/Alaska Natives (4.4 and 3.9 per 100,000 person-years, respectively), while Blacks and Asians/ Pacific Islanders have incidence rates (3.0 and 2.8 per 100,000 person-years)-less than half of the rate of Whites [8]. This is consistent with the observation that Northern Europe, Australia, Canada, the United States, and New Zealand, have a primary malignant brain tumor incidence that is much higher than that of Asian countries, such as the Philippines, India and Japan [10]. Although considered as risk factors, epilepsy, seizures and convulsions are probably the early symptoms of glioma [7].

Mutagen sensitivity and family history of gliomas are probable glioma risk factors [7]. Constructive gene polymorphisms in drug metabolism enzyme genes (GSTs, CYP2D6 and CYP2E1), DNA repair genes (ERC1, ERCC2, MGMT, and XRCC7), immune related genes (IL-4RA, IL-13, HLA-B*13, and HLA-B*07-Cw*07), as well as GLTSCR1, are also considered as possible risk factors. Together with the aforementioned 
rare genetic syndromes, all these factors provide insights on a genetic predisposition to glioma.

The relationship between radiofrequency electromagnetic fields (non-ionizing radiation), especially cell phone usage and glioma risk, has been controversial [14]. A recent Interpone study suggests a 40\% increase of glioma risk at the highest exposure levels (10th decile of recalled cumulative call time, $\geqslant 1640 \mathrm{~h}$ over 10 years), while no increase was found in other exposure levels [15].

There are also some negative risk factors inversely associated with glioma incidence, such as high intake of calcium and antioxidants, usage of NSAIDs, history of allergies or asthma, high serological levels of IgE, history of varicella-zoster virus (VZV) infection (chickenpox), and presence of anti-VZV IgG $[7,10]$.

\subsubsection{Diagnosis}

Patients with glioma can present symptoms including headaches, personality changes, nausea, vomiting, hemiparesis, sensory loss, visual loss, and seizures [16]. Since the symptoms are more related to the location of the tumor rather than the pathological properties, diagnosis of glioma may be delayed until the tumor progresses and invades to produce clinical symptoms. T1-weighted gadolinium-enhanced magnetic resonance imaging (MRI) is a standard tool for diagnosis patients with glioma. It is believed that tumor cells can still be found at $2 \mathrm{~cm}$ beyond the enhancing border. Magnetic resonance spectroscopy (MRS) is commonly used in the clinic to measure metabolic activity, thus providing important information for monitoring the therapeutic response and early detection of relapse. In addition, Positron emission tomography (PET) is also being applied in the clinic in diagnosing gliomas [17].

\subsubsection{Current treatment and difficulties}

\subsubsection{Surgery}

Surgery is the first modality for the treatment of malignant glioma [4]. However, in contrast to tumors that have metastasized to the brain, where sharp tumor borders are observed, borders of most glioma are ill-defined. Due to the high invasive and infiltration property of glioblastoma, groups of tumor cells or single tumor cells can detach from the

primary tumor and travel a long distance to other sites of the brain. Thus it is not possible to achieve complete tumor recession during surgery, which may contribute to the poor prognosis of glioblastoma. Whether the extent of surgical resection statistically correlates with overall survival is still a controversy in the literature. But decompressing the brain by surgery temporally reduces the related clinical symptoms caused by the tumor, thus improving the quality of life. Tumor samples taken during surgery can be sent for histopathology review. 
In 2006, Stummer et al. reported that 6 month event-free survival of patients with malignant brain tumors can be doubled using fluorescence-guided surgery [18]. They conducted a randomized, controlled multicentre phase III trial giving treatment group patients the non-fluorescent prodrug 5-aminolevulinic acid (ALA) by oral administration. This prodrug was then metabolized to fluorescent protoporphyrin IX (PpIX). PpIX accumulates high in tumor tissue and very low in normal tissue. Under blue light, neurosurgeons can visualize the tumor as "red" in color, thus optimizing tumor resection. Currently, ALA is not approved by the FDA for using during surgery.

In addition to classic surgery, neuroendoscopy provides a novel, minimally invasive approach for the diagnosis and treatment of glioblastoma [19]. Utilizing a fiber optic camera (endoscope), neuroendoscopy can be performed by a neurosurgeon to visualize the tumor and perform biopsy, resection, and the concurrent management of obstructive hydrocephalus associated with a tumor. The diameter of the neuroendoscope is less than $1 \mathrm{~cm}$, the skin incisions are less than $2 \mathrm{~cm}$, and the opening of the skull is less than $1 \mathrm{~cm}$. This technique is very attractive, because it causes less damage to the brain during the surgery. The visualization property of neuroendoscopy can help in getting accurate glioma sampling for accurate pathological diagnosis. But some limitations of this technique still need to be solved before it can get widespread popularity.

\subsubsection{Radiation therapy}

Radiation therapy is a mainstay treatment of malignant glioma in adults. Published data that showed significant prolongation of survival for patients receiving post-surgery radiotherapy ( 9 - 10 months) compared to surgery alone with supportive care (4 - 5 months) [20-22]. The current routine regimen is 6 weeks of fractionated (60 Gy in 30 fractions) external-beam partial brain radiation starting at least 2 weeks after tumor resection [20]. If the radiation source is focused precisely on the tumor, radiation may cause more damage to tumor cells than it does to normal cells. The target volume for radiation is often set as a $2 \mathrm{~cm}$ ring of brain tissue beyond the preoperative contrast-enhancing rim of tumor determined by MRI or CT scan [20].

Radiation therapy for recurrent glioblastoma is more toxic and risky than for newly diagnosed disease. Therefore, re-irradiation is limited to patients with focal disease and good performance status, and both treatment volumes and dose are reduced [16].

Recent technical advances, such as modern treatment planning software and commercial onboard imaging systems, have improved focusing of radiation by mapping the tumors and setting up patients more accurately. Proton therapy is the most promising frontier in radiation delivery [16].

\subsubsection{Chemotherapy}

Historically, chemotherapy plays a less prominent role in glioma treatment. Currently, there are five FDA-approved antiglioma drugs: oral lomustine (CCNU), 
intravenous carmustine (BCNU), oral temozolomide (TMZ), biodegradable polymer wafer impregnated with BCNU (Gliadel $\left.{ }^{\circledR}\right)$, and monoclonal antibody bevacizumab [23].

Nitrosoureas CCNU and BCNU got approved for brain tumors in the 1970s. They are DNA alkylating agents capable of crossing the blood-brain barrier (BBB) [23]. Adding them to radiotherapy provides a survival advantage of about 2 months. CCNU is a component of the once popular PCV (procarbazine, CCNU, and vincristine) combination therapy. BCNU has been the gold standard for evaluating new chemotherapy for more than 20 years. However, substantial hematopoietic, pulmonary, and renal toxicity have limited the usage of systemic nitrosoureas [21].

Gliade ${ }^{\circledR}$ are $1.4 \mathrm{~cm} \times 1 \mathrm{~mm}$ polifeprosan 20 wafers containing $7.7 \mathrm{mg} / \mathrm{disc}$ of $\mathrm{BCNU}$. Usually, up to 8 discs are implanted into the cavity after tumor mass resection. $\mathrm{BCNU}$ can be released into brain parenchyma over days or weeks, while the polymer matrix is degraded under the effect of interstitial water. The local BCNU concentrations can be 1200-fold higher than the concentrations after intravenous administration. In the meantime, peripheral toxicity can be largely reduced. Gliadel was first approved by the FDA in 1996 for treatment of recurrent glioblastoma. Then in 2003, the FDA approved it for initial treatment of all high-grade malignant gliomas since clinical trials showed that median survival of the Gliadel group was more than 2 months longer than the placebo group [21].

TMZ is an imidazotetrazine derivative of alkylating agent dacarbazine (DTIC). It works as a prodrug: Under physiological $\mathrm{pH}, \mathrm{TMZ}$ is hydrolyzed to the compound monomethyl triazone imidazole carboxamide (MTIC). Unlike other approved antiglioma drugs or the intravenous anti-melanoma agent dacarbazine, TMZ is almost $100 \%$ bioavailable and can cross BBB after oral dosing [20, 21]. Its mechanism of action is the methylation of DNA. TMZ got accelerated approval in 1999 for refractory anaplastic astrocytoma and then regular approval in 2005 for newly diagnosed glioblastoma [23]. It has become the current standard treatment for gliomas due to causing fewer side effects (mainly hematopoietic and some moderate gastrointestinal toxicity) and offering convenient oral dosing. The approved dosing regimen is $75 \mathrm{mg} / \mathrm{m}^{2}$ daily concomitantly with radiotherapy, followed by $200 \mathrm{mg} / \mathrm{m}^{2}$ for 5 days every 4 weeks for a total of 6 months. The median survival benefit from adding TMZ to radiotherapy is 2.5 months [21].

TMZ and nitrosoureas are both confronted by the drug resistance conferred by DNA repair enzymes in glioma cells, such as apurinic/apyrimidinic endonuclease (APE), poly-ADP-ribose-polymerase (PPAR), and especially the $\mathrm{O}^{6}$-methylguanine-DNA methyltransferase (MGMT) $[4,20,21,24]$. MGMT silencing by the promoter methylation, which is found in less than half of glioblastoma patients, is associated with a better response to TMZ. Depletion of MGMT by using more intense TMZ dose is also believed to increase survival time. However, MGMT inhibitors have limited efficacy to boost the effect of TMZ and nitrosoureas. In a rat glioma model, PPAR inhibitor veliparib enhanced the efficacy of TMZ [25]. 
In recent years, molecular targeted therapies for glioblastoma, which are supposed to be more effective and selective, have been a hot topic. The underlying rationale for these therapies is that some common genetic alterations occur within most glioblastomas, which lead to dysregulation of cellular signaling pathways (e.g., Ras/Raf/ PI3K, p53, and RB) and enable invasiveness, proliferation, evasion of apoptosis, avoidance of immune surveillance, and angiogenesis. Many different types of targeted agents have been investigated for malignant glioma treatment. They are EGFR inhibitors (gefitinib and erlotinib), EGFR McAbs (cetuximab and nimotuzumab), VEGFR inhibitors (cediranib), VEGF McAbs (bevacizumab and aflibercept), PDGFR inhibitors (imatinib), multiple targeted RTK inhibitor (vandetanib ,sunitinib, and sorafenib), Akt inhibitors (perifosine), PI3K inhibitors (BEZ235), Src/Abl inhibitors (dasatinib), PKC- $\beta$ inhibitors (enzastaurin), farnesyltransferase inhibitors (tipifarnib and ionafarnib), mTOR Inhibitors (sirolimus, temsirolimus, and everolimus), proteasome inhibitors (bortezomib), HSP90 inhibitors (AT13387), hepatocyte growth factor McAbs (AMG-102), integrin inhibitors (cilengitide), as well as histone acetyltransferase and histone deacetylase (HDAC) inhibitors (vorinostat and depsipeptide) [26, 27]. Challenges for molecular targeted therapies include the molecular diversity and heterogeneity as well as redundant parallel signaling pathways in glioblastomas. Most single-agent clinical trials of first generation molecular targeted agents have been disappointing. Combination therapies may be helpful in overcoming this problem. Another important finding is that the toxicities of molecular targeted agents are higher than expected [28].

Despite of these frustrations, one molecular target agent, bevacizumab, made its way to FDA approval for treatment of recurrent glioblastomas in 2009. Glioblastoma is one of the most vascularized cancers. The level of angiogenesis mediator VEGF in glioblastomas is correlated with malignancy and aggressiveness as well as recurrence and poor survival. The accelerated approval for bevacizumab is based on high radiographic response rates and low toxicity. It can also provide symptom relieve by decreasing tumoral and peritumoral edema. The recommended dose is $10 \mathrm{mg} / \mathrm{kg}$ intravenously every 2 weeks. Besides direct inhibition of tumor angiogenesis, other mechanisms of action of this drug include a direct antiglial effect on VEGF receptor-expressing tumor cells, disruption of the microvascular niches for tumor stem cells, as well as improvement of drug and oxygen delivery by vascular normalization [29-31].

Irinotecan, a topoisomerase I inhibitor currently approved for metastatic colorectal cancer, can readily cross BBB. Irinotecan is synergistic with both temozolomide and bevacizumab in combination therapy studies for glioblastomas. The toxicities of these combinations are acceptable. The irinotecan and bevacizumab combination may significantly improve survival in newly diagnosed glioblastoma cases $[32]$.

Other novel chemotherapies under development include dendritic cell vaccines (DCVax), tumor-specific peptide vaccines (EGFRvIII peptides), immunotoxin (TP-38), radiolabeled antibodies, and various gene therapies [27]. 


\subsubsection{Multimodal treatment}

For newly diagnosed glioblastoma, a multimodal treatment, including tumor resection, irradiation, and chemotherapy is recommended for adults whenever possible. For recurrent glioblastoma, reoperation may relieve symptoms, but can only prolong survival for 3 months, while re-irradiation is controversial [33]. Thus chemotherapy-only regimens using $\mathrm{TMZ}$ or bevacizumab are often adopted. Guidelines for the management of newly diagnosed glioblastoma [34] are summarized in Table 1-2.

\subsection{Pharmacokinetics Considerations in Antiglioma Drug Discovery and Development}

\subsubsection{Role of pharmacokinetics in drug discovery and development}

Drug discovery and development is a high-risk and high-cost process. A recent study shows that the total capitalized cost per approved new molecule have risen to around 1.3 billion (2005 US dollars) [35]. A significant part of this figure is the cost of failures, especially the attrition in clinical development. The clinical approval success rate in the United States is only $19 \%$ for drug candidates that entered clinical trials between 1993 and 2004 [36].

Since clinical development is the most expensive stage in the whole drug discovery and development process, an important strategy has been to "fail early" the compounds with poor "drugability" based on drug metabolism and pharmacokinetics (DMPK) evaluation. In 1991, poor pharmacokinetic characters were the most frequent cause $(\sim 40 \%)$ of attrition in clinical development [37]. By 2000, these type of issues are responsible for less than $10 \%$ of attrition after the pharmaceutical industry addressed this problem by improving the DMPK evaluation in the drug discovery stage [38].

\subsubsection{A major challenge for antiglioma chemotherapy: the blood-brain barrier}

For discovery and development of drugs that have a site of action in the brain, like antiglioma drugs, biopharmaceutic evaluation is critical since these drugs need to overcome an additional obstacle: the blood-brain barrier (BBB).

The brain is a well-perfused organ with the average human brain receiving 14\% of cardiac output. The brain capillaries have a total length of about 400 miles, and total area of about $20 \mathrm{~m}^{2}$. The thickness of the endothelial cell is only $200 \mathrm{~nm}$, less than $5 \%$ of the thickness of most cells, and each brain cell is less than $25 \mu \mathrm{m}$ away from the blood flow [39]. However, more than $98 \%$ of small molecule drugs and almost all large molecular drugs are kept from entering the brain by the BBB - a combination of a proteinaceous layer (basal lamina) and three types of cells (brain capillary endothelial cells (BCECs) monolayer, astrocytes, and pericytes) [40]. 
Table 1-2. Guideline for the management of newly diagnosed glioblastoma

\begin{tabular}{|c|c|c|c|}
\hline Therapeutic modalities & Level I recommendations & Level II recommendations & Level III recommendations \\
\hline Neurosurgery & $\mathrm{N} / \mathrm{A}$ & $\begin{array}{l}\text { "Maximal safe resection" is } \\
\text { recommended for newly } \\
\text { diagnosed supratentorial } \\
\text { malignant glioma in adults. }\end{array}$ & $\begin{array}{l}\text { Biopsy, partial resection or gross total } \\
\text { resection is recommended to be } \\
\text { considered in the initial management } \\
\text { of malignant glioma. }\end{array}$ \\
\hline Radiation therapy & $\begin{array}{l}\text { Radiation therapy is } \\
\text { recommended for the treatment } \\
\text { of newly diagnosed malignant } \\
\text { glioma in adults. Treatment } \\
\text { schemes should include dosage } \\
\text { of up to } 60 \text { Gy given in } 2 \text { Gy } \\
\text { daily fractions that includes the } \\
\text { enhancing area. }\end{array}$ & $\begin{array}{l}\text { Radiation therapy planning } \\
\text { includes a } 1 \text { to } 2 \mathrm{~cm} \text { margin } \\
\text { around the radiographically } \\
\text { defined } \mathrm{T} 1 \text { contrast- } \\
\text { enhancing tumor volume or } \\
\text { the T2 weighted } \\
\text { abnormality on MRI. }\end{array}$ & \\
\hline Chemotherapy & $\begin{array}{l}\text { Concurrent and post-irradiation } \\
\text { temozolomide is recommended } \\
\text { in patients } 18 \text { to } 70 \text { years of age } \\
\text { with adequate systemic health. }\end{array}$ & $\begin{array}{l}\text { BCNU-impregnated } \\
\text { biodegradable polymers are } \\
\text { recommended in patients for } \\
\text { whom craniotomy is } \\
\text { indicated. }\end{array}$ & $\begin{array}{l}\text { 1) } \mathrm{TMZ}+\text { radiation for patients ( }>65 \\
\text { years old) with newly diagnosed } \\
\text { glioblastoma with KPS }>50 ; 2 \text { ) For } \\
\text { patients are } \geqslant 70 \text { years old, with } \\
\text { newly diagnosed glioblastoma, TMZ } \\
\text { alone is a well-tolerated alternative to } \\
\text { radiation therapy; 3) Radiation } \\
\text { therapy, followed by one of the } \\
\text { nitrosoureas, is recommended for } \\
\text { those patients not eligible for TMZ. }\end{array}$ \\
\hline
\end{tabular}

Source: Adapted with permission. Olson, JJ, et al., Management of newly diagnosed glioblastoma: guidelines development, value and application. J Neurooncol, 2009. 93(1): p. 1-23. 
Unlike endothelial cells, which are only connected by adhesion junctions to form the porous peripheral capillaries, BCECs are connected by both adhesion junctions and tight junctions. Tight junctions are protein complexes that consist of the intercellular cleft proteins occludin and claudins as well as junctional adhesion molecules (JAMs). Occludin and claudins are linked to cytoplasmic scaffolding proteins zonula-occludens (ZO)-1, ZO-2 and ZO-3, which are in turn linked to the actin/myosin cytoskeletal system via cingulin. Paracellular transportation is effectively prevented by tight junctions [40]. In addition, alternate transport pathways, e.g., fenestrations, transendothelial channels and pinocytotic vesicles are also lacking in BCECs [41].

On the other hand, BCECs have a large number of mitochondria and drug metabolic enzymes that make them metabolically competent. The ABC (ATP-binding cassette) family of efflux transporters, e.g., P-glycoprotein (P-gp), breast cancer resistance protein (BCRP), and multidrug resistance protein-1,2,4,5 (MRP-1,2,4,5) are expressed on the luminal membrane of BCECs as an additional layer of protection from xenobiotics [40-42].

The outside of the BCEC is partially covered by discontinuously distributed pericytes. Also, the basal lamina covers both pericytes and BCECs as an extracellular matrix. The outermost layer of the BBB is formed by the astrocyte foot processes surrounding the basal lamina, pericytes, and BCECs. These astrocytes and pericytes help induce and maintain the properties of BBB [40].

Given all these limiting factors, there are still some ways that molecules can cross the $\mathrm{BBB}$ and get into the brain $[40,43,44]$ :

- Hydrophilic polar small molecular nutrients, e.g., glucose, amino acids, nucleotides, nucleosides, monocarboxylates, organic cations, and organic anions, can enter the brain through carrier-mediated transport (CMT) i.e., via solute carriers (SLCs), at the luminal (blood) and basolateral (brain) side of BCECs.

- Certain proteins and peptides, e.g., transferrin, melanotransferrin, lipoproteins, insulin, leptin, tumour necrosis factor $\alpha$ (TNF- $\alpha$ ), epidermal growth factor (EGF), leukaemia inhibitory factor (LIF), and diphtheria toxin can be transported through receptor-mediated transcytosis (RMT).

- Some protein with excess positive charge, e.g., histone, protamine, avidin, and cationised albumin can be transported through adsorptive-mediated transcytosis (AMT).

- Oxygen and lipophilic non-polar small molecules may passively diffuse through the cell membranes and enter the brain. However, many small molecular drugs that enter the BCECs will be kicked back to the blood by the efflux transporters at the luminal side and/or exposed to drug metabolism inside the BCECs.

The blood-cerebrospinal fluid (CSF) barrier (BCSFB), which separates blood from the CSF in the choroid plexus, has a structure different from the BBB. The fenestrated choroid plexus capillary endothelium allows diffusion of small molecules, 
while the barrier function is carried out by choroid epithelial cells that form tight junctions [40].

Malignant gliomas can secrete excess vascular endothelial growth factor (VEGF) and induce angiogenesis. In the tumor neovasculature, the tight junction proteins claudins and occludin as well as the cytoplasmic scaffolding protein ZO-1 are often either downregulated or lost. The number of pinocytic vesicles is increased in tumor endothelial cells [45]. In addition, abnormalities have been found in pericyte and basal lamina [45]. All these changes lead to a partially functional blood-brain barrier, or so-called blood-brain tumor barrier (BBTB) [46]. The peritumoral edema, endothelial hyperplasia, and gadolinium-contrast enhancing lesions in MRI are caused by this leaky barrier [45].

It has been posited that the BBB should not hinder glioma chemotherapy at all, since drugs should be able to pass at the leaky BBTB area [47]. However, the mainstream opinion is that even the BBTB is still a real barrier to transportation of antiglioma drugs. Although weakened, the tight junction is still present in BBTB, and the fenestrations are still rare $(\sim 2 \%)$ [45]. High interstitial pressure in the tumor caused by the leaky vasculature can slow drug extravasation, which can at least partially counterbalance the leaking-caused penetration increase [46]. Expression of some drug efflux trasporters, such as MRP1, is upregulated in the BBTB [46]. The most important point is that the leaky BBTB is only formed in the center of well-established tumors as a result of tumor neovascularization. The proliferating edge of the tumor and wide-spread tumor cells at the infiltrated area are still fed by established microvessels, thus being protected by normal BBB [46, 48-50].

\subsubsection{Strategies for enhancing brain penetration of antiglioma drugs}

Various strategies have been developed to overcome the limitations of the $\mathrm{BBB} / \mathrm{BBTB}$ on antiglioma drugs.

\subsubsection{Circumventing BBB by local administration}

Challenges posed by BBB can be overcome directly by administering drugs to the brain interstitium. There are three types of approaches for local administration of antiglioma drugs: intraventricular/intracavitary injection, impregnated polymer implantation, and convention enhanced delivery (CED).

\subsection{Intracerebroventricular or intracavitary injection. A frequently used} intracerebroventricular or intracavitary delivery device is the Ommaya reservoir, which is named after the inventor, Ayub Khan Ommaya. It consists of a mushroom-shaped self-sealing silicone dome placed under a flap of scalp and a connected catheter that goes to the ventricle or cavity through a small opening on the skull. Drug is injected into the dome first. Then the dome is flushed and gently pressed to force the drug through the catheter and into the brain. In this way, intermittent bolus injections of anticancer drugs can enter directly into the CSF, tumor cyst, or resection cavity. Prolonged 
intracerebroventricular infusion can be carried out by other pump and catheter systems $[49,51,52]$.

This type of drug delivery approach is limited by the slow rate of drug diffusion to brain parenchyma. With the intracerebroventricular route, the situation is even worse. Although CSF and interstitial fluid (ISF) can communicate freely, the CSF bulk flow passes through the ventricle and is absorbed into blood at the superior sagittal sinus in a rate much faster than the rate of drug diffusion. As a result, a remarkable portion of the intracerebroventricular-administrated drug exits to peripheral blood flow before entering the brain parenchyma [39]. Other disadvantages of this type of approach include infection and catheter obstruction [52].

1.2.3.1.2. Impregnated polymer implantation. Another type of local delivery approach is implantation of various drug-impregnated polymers into the tumor resection cavity. These polymer implants are different from each other in impregnated drugs, ratecontrolling mechanisms, degree of biodegradability, and also shapes and sizes [46].

As mentioned in 1.1.3.3., Gliadel®, a poly(carboxypropane)-sebacic acid (PCPPSA, belonging to polyanhydrides)-based biodegradable polymer wafer containing carmustine (BCNU), has been approved for gliobalstoma treatment. Clinical trials for paclitaxel- and cisplatin-containing polymer implants have been conducted. In addition, polymers impregnated with other drugs, such as adriamycin, 5-fluorouracil, mitomycin, nimustin hydrochloride, and mitoxantrone have been studied in preclinical settings [46, $52,53]$. Besides wafers, the polymer implant can also take the form of drug-loaded microspheres [49].

Release of drug from the implant is driven by hydrolytic degradation of polymer, while the distribution is driven by a concentration gradient, i.e., the principle of diffusion. A very high drug concentration can be achieved at the tumor resection site where the polymer is planted $[49,52,53]$, and that concentration can be maintained for weeks [48]. Although BCNU can pass the blood-brain barrier after systemic administration due to its high lipophilicity, when it is given as Gliadel, the dose-limiting systemic toxicities can be minimized [53].

As a result of the diffusion process, the concentration of the drug decreases exponentially with distance in brain parenchyma surrounding the resection cavity [43]. The interstitial pressure adjacent to the cavity can also hinder the drug diffusion [53]. Thus, the drug concentration just millimeters away from the resection cavity is often too low to treat the glioma cells effectively $[48,50]$.

Other limitations of the impregnated polymer approach include local neurotoxicity, poor wound healing, infections, cerebral edemas, and obstructive hydrocephalus $[49,53]$.

1.2.3.1.3. Convention-enhanced delivery. Convention-enhanced delivery (CED) is a novel approach proposed by Bobo et al. It infuses antiglioma drugs via a catheter (s) 
within or around the tumor by hydrostatic pressure. Unlike the aforementioned intraventricular/intracavitary injection and impregnated polymer implantation approaches, the drug movement from the site of administration is driven by not only the principle of diffusion, i.e., the concentration gradient, but also the bulk flow of the infusate, i.e., the pressure gradient. Thus, a quicker and wider distribution can be achieved through CED. Targeted delivery of antiglioma drugs is achieved by selection of the catheter location. Using CED can limit systemic toxicity as well as widespread neurotoxicity $[46,50,52]$.

Key parameters that need to be considered in CED are: infusion rate, catheter size, infusion volume, interstitial fluid pressure, particle characteristics, and tumor tissue structure. When carefully implemented, CED only causes inflammation within $50 \mu \mathrm{m}$ of the catheter surface and does not cause cerebral edema or measurable increases in intracranial pressure. CED has been used for delivery of viral vectors, paclitaxel, topotecan, transferrin/diphtheria toxin, IL-4 and IL-13 targeted toxins, IL-4, TP-38, and TGF- $\beta[52]$.

In the other hand, CED is still plagued by a limited distribution area, like other local delivery routes. As a result, it is best used against small solid tumors. In order to kill infiltrative tumor cells, multiple catheters and multiple day infusions may be necessary. This makes CED a rather invasive approach. Some indigenous drawbacks of CED, such as catheter-induced tissue damage, reflux of solute adjacent to the catheter, "intrinsic" backflow of solute, and air bubbles, can lead to unpredictable and undesirable drug distribution $[46,48,50,52]$.

\subsubsection{BBB disruption}

Another class of strategy to overcome the limitation of BBB is to disrupt it physically or biochemically when administrating an antiglioma drug systemically.

1.2.3.2.1. Osmotic disruption. Intracarotid infusion of hyperosmotic solution, e.g., mannitol solution, can draw intracellular water to the vascular lumen from BCECs. This leads to BCECs shrinkage and subsequent opening of the tight junctions for hours. Thus the paracellular transportation is permitted at that time. Chemotherapy drugs are often dosed through intra-arterial route when this approach is used $[49,52,53]$.

Animal studies show that osmotic BBB disruption can increase drug concentrations in the brain parenchyma by up to 90-fold [52]. Enhanced drug delivery to the brain by this method has also been shown in humans [50].

However, this method causes greater disruption of the normal BBB than to the $\mathrm{BBTB}$, which may result passage of toxic proteins and too much chemotherapy drug to normal brain tissue. Other adverse effects include physiological stress and increase in intracranial pressure $[48,50]$. 
1.2.3.2.2. MRI-guided ultrasound disruption. This approach can generate a focal BBB disruption, other than the global disruption caused by osmotic disruption $[43,52]$. Since the cranium can attenuate ultrasound, a bone window is usually a prerequisite. Then the process begins with intravenous injection of preformed bubbles. The pulsed ultrasound guided by MRI is applied to the desired area to localize cavitation-generated mechanical stresses to brain capillary walls. The resulting BBB disruption is reversible and can completely recover in $24 \mathrm{hr}$. Increased brain penetration of herceptin and liposomal doxorubicin has been shown after using this approach in mice and rat, respectively.

1.2.3.2.3. Biochemical disruption. Biochemical BBB disruption involves using vasomodulators, such as leukotrienes, histamine, bradykinin, nitric oxide donors, soluble guanylate cyclase activator, potassium, calcium, and ATP channel agonists. Unlike the osmotic disruption, this method primarily affects BBTB $[48,52]$. Thus chemotherapy after biochemical BBB disruption is more selective on tumor mass with neovascularization, and is less toxic to normal brain tissue. However, as discussed in 1.2.2, glioma cells at the edge of the tumor or infiltrated areas is still protected by normal $\mathrm{BBB}$ and thus are not exposed to drug concentration that is high enough to be effective.

Calcium can regulate tight junction assembly and the effectiveness of the tight junctions as a barrier [40]. Bradykinin analogue RMP-7 can indirectly activate calcium-mediated tight junction opening by activating B2 bradykinin receptors [43]. In animal studies, RMP-7 increased brain penetration of the hydrophilic compounds carboplatin and dextran, with greater impact in regions of BBTB [52]. However, it failed in clinical trials in combination with carboplatin [43].RMP-7 had no obvious impact on brain penetration of the lipophilic drug BCNU.

Common shortcomings of all of these three BBB disruption approaches include [43] requirement of anesthesia and hospitalization, potential damage of neurons caused by entering of some blood components, and potential of facilitating tumor dissemination.

\subsubsection{Inhibition of drug efflux transporters}

Drug transporters in BBB form an additional functional barrier. Thus inhibition of these transporters will also benefit the drug brain penetration. P-gp is the most important drug efflux transporter at the BBB. Brain penetration of paclitaxel, docetaxel, and imatinib has been improved by co-administration of P-gp inhibitors in animal studies. Classical P-gp inhibitors, e.g., verapamil and cyclosporine A have low affinities and high toxicity. Using cyclosporine A analogue valspodar can overcome these problems. Like verapamil and cyclosporine $\mathrm{A}$, valspodar is also a CYP3A inhibitor. This may not be a desirable characteristic, because CYP3A does not express at a high level in the human $\mathrm{BBB}$ [54] but plays a key role in the peripheral drug metabolisms of many drugs. The newest generation of P-gp inhibitors without CYP3A-inhibiting activity, such as elacridar (also a BCRP inhibitor), zosuquidar, and tariquidar, are better tools to increase brain penetration of antiglioma drugs. BCRP inbibitors such as pantoprazole may also useful 
for this purpose [46]. Some nanocarriers, such as Pluronic block copolymers micelle can also inhibit drug efflux transporters in the BBB [55].

\subsubsection{Taking advantage of BBB carriers and transporters}

Carrier and transporter systems in the BBB also have been utilized to develop noninvasive strategies for brain penetration enhancement. These strategies can be either using nano-sized drug carriers conjugated to ligands of those transporter systems or making the drug molecules mimic or directly coupled to those ligands.

OX26 is a murine monoclonal antibody (McAb) against rat transferrin receptor (TfR). As a peptidomimetic McAb, OX26 binds TfR through a domain not in the transferrin (Tf)-binding site and thus does not interfere with endogenous Tf binding. OX26-conjugated liposomes can significantly increase the brain penetration of daunomycin through TfR-mediated transcytosis [49].

Some evidence suggests existence of a sodium-dependent, reduced glutathione (GSH) transporter in BBB [56]. Recently, GSH-conjugated PEGylated liposomes of doxorubicin showed promising results in proof-of-concept studies.

Polysorbate-80 (Tween 80)-coated nanoparticles also can increase drug brain uptake. The mechanism supported by most abundant evidence is as follows: The polysorbate-80-coated nanoparticles adsorb apolipoprotein (Apo) E or B from blood to their surface-in other words, indirectly conjugated to apolipoproteins - and then cross the BBB through low density lipoprotein (LDL) receptor-mediated transcytosis.

Polysorbate-80 coated-poly (butylcyanoacrylate) (PBCA) nanoparticles can increase the brain concentration of doxorubicin after systemic administration for more than 50 times $[57,58]$.

DL-2-amino-7-bis (2-chloroethyl)amino]-1,2,3,4-tetrahydro-2-naphthoic acid (DL-2-NAM-7), a melphalan analog with higher affinity to large amino acid (LAT) transporter, shows 20 times higher brain uptake than melphalan [59].

Angiopep-2, a 19 amino acid peptide, can cross the BBB though lipoprotein receptor-related protein-1 (LRP1)-mediated transcytosis. Paclitaxel conjugated to Angiopep-2 (ANG1005) distributes into the brain at a level 4 to 5 times higher than paclitaxel alone [48].

\subsubsection{Passive diffusion enhancement by drug structure modification}

The physio-chemical parameters of anticancer drugs can be tuned to optimize passive diffusion across the BBB. For example, making a lipophilic analog or prodrug of a highly hydrophilic drug may help its diffusion. More details on the optimal drug physio-chemical properties for brain penetration are discussed in the next section. 


\subsubsection{Physiochemical characteristics of successful CNS drugs}

Prediction of brain penetration of new chemical entities (NCEs) from their physiochemical properties is a hot but controversial area [60]. Following are some simple physiochemical rules for successful CNS drugs summarized by Pajouhesh et al. [61]:

- Molecular weight $<450$

- $\quad \operatorname{cLog} \mathrm{P}<5$

- H-bond donors $<3$

- $\quad$ H-bond acceptors $<7$

- $\quad$ Rotatable bonds $<8$

- $\quad$ Polar surface area (PSA) $<60-70 \AA^{2}$

These rules can serve as a rough guideline for discovery of novel antiglioma drug intended for systemic administration or structure modification of current drugs.

Comparison between these rules and Linpinski's "rule of five", i.e.,

- Molecular weight $\leqslant 500$

- $\log \mathrm{P} \leqslant 5$

- H-bond donors $\leqslant 5$

- $\quad$ H-bond acceptors $\leqslant 10$

- $\quad$ Rotatable bonds $\leqslant 10$

shows CNS drugs have lower molecular weights, less flexibility, and fewer hydrogen bond donors and acceptors [61].

The limit on LogP may be explained as follows: While higher lipid solubility helps passing the phospholipids bilayer, it can also lower the concentration of the free drug available for diffusion at BBB [62] because of increased peripheral tissue and plasma protein binding. In addition, drugs already in the BCECs need to partition into the aqueous environment of brain interstitial fluid before reaching their target behind the BBB [41]. Also, high non-specific binding to brain tissue will hinder drugs with very high lipophilicity from exerting their effect. Some earlier reports even suggested a value around 2 as the optimal $\log$ P for CNS drugs [61].

Compared to the absorption process in the gastrointestinal tract, BBB crossing is more dependent on transcellular diffusion. The movement of lipid-soluble molecules through the cell membrane is hypothesized to be through transient pores created by kinking of the mobile unsaturated fatty acyl side chains in the phospholipid bilayer. Thus the size and shape of those holes determine the size and shape of the molecules that can pass [39]. This may explain why CNS drugs are smaller than general oral drugs and have more compact and less flexible structures. 
In addition, certain physiochemical features may play a role in substrate specificity of efflux transporters and drug metabolism enzymes, thus affecting drug brain penetration.

\subsubsection{Overview of DMPK of last generation of EDL compounds}

1-[(4-phenylphenyl)methyl]-1,2,3,4-tetrahydroisoquinoline-6,7-diol (Figure 1-2), i.e., EDL-155, also known as EDL-1, is a tetrahydroisoquinoline derivative with in vivo antiglioma activity selected from about 500 compounds synthesized by Dr. Duane Miller's laboratory at The University of Tennessee Health Science Center (UTHSC, Memphis, TN) [63, 64]. It was the subject of a detailed DMPK evaluation in Pengfei Song's dissertation [63].

After $10 \mathrm{mg} / \mathrm{kg}$ intravenous injection to rats, EDL-155 demonstrated extraordinarily rapid clearance $(342.5 \mathrm{~mL} / \mathrm{min} / \mathrm{kg})$, which is around 6 times the rat liver blood flow. The volume of distribution was estimated at $13.0 \mathrm{~L} / \mathrm{kg}$. Elimination of EDL-155 can be described by a one-compartment model [65]. EDL-155 is extensively bound to plasma proteins, with the percentage bound being larger than 93 at concentrations of 150,650 , and 2,500 ng/mL [65]. The most abundant EDL-155 metabolite is formed by $\mathrm{C}$-ring hydroxylation, which may be catalyzed by a cytochrome P450 enzyme. The next abundant metabolite is formed by A-ring mono-methylation, which may be catalyzed by catechol O-methyltransferase (COMT) in blood and tissue [65]. EDL-155 was predicted by Song to be a P-gp substrate using an in silico classification structure-activity relationship (C-SAR) model based on physicochemical properties, which was verified subsequently using Calcein-AM assay [63].

Some potential reasons for the high clearance value were proposed: 1) accumulation in blood cells, fat, and other organs, 2) degradation/metabolism in the blood, 3) first pass effect in the lung, and 4) exsorption into the gut by uptake transporters. However, these possibilities were not examined by experiments in Song's study [63].

The brain penetration of EDL-155 was evaluated in vivo by CSF sampling after $20 \mathrm{mg} / \mathrm{kg}$ intravenous injection in rats. The dose-normalized ratio of $\mathrm{AUC}_{\mathrm{CSF}} / \mathrm{AUC}_{\text {Plasma }}$ was calculated to be $1.4 \%$ [65]. As an attempt to overcome the poor brain penetration problem, $9.25 \mathrm{mg} / \mathrm{mL}$ EDL-155 solution was delivered as $4 \mu \mathrm{L} / \mathrm{min} \times 100 \mathrm{~min}$ CED infusion in caudate nucleus. Although EDL-155 can be detected in the contralateral frontal lobe, ipsilateral lobe, occipital lobe, and the cerebellum, the concentration in these areas is less than $0.2 \%$ of the injection site concentration [63].

EC50 of EDL-155 is $1.5 \mathrm{mM}$ for rat C6 glioma cells [64]. Despite its limited brain penetrability, after 7 days of $20 \mathrm{mg} / \mathrm{kg}$ intraperitoneal injections, it still can cause $29.4 \%$ growth inhibition of the intracranial implanted C6 glioma in rats [66]. This suggests that analogs with increased metabolic stability and brain penetrability may provide a therapeutic option for glioma. 


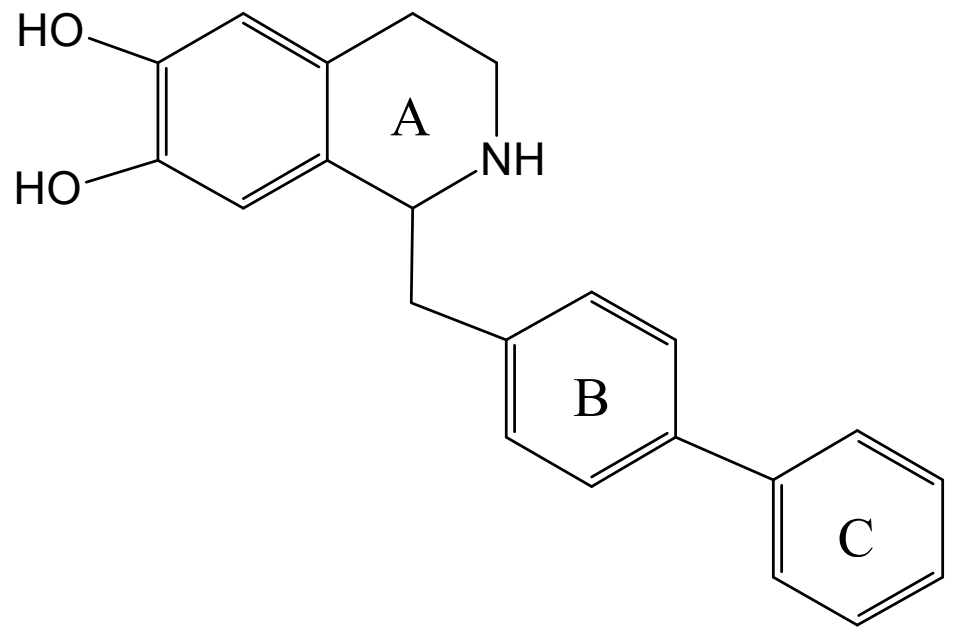

Molecular Weight: 331.41

Exact Mass: 331.16 CLogP: 4.16

H-bond Donor: 3

H-bond Acceptor: 3

Rotable Bonds: 3

PSA: $52.49 \AA^{2}$

Figure 1-2. Structure and selected physiochemical properties of EDL-155

Exact mass and cLogP are calculated by ChemDraw Ultra 12.0 (CambridgeSoft

Corporation, Cambridge, MA). All other values are calculated by Marvin Calculator Plugins (ChemAxon Kft., Hungary). 
Study of analogs of EDL-155 showed that replacing the A-ring catechol hydroxyl groups with dimethoxy may sometimes increase metabolic stability and decrease clearance. However, their CSF concentration is lower than that of some EDL-155 analogs that keep A-ring catechol hydroxyl groups. A closer inspection showed that $\mathrm{AUC}_{\mathrm{CSF}} / \mathrm{AUC} \mathrm{C}_{\text {Plasma }}$ decreased with the increase of $\log \mathrm{P}[63]$.

\subsection{Background for Mechanism of Action Study}

\subsubsection{Drug discovery with unknown target}

Phenotypic (physiological or cellular) screening is a classical drug discovery method [67-69]. Since 1990s, this low-through-put approach has been largely replaced by the molecular target-based screening, which is powered by advances in molecular biology, genomics, and combinatorial chemistry. However, after the initial euphoria, the new gene-to-drug paradigm turned out to be not as productive as expected, and was criticized for "targephilia" and overtly reductionism [70]. Therefore, the old route, phenotypic screening, has seen a renaissance, as supporters argue that it can test the compounds against the actual complex biological system in the very beginning [71]. In 2002, Merck received approval of ezetimibe, a cholesterol-lowering agent discovered through phenotypic screening. Eli Lilly also announced a Phenotypic Drug Discovery (PD2) Initiative in 2009.

The phenotypic screening can bypass the prior target identification and validation, and thus allows discovery of drug candidates with unknown targets. However, at the present time, a drug candidate discovered via this route must undergo a mechanism of action study or even a retrospective target identification [68]. In the case of ezetimibe, if the decade long mechanism-finding effort had been unsuccessful, it would not likely gain approval. A successful mechanism study can also facilitate further optimization of structure, identification of potential toxicities or side effects, and selection of possible responders for clinical trials $[67,68,71]$.

\subsubsection{Discovery of EDL compounds}

The lead compound of EDL series compounds was found in an anti-hepatitis $\mathrm{C}$ drug discovery project at The University of Tennessee Health Science Center. It was designed as a blocker of CD81 (TAPA-1, target of antiproliferative antibody-1), a cell membrane protein that is important for Hepatitis $\mathrm{C}$ virus $(\mathrm{HCV})$ attachment and cell entry. CD81 signals for antiproliferation when bound by antibodies. Rat astrocytes are CD81 enriched, while C6 rat glioma cells are CD81-deficient. Thus, CD81 blocker that mimics the effect of CD81 antibodies should have an antiproliferative effect on rat astrocytes but not on C6 cells. Surprisingly, that lead compound inhibits the growth of C6 glioma cells instead of rat astrocytes [72,73]. After that discovery, structure modifications were made to improve the antiglioma activity and give birth to the EDL 
series of 1,2,3,4-tetrahydroisoquinoline derivatives [64]. The cell proliferation assays of rat astrocytes, C6 cells, and human glioblastoma cell lines were used to screen these compounds. Therefore, EDL series of antiglioma compounds were discovered by serendipity and screened by phenotypic screening. Their mechanism of action was unknown before the start of this dissertation research.

\subsubsection{Cell death pathways induced by chemotherapy}

All anticancer drugs induce cancer cells' death, but those cells die through different pathways. The five major modes of cell death induced by chemotherapy are apoptosis, autophagic cell death, necrosis, mitotic catastrophe, and senescence [74].

\subsubsection{Apoptosis}

Apoptosis also called type I programmed cell death, is a well-known means of cancer cell death after chemotherapy. The morphologic characters of apoptosis include cell shrinkage, nuclear condensation and fragmentation, exposing of phosphatidylserine on the cell surface, membrane blebbing, and eventually fragmentation into membrane -bound apoptotic bodies. The two most well-known apoptosis signaling pathways are the intrinsic pathway and extrinsic pathway [74-78].

Many traditional chemotherapeutic drugs can trigger the intrinsic pathway by transcriptional upregulation and activation of BH3-only pro-apoptotic members of Bcl-2 family proteins such as Bad, Bim, Bmf, Noxa, and Puma. These proteins can antagonize the effect of BH1-2-3-4 anti-apoptotic members of the BCL2 family proteins, such as Bcl-2, Bcl-xl, and Mcl-1. The changed balance between BH3 only and BH1-2-3-4 proteins induces homooligomerization and mitochondrial outer membrane insertion of the BH1-2-3 pro-apoptotic members of the Bcl-2 family proteins, like Bax and Bak, then lead to mitochondrial outer membrane permeabilization (MOMP) through a MPT (mitochondrial permeability transition)-dependent or a MPT-independent mechanism.

MOMP is a critical event in the intrinsic pathway; it demarcates the boundary between death and survival. Once triggered, it irreversibly leads to cell death through three mechanisms: 1) release of proteins that help caspase activation, such as cytochrome $\mathrm{C}$, Smac/DIABLO, and Omi/HtrA2; 2) release of pro-apoptotic proteins unrelated to caspase activation, such as AIF (apoptosis-inducing factor) and Endo G (endonuclease G); and 3) loss of mitochondrial functions essential for cell survival.

Cytochrome $\mathrm{C}$ released in MOMP binds Apaf-1, resulting in the formation of a complex called apoptosome in the presence of ATP/dATP. The apoptosome can recruit procaspase- 9 , cause procaspase- 9 oligerization and auto-cleavage, which generates the caspase 9. The caspase-9 and the apoptosome then form an active holoenzyme to activate downstream executioner caspases $-3,-6$ and -7 through an internal cleavage to separate the large and small subunits. The executioner caspase activities are essential for the apoptotic phenotype. The bona fide substrates of executioner caspases include PARP, 
DFF45/ICAD, Rb, and ROCK I. As a positive feedback mechanism, the executioner caspases also activate caspase-9.

IAPs (inhibitor of apoptosis proteins), such as XIAPs (X-linked inhibitor of apoptosis proteins), inhibit caspase activity by directly binding to the active enzymes. Smac/DIABLO and Omi/HtrA2 can enhance caspase activation as competitive inhibitors of IAPs.

The so-called caspase-independent apoptosis is mediated by aforementioned AIF and Endo G. They can translocate to the nucleus, induce peripheral chromatin condensation and DNA fragmentation without the involvement of caspases.

Sometimes chemotherapeutic drugs can also activate the extrinsic apoptosis pathway by upregulating the plasma membrane death receptors Fas, TNFR1, or DR $4 / 5$ through the involvement of $\mathrm{p} 53$. Binding of homotrimeric death ligands FasL, TNF- $\alpha$, or TRAIL to corresponding death receptors induces oligomerization of the death receptors. The resultant ligand-receptor complex then further forms a DISC (death-inducing signaling complex) by recruiting adapter proteins, such as FADD (Fas-Associated protein with Death Domain) and TRADD (TNF-R1-Associated Death Domain). Three molecules of procaspase- $8 / 10$ can join the DISC by binding to FADD, and then are activated by auto-cleavage. In some cases (type I cells), the activation of executioner caspases $-3,-6$, and -7 by caspase- 8 and -10 is sufficient for apoptosis. In other cases (type II cells), the caspase- 8 also activate Bid, a pro-apoptosis member of the Bcl-2 family, thus activating the intrinsic pathway.

A newer class of chemotherapy drugs, i.e., apoptosis-inducing molecular targeted drugs, kills cancer cells by modulating the activity of particular molecules involved in apoptosis, which are often dysregulated or even mutated in cancer cells [74-76]. Examples of these drugs include TRAIL ligand, TRAIL antibody, BH3 mimic (gossypol), Bcl-2 antisense oligonucleotide, and proteasome inhibitor (bortezomib).

In addition to the aforementioned intrinsic, extrinsic, and caspase-independent pathway, an ER (endoplasmic reticulum) stress-induced apoptosis pathway has been reported recently [77-84]. Human caspase-4 and mice caspase-12 [85] are the initiator caspases in this route [86]. They can directly activate caspase- $3[85,87]$ and thus trigger the downstream apoptosis events. Celecoxib, bortezomib and tunicamycin are examples of drugs that induce apoptosis through this pathway [79].

\subsubsection{Autophagic cell death}

"Autopahgy" means self-eating. Briefly, in this process, a double membrane vesicle forms in the cytosol that encapsulates whole organelles and bulk cytoplasm. These so-called autophagosome structures then fuse with the lysosomes where the contents are degraded and recycled [74-76, 88-90].

Autophagy can be triggered by various stimuli, including chemotherapy, 
radiation, nutrient deprivation, growth-factor withdrawal, bacterial infection, aggregated and misfolded proteins (ER stress), and damaged organelles [74-76, 88-90]. In many case, autophagy can be a pro-survival mechanism. It can produce amino acids during nutrient starvation and eliminate unwanted and damaged organelles and molecules, thus increasing the chance of a cell to survive stresses. But when this process becomes too extensive, it leads to autophagic cell death, or type II programmed cell death [74-76, 88-90] .

The molecular events leading to autophagy are briefly summarized as follows [74-76, 88-90]: Autophagy begins from cup-like double-layered membrane structures, the isolation membranes. This autophagy induction/membrane nucleation process is regulated by type I PI3K (phosphoinositide 3-kinase), type III PI3K, and mTOR (mammalian target of rapamycin). Type I PI3K is active in a nutrient-rich environment and can activate the mTOR through the serine/threonine protein kinases PDK1 (phosphoinositide-dependent kinase-1) and Akt (PKB). mTOR is a serine/threonine kinase that inhibits autophagy through controlling transcription, translation, and modification of autophagy-related (Atg) proteins. Thus inhibition of the type I PI3K-mTOR pathway can induce autophagy. mTOR activity can also be affected by many other mechanisms, and thus can coordinate signaling pathways that are initiated by many nutritional and mitogenic factors. Autophagy can also be induced by lowering inositol trisphosphate (IP3) level, an mTOR-independent way. Vps34, a type III PI3K that includes berclin-1 (Atg6) in its complex, promotes the nucleation of autophagic vesicles.

Autophagosomes are formed after elongation and closure of the isolation membranes, which engulf the cytoplasmic materials (cytosol and/or organelles) [74-76, 88-90]. Two ubiquitin-like conjugation systems are part of this process. One system involves the covalent conjugation of Atg12 to Atg5, with the help of the E1 (ubiquitin-activating enzyme) -like enzyme Atg7 and the E2 (ubiquitin carrier) -like enzyme Atg10. Atg16L-binding to the Atg12-Atg5 complex is necessary for the elongation of the isolation membrane and formation of the autophagosomal membrane. This complex finally dissociates from the mature autophagosome. The second system involves the conjugation of phosphatidylethanolamine (PE) to microtubule-associated protein 1-light chain 3 (LC3)/Atg8 by the sequential action of the protease Atg4, the E1-like enzyme Atg7, and the E2-like enzyme Atg3. Lipid conjugation causes conversion of the soluble form of LC3 (named LC3-I) to the autophagic vesicle-associated form (LC3-II).The targeting of LC3-PE to the isolation membrane or autophagosomal membrane relies on the Atg12-Atg5 complex, but it will keep binding to the membrane after Atg12-Atg5 leaves.

As the last step, the autophagosomes fuse with lysosomes [74-76, 88-90]. Before this fusion, the autopahgosomes can fuse with endosomal vesicles first (amphisome). The autophagosome outer membrane fuses with the lysosome (or endosome) membrane while the inner sac (autophagic body) enters the lysosome, where its membrane as well as the luminal content is degraded by lysosomal enzymes that act optimally within this acidic 
compartment. The formed single membrane-surrounded vesicle is called an autophagolysosome or autolysosome.

The current first-line antiglioma drug, DNA-alkylating agent TMZ can induce both autophagic cell death and apoptosis. Other drugs or drug candidates that can induce autophagy in cancer cells include mTOR inhibitors everolimus and deforolimus, arsenic trioxide, ceramide, endostatin, the histone deacetylase (HDAC) inhibitors butyrate and vorinostat, neodymium oxide, saponins, curcumin, and resveratrol [74-76, 88-90].

\subsubsection{Necrosis}

Necrosis can be defined morphologically as cell and organelle swelling, or rupture of surface membranes with spillage of intracellular contents [74, 75, 91]. Necrosis was thought to be an uncontrolled process. But recently, more and more evidence shows that necrosis can be a regulated event $[74,75,91]$. Some researchers called the regulated form of necrosis type III programmed cell death. Inducers of necrosis include DNA damage, inhibition of cellular energy production (ATP depletion), imbalance of intracellular calcium flux, viral infection, excess generation of reactive oxygen species (ROS), and activation of nonapoptotic proteases (e.g., calpain and cathepsin).

Necrosis can also be induced by chemotherapy [74, 75, 91]. DNA-alkylating agents can activate PARP, while the hyperactivation of PARP depletes cytosolic nicotinamide adenine dinucleotide (NAD) and induces necrosis. Photodynamic treatment, $\beta$-lapachone, apoptolidin, and honokiol can also induce necrosis in cancer cells. Necrosis inducing is not likely to be a promising approach to treat gliomas. In fact, pseudopalisading necrosis is a hallmark of glioblastoma.

\subsubsection{Mitotic catastrophe}

Mitotic catastrophe refers to death that occurs during mitosis, resulting from a combination of deficient cell-cycle checkpoints and cellular damage $[75,92,93]$. The aforementioned cell-cycle checkpoints can be DNA structure checkpoints or the spindle assembly checkpoint. Since cancer cells often have deficient cell cycle checkpoints, when compared to normal cells, cancer cells are more susceptible to the induction of mitotic catastrophe by chemotherapy drugs acting as DNA damaging agents or microtubule poisons.

Some researchers believe that mitotic catastrophe is not an independent mode of cell death $[75,92,93]$. They propose an alternative definition: Mitotic catastrophe is a process characterized by the formation of multinucleated cells resulting from aberrant mitosis, and is a "prestage" of apoptosis or necrosis. 


\subsubsection{Senescence}

Senescence is a state of permanent cell-cycle arrest [92, 94]. Senescent cancer cells although alive, can be cleared by immune cells, resulting in cancer regression. Therefore, senescence is also included in the cell death pathways.

Cellular stresses can activate tumor suppressors, e.g., p53, INK4A and ARF, and trigger senescence $[92,94]$. Senescent cells can secrete both tumor-suppressing factors that reinforce the senescent phenotype and tumor-promoting factors that stimulate malignant phenotypes in nearby cells. In pre-malignant tumors, most cells are senescent. In malignant tumors, their ability to undergo senescence is impaired, but they can still be forced into senescence by chemotherapy $[92,94]$. In vitro studies show that classic chemotherapy often induces senescence at moderate doses and apoptosis at higher ones. Senescence markers have also been found in biopsy from patients undergoing chemotherapy. 


\section{CHAPTER 2. PHARMACOKINETICS OF EDL-291}

\subsection{Introduction}

As described in 1.2.5, previous studies show that replacement of the A-rings catechol group in EDL-155 with dimethoxy may decrease the clearance (CL) by blocking the metabolic "soft-spot". However, the increase of LogP caused by this modification may also decrease the brain penetration [63].

Based on these findings, efforts were made by our collaborating laboratories to decrease the LogP, block the metabolic "soft-spot," and increase antiglioma potency at the same time. EDL-291, i.e., 6,7-dimethoxy-1-[4- (4-methoxypyridin-3-yl) phenyl] methyl-1,2,3,4-tetrahydroisoquinoline, is one of the best EDL-155 analogs to achieve these goals. Chemical structure and selected physiochemical properties of EDL-291 are shown in Figure 2-1. By also replacing the $\mathrm{C}$ phenyl ring with 4-methoxypyridin while blocking the A-rings catechol group, the LogP is reduced rather than increased. A pilot study indicates that at $10 \mathrm{~min}$ after intravenous (though vena cava) injection of $10 \mathrm{mg} / \mathrm{kg}$ to rats, the brain concentration of EDL-291 is higher than that of EDL-155 (2.45 vs. 1.16 $\mathrm{ng} / \mathrm{mg}$ ). In addition, the EC50 on C6 rat glioma cells is also reduced from 1.5 to $0.6 \mathrm{mM}$ [95]. Therefore, EDL-291 could be a promising drug candidate for glioma treatment. And this warrants a detailed, preclinical pharmacokinetic characterization.

\subsection{Materials and Methods}

\subsubsection{Materials}

Ammonium acetate (ACS), HPLC grade acetonitrile and HPLC grade water were purchased from Fisher Scientific (Fair Lawn, NJ). Heparinized drug free rat plasma (Cat\# ES1009P, Lot\# 341234-P) was obtained from Biomeda (Foster City, CA). Test compounds EDL-115 (internal standard for EDL-155), EDL-155, EDL-291 (internal standard for EDL-313 and EDL-291MD), EDL-291MD, EDL-313 (internal standard for EDL-291) and EDL-323 were synthesized in Dr. Duane Miller's laboratory.

\subsection{2. $\mathrm{LC} / \mathrm{MS} / \mathrm{MS}$ method}

The LC/MS/MS system was composed of an AB Sciex (Foster City, CA) API 3000 tandem mass spectrometer and Shimadzu (Columbia, MD) LC-10ADvp pumps, and a LEAP (Carrboro, NC) HTS PAL autosampler. Data were processed using Analyst ${ }^{\circledR}$ software 1.4.2 (AB Sciex, Foster City, CA).

Chromatographic separation was performed using a Cadenza CD-C18 column $(100 \times 2.0 \mathrm{~mm}, 3 \mu \mathrm{m}$, purchased from Silvertone Sciences, Philadelphia, PA $)$. Mobile 

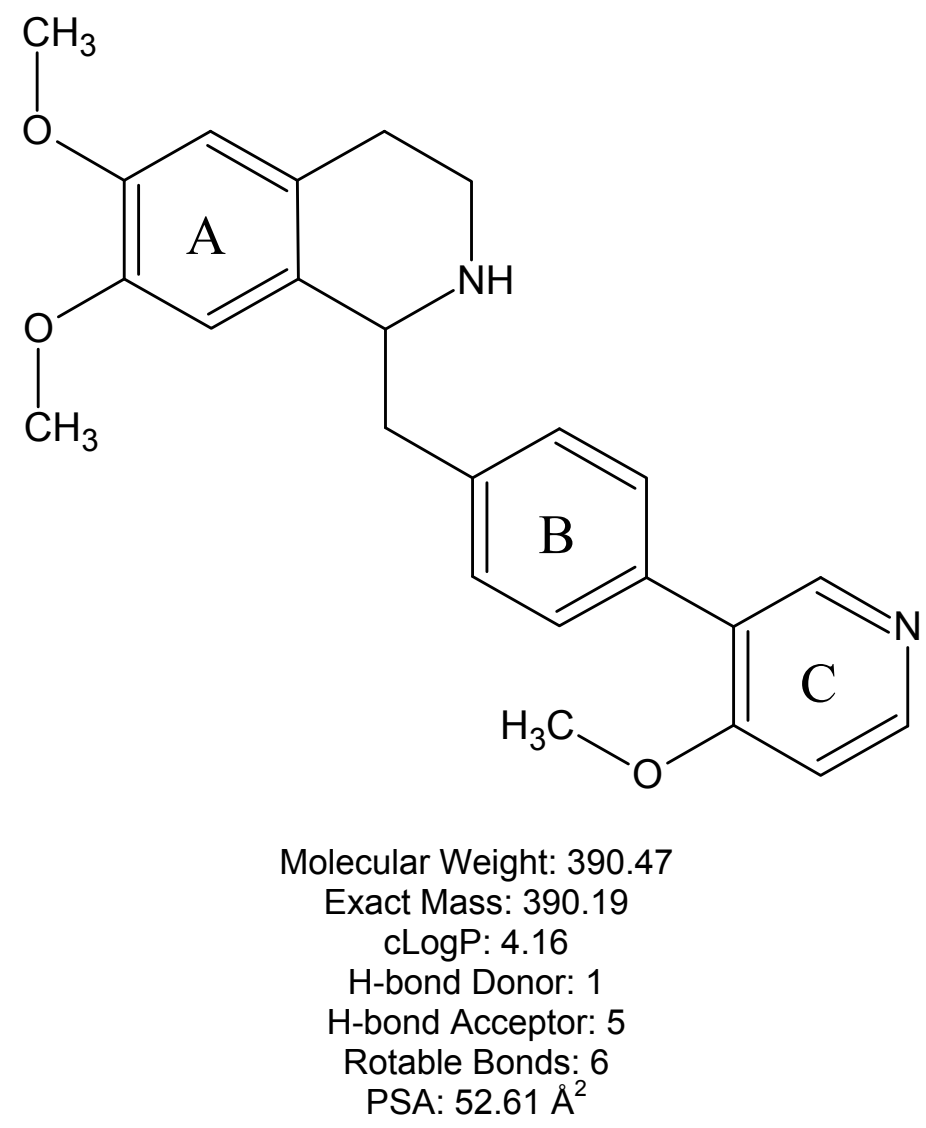

Figure 2-1. Structure and selected physiochemical properties of EDL-291

Exact mass and cLogP are calculated by ChemDraw Ultra 12.0 (CambridgeSoft Corporation, Cambridge, MA). All other values are calculated by Marvin Calculator Plugins (ChemAxon Kft., Hungary). 
phase, consisting of $\mathrm{A}\left(10 \mathrm{mM} \mathrm{NH}_{4} \mathrm{Ac}\right.$ in HPLC grade water, $\left.\mathrm{pH} 7.4\right)$ and $\mathrm{B}$ (acetonitrile), was delivered at $0.5 \mathrm{~mL} / \mathrm{min}$. The total run time was $3.5 \mathrm{~min}$. Gradient elution began at $30 \% \mathrm{~B}$ and was held for $1 \mathrm{~min}$, then increased to $70 \% \mathrm{~B}$ over $1 \mathrm{~min}$, decreased to $30 \% \mathrm{~B}$ over 1 minute, and finished at $30 \% \mathrm{~B}$ for $0.5 \mathrm{~min}$.

The mass spectrometer was operated in the positive electrospray ionization (ESI) mode (TurbolonSpray) with the following parameters: ionspray voltage (IS) $1500 \mathrm{~V}$, nebulizing gas (NEB) 14.0, curtain gas (CUR) 14.0, source temperature (TEM) $550.0^{\circ} \mathrm{C}$, collision-activated dissociation (CAD) gas 7.0, declustering potential (DP) $76.0 \mathrm{~V}$, focusing potential (FP) $150.0 \mathrm{~V}$, entrance potential (EP) $10.0 \mathrm{~V}$, collision energy $31.0 \mathrm{~V}$, collision cell exit potential (CXP) $18.00 \mathrm{~V}$, deflector (DF) -200 V, channel electron multiplier (CEM) $2200 \mathrm{~V}$, and turbo gas (GS2) $7.0 \mathrm{~L} / \mathrm{min}$.

The MS/MS measurements were performed in multiple reaction monitoring (MRM) mode. The molecule ions $[\mathrm{M}+\mathrm{H}]^{+}$selected in Q1 were subjected to collision-activated dissociation by $\mathrm{N}_{2}$ in the collision cell (Q2), and the product ions were monitored by scanning the third quadrupole (Q3). Monitored MRM transition were $332.4 \rightarrow 167.2$ for EDL-155, 361.0 $\rightarrow$ 168.1 for EDL-115, 391.2 $\rightarrow 200.1$ for EDL-291, $375.0 \rightarrow 200.1$ for EDL-291MD, 395.0 $\rightarrow 202.2$ for EDL-313, and 379.2 $\rightarrow 202.2$ for EDL-323.

For metabolite identification, a slow gradient and Q1 scan were used. Then the total ion current (TIC) chromatograph was extracted using the molecular weight of each putative metabolite $\pm 0.5 \mathrm{amu}$. The possible metabolites found were further verified by neutral loss, precursor, and/or MRM scan.

\subsubsection{Animals}

Male Sprague-Dawley rats weighing between 250 and 275 grams were purchased from Charles River Laboratories (Wilmington, MA) and maintained in the animal facility at UTHSC. Rats were fed ad libitum on normal laboratory diet and water. A $12 \mathrm{hr}$ light-dark cycle and ambient temperature of $25{ }^{\circ} \mathrm{C}$ were maintained. Rats for the peripheral pharmacokinetic study were individually housed in the metabolism cages and rats for the CNS pharmacokinetic study were individually housed in regular plastic cages.

Rats bearing both jugular and femoral vein catheters were used for the peripheral pharmacokinetic study after intravenous bolus injection $(n=6)$. Rats bearing only jugular vein catheters were used for the CNS pharmacokinetic study after intravenous bolus injection $(n=9)$ or for the peripheral pharmacokinetic study after oral gavage $(n=5)$. The patency of the jugular vein and femoral vein catheters was maintained every other day with heparinized glycerol solution (500 IU heparin/mL final solution in $75 \%$ glycerol) according to vendor's instructions.

Male C57BL/6J mice weighing between 25 and 35 grams were purchased from The Jackson Laboratory (Bar Harbor, ME) and maintained in the animal facility at 
UTHSC. Mice were fed ad libitum on normal laboratory diet and water. A $12 \mathrm{hr}$ light-dark cycle and ambient temperature of $25^{\circ} \mathrm{C}$ were maintained.

\subsubsection{Drug solution}

EDL-291 was dissolved in sterile normal saline at $10 \mathrm{mg} / \mathrm{mL}$ concentration.

\subsubsection{Plasma protein binding}

Pooled rat plasma or pooled human plasma from healthy donors was spiked with aqueous EDL-291 stock solution to the desired concentrations $(5 \mu \mathrm{g} / \mathrm{mL}$ and $10 \mu \mathrm{g} / \mathrm{mL})$. All samples were incubated at $37^{\circ} \mathrm{C}$ for $1 \mathrm{~h}$ before being centrifuged in Microcon Ultracel YM-30 (molecular weight cut-off 30,000 Da; Millipore, Billerica, MA) at room temperature, $10,000 \mathrm{~g}$, for $15 \mathrm{~min}$. Filtrate or non-filtrated spiked plasma was mixed with 4 volume of ice-cold acetonitrile and then centrifuged at $4{ }^{\circ} \mathrm{C}, 10,000 \mathrm{~g}$, for $5 \mathrm{~min} .10 \mu \mathrm{L}$ supernatant from each sample was injected into LC/MS/MS, respectively. Phosphate buffered saline (PBS) was also treated in the same way to determine the effect of non-specific binding. The plasma protein binding (PPB) was calculated as follows:

$$
\operatorname{PPB}(\%)=\left[\left(1-\mathrm{I}_{\mathrm{u}} / \mathrm{I}_{\mathrm{t}}\right)-\left(1-\mathrm{I}_{\mathrm{cu}} / \mathrm{I}_{\mathrm{ct}}\right)\right] \times 100 \%
$$

where $I_{u}, I_{t}, I_{c u}$, and $I_{c t}$ refer to EDL-291 peak area in filtrate of spiked plasma sample, non-filtrated spiked plasma sample, filtrate of spiked PBS sample, and non-filtrated spiked PBS sample, respectively.

\subsubsection{Erythrocyte partitioning}

The method used was adopted from the depletion method reported by Yu et al. [96]. Fresh human blood from healthy male donors was spiked to $500 \mathrm{nM}$ EDL-291 concentration. Fresh human plasma prepared from the same batch of fresh whole blood was used as a reference and treated in the same way. The reference plasma volume was identical to the whole blood volume. Both sample tubes were gently mixed and then incubated at $37^{\circ} \mathrm{C}$ for up to $2 \mathrm{~h}$. During the incubation, at 0,60 , and $120 \mathrm{~min}$, a $200 \mu \mathrm{L}$ aliquot of incubated whole blood was removed from each sample tubes and centrifuged in Microtainer® tubes with lithium heparin and plasma separation gel (Catalog \# 365958, $\mathrm{BD}$, Franklin Lakes, NJ) at $10,000 \mathrm{~g}, 4^{\circ} \mathrm{C}$ for $2 \mathrm{~min}$. A $50 \mu \mathrm{L}$ aliquot of generated plasma was transferred into a new tube. At each of these time points, a $50 \mu \mathrm{L}$ aliquot of incubated reference plasma sample was also sampled and transferred into a new tube. 200 $\mu \mathrm{L}$ of ice-cold acetonitrile was then added to each of $50 \mu \mathrm{L}$ plasma or whole blood samples. The resulting mixture was vortexed and centrifuged at $10,000 \mathrm{~g}, 4^{\circ} \mathrm{C}$ for 10 min. $10 \mu \mathrm{L}$ of the supernatant was injected for LC/MS/MS analysis. The red blood cells

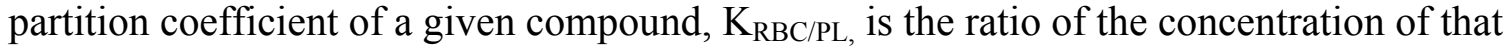


compound in the red blood cells to concentration of that compound in plasma. $\mathrm{K}_{\mathrm{RBC} / \mathrm{PL} \text {, }}$ can be determined from following equation:

$$
\mathrm{K}_{\mathrm{RBC} / \mathrm{PL}}=\frac{1}{\mathrm{H}}\left(\frac{\mathrm{I}_{\mathrm{PL}}^{\mathrm{REF}}}{\mathrm{I}_{\mathrm{PL}}}-1\right)+1
$$

where $\mathrm{H}=$ hematocrit value, $\mathrm{I}_{\mathrm{PL}}^{\mathrm{REF}}=$ peak area of EDL-291 in reference plasma, and $\mathrm{I}_{\mathrm{PL}}=$ peak area of EDL-291 in equilibrating plasma from whole blood.

\subsubsection{Stability in whole blood}

Fresh blood from a male SD rat was spiked to $1 \mu \mathrm{M}$ EDL-291 or EDL-155 concentration and then incubated in a shaker at $37^{\circ} \mathrm{C}, 250 \mathrm{rpm}$ for up to $3 \mathrm{~h}$. During the incubation, a $30 \mu \mathrm{L}$ aliquot was removed at $0,60,120$, and $180 \mathrm{~min}$, respectively. $270 \mu \mathrm{L}$ of distilled water was added first; then the mixture was vortexed for $30 \mathrm{~s}$, kept at room temperature for $15 \mathrm{~min}$, and then $1200 \mu \mathrm{L}$ ice-cold acetonitrile with $0.1 \%$ formic acid (v/v) was added to the aliquot and kept at $4{ }^{\circ} \mathrm{C}$ for $15 \mathrm{~min}$. The resulting mixture was vortexed for $30 \mathrm{~s}$ and then centrifuged at $10,000 \mathrm{~g}, 4^{\circ} \mathrm{C}$ for $10 \mathrm{~min}$. A $100 \mu \mathrm{L}$ of the supernatant was mixed with $100 \mu \mathrm{L}$ of distilled water in a glass vial, and then was kept at $-20{ }^{\circ} \mathrm{C}$ until analysis next day. Then $10 \mu \mathrm{L}$ was injected for LC/MS/MS analysis. The parent compound remaining in the incubation mixture at various time points was determined by comparing peak area of those time points to that of $0 \mathrm{~min}$ sample.

\subsubsection{Stability to pulmonary metabolism}

A $4 \times$ NADPH regenerating system master mix was prepared by mixing BD Gentest NADPH-regenerating system solution A $(20 \times)$ (Catalog Number: 451220), solution B $(100 \times)($ Catalog Number: 451200$)$, and an appropriate volume of HPLC-grade water. Test compound stock solution was prepared at $1 \mathrm{mg} / \mathrm{mL}$ in HPLC grade water. Male SD rat pulmonary microsomes $(10 \mathrm{mg} / \mathrm{mL})$ were purchased from XenoTech (Lenexa, Kansas). The final concentration of each component in the incubation system was $50 \mu \mathrm{M}$ drug, $2.0 \mathrm{mg} / \mathrm{mL}$ microsomes, $1.3 \mathrm{mM} \mathrm{NADP}{ }^{+}, 3.3 \mathrm{mM}$ glucose-6-phosphate, $0.4 \mathrm{U} / \mathrm{mL}$ glucose-6-phosphate dehydrogenase, $3.3 \mathrm{mM}$ magnesium chloride, and $50 \mathrm{mM} \mathrm{pH} 7.4$ potassium phosphate buffer. The total volume of each reaction was $500 \mu \mathrm{L}$. The reaction was initiated by adding microsomes and was incubated in a $37^{\circ} \mathrm{C} \mathrm{CO}_{2}$ incubator. $100 \mu \mathrm{L}$ mixtures were removed from one of the reactions at 0 and $120 \mathrm{~min}$ after start and then mixed thoroughly with $100 \mu \mathrm{L}$ ice-cold acetonitrile containing IS. These samples were centrifuged at 10,000 g for $30 \mathrm{~min}$, and the supernatant was injected into LC/MS/MS directly.

The parent compound remaining in the incubation mixture at various time points was determined by comparing the internal standard normalized peak area of the parent compound $\left(\mathrm{I}_{\text {compound }} / \mathrm{I}_{\mathrm{IS}}\right)$ to that of 0 min sample as follows: 


$$
\text { Percent of remaining }(\%)=\left(\mathrm{I}_{\text {compound }} / \mathrm{I}_{\mathrm{IS}}\right)_{\mathrm{t}} /\left(\mathrm{I}_{\text {compound }} / \mathrm{I}_{\mathrm{IS}}\right)_{0} \times 100 \%
$$

where ( $\left.\mathrm{I}_{\text {compound }} / \mathrm{I}_{\mathrm{IS}}\right)_{\mathrm{t}}$ and $\left(\mathrm{I}_{\text {compound }} / \mathrm{I}_{\mathrm{IS}}\right)_{0}$ represent the internal standard normalized peak areas of the parent compound measured at various time points and $0 \mathrm{~min}$, respectively.

\subsubsection{Pharmacokinetic sampling and processing}

\subsubsection{Peripheral pharmacokinetics}

2.2.9.1.1. Intravenous bolus injection. EDL-291 was administered $(10 \mathrm{mg} / \mathrm{kg})$ to SD rats $(n=6)$ by intravenous bolus via the femoral vein catheter. Blood $(100 \mu \mathrm{L})$ was collected into Microtainer ${ }^{\circledR}$ tubes with lithium heparin and plasma separation gel from the jugular vein catheter at $5,15,30,45,60,75,90,120,180,240,360,480,600$, and 1440 min after dosing. Samples were centrifuged at $10,000 \mathrm{~g}, 4{ }^{\circ} \mathrm{C}$ for $2 \mathrm{~min}$. Plasma was stored at $-80^{\circ} \mathrm{C}$ until analysis. Drug-free urine and feces were collected the day before the drug administration. At $24 \mathrm{hr}$ post-dose, the feces were carefully collected into $50 \mathrm{~mL}$ polypropylene centrifuge tubes and weighed. The volume of the total urine sample was obtained by subtracting the bottle weight from the total weight. All the feces and urine samples were then stored at $-80^{\circ} \mathrm{C}$ until analysis using LC/MS/MS.

2.2.9.1.2. Oral gavage. EDL-291 was administered $(40 \mathrm{mg} / \mathrm{kg})$ to $\mathrm{SD}$ rats $(\mathrm{n}=5)$ by oral gavage with an $18 \mathrm{G}$ stainless steel feeding needle. Blood $(100 \mu \mathrm{L})$ was collected into Microtainer ${ }^{\circledR}$ tubes with lithium heparin and plasma separation gel from the jugular vein catheter at 20,40,60,80,100,120,180,240,360, 480, 600, and 1440 min after dosing. Samples were centrifuged at $10,000 \mathrm{~g}, 4^{\circ} \mathrm{C}$ for $2 \mathrm{~min}$, and the plasma was stored at $-80{ }^{\circ} \mathrm{C}$ until analysis.

\subsubsection{CNS pharmacokinetics}

2.2.9.2.1. Rat intravenous bolus injection. EDL-291 was administrated (10 $\mathrm{mg} / \mathrm{kg})$ to SD rats $(\mathrm{n}=9)$ by intravenous bolus via the jugular vein catheter. Rat was then anesthetized by $0.65 \mathrm{ml} / \mathrm{kg}$ ketamine/xylazine premix and perfused transcardially by normal saline for $2 \mathrm{~min}$. Rat brains were collected at $20 \mathrm{~min}(\mathrm{n}=5), 90 \mathrm{~min}(\mathrm{n}=2)$, and $180 \mathrm{~min}(\mathrm{n}=2)$ post-dose, respectively after perfusion. These samples were kept at $-80{ }^{\circ} \mathrm{C}$ until analyzed by $\mathrm{LC} / \mathrm{MS} / \mathrm{MS}$.

2.2.9.2.2. Mouse subcutaneous injection. EDL-291 was administered $(50 \mathrm{mg} / \mathrm{kg})$ to $\mathrm{C} 57 \mathrm{BL} / 6 \mathrm{~J}$ mice $(\mathrm{n}=12)$ by subcutaneous injection. Two of these mice were anesthetized by ketamine/xylazine at $5,15,25,55,85$, or 175 min post-dose, respectively. The blood samples were collected by cardiac puncture at 10, 20,30, 60, 90, and $180 \mathrm{~min}$ post-dose then centrifuged at $10,000 \mathrm{~g}, 4^{\circ} \mathrm{C}$ for $2 \mathrm{~min}$, and the plasma was stored at $-80^{\circ} \mathrm{C}$ until analysis. The brains were collected after $5 \mathrm{~min}$ of transcardial perfusion and kept at $-80{ }^{\circ} \mathrm{C}$ until analyzed by LC/MS/MS. 


\subsubsection{Sample preparations}

2.2.9.3.1. Plasma sample preparations. $200 \mu \mathrm{L}$ of ice-cold acetonitrile and $20 \mu \mathrm{L}$ of IS (internal standard solution) were added to each of $50 \mu \mathrm{L}$ plasma samples. The resulting mixture was vortexed and centrifuged at $10,000 \mathrm{~g}, 4^{\circ} \mathrm{C}$ for $10 \mathrm{~min} .10 \mu \mathrm{L}$ of the supernatant was injected for LC/MS/MS analysis.

2.2.9.3.2. Feces sample preparations. $4 \mathrm{ml}$ per gram of acetonitrile was added to feces; then the mixture was homogenized by PowerGen 125 handheld homogenizer (Fisher Scientific, Fair Lawn, NJ) for $30 \mathrm{~s}$ at maximal speed. $250 \mu \mathrm{L}$ homogenate was transferred to another $2 \mathrm{~mL}$ tube and $20 \mu \mathrm{L}$ of IS was added. The resulting mixture was vortexed and centrifuged at $10,000 \mathrm{~g}, 4^{\circ} \mathrm{C}$ for $10 \mathrm{~min} .10 \mu \mathrm{L}$ of the supernatant was injected for LC/MS/MS analysis.

2.2.9.3.3. Urine sample preparations. $200 \mu \mathrm{L}$ of ice-cold acetonitrile and $20 \mu \mathrm{L}$ of IS (internal standard solution) were added to each of $50 \mu \mathrm{L}$ urine samples. The resulting mixture was vortexed and centrifuged at $10,000 \mathrm{~g}, 4^{\circ} \mathrm{C}$ for $10 \mathrm{~min} .10 \mu \mathrm{L}$ of the supernatant was injected for LC/MS/MS analysis.

2.2.9.3.4. Brain sample preparations. $1 \mathrm{~mL}$ per gram of HPLC grade water was added to the collected brains; then the mixture was homogenized by PowerGen 125 handheld homogenizer for $30 \mathrm{~s}$ at maximal speed. $100 \mu \mathrm{L}$ homogenate was transferred to another $2 \mathrm{~mL}$ tube; then $50 \mu \mathrm{L}$ of IS and $500 \mu \mathrm{L}$ of ice-cold acetonitrile were added. The resulting mixture was vortexed and centrifuged at $10,000 \mathrm{~g}, 4^{\circ} \mathrm{C}$ for $10 \mathrm{~min} .10 \mu \mathrm{L}$ of the supernatant was injected for LC/MS/MS analysis.

\subsubsection{Pharmacokinetics data analysis}

The in vivo pharmacokinetic data of EDL-291 were processed using WinNonlin ${ }^{\text {TM }}$ Professional version 5.2 (Pharsight Corporation, Mountain View, CA) for the estimates of pharmacokinetic parameters based on noncompartmental analysis (NCA), or user-defined three-compartment model (Figure 2-2). WinNonlin codes for the user-defined model are shown in Figure 2-3.

The user defined three-compartment model was used to fit simultaneously the naïve averaged EDL-291 plasma concentration data from the intravenous bolus injection peripheral pharmacokinetics study mentioned in 2.2.9.1.1 and naïve pooled and averaged brain concentration data from the CNS pharmacokinetics study mentioned in 2.2.9.2.1. A two-compartment model analysis (without the brain compartment) was performed first to get the initial estimate of parameters. This approach is similar to the one used by Rai et al. [97]. Nelder-Mead method with iterative reweighting $\left(1 / \hat{Y}^{2}\right)$ was used in minimization process. 


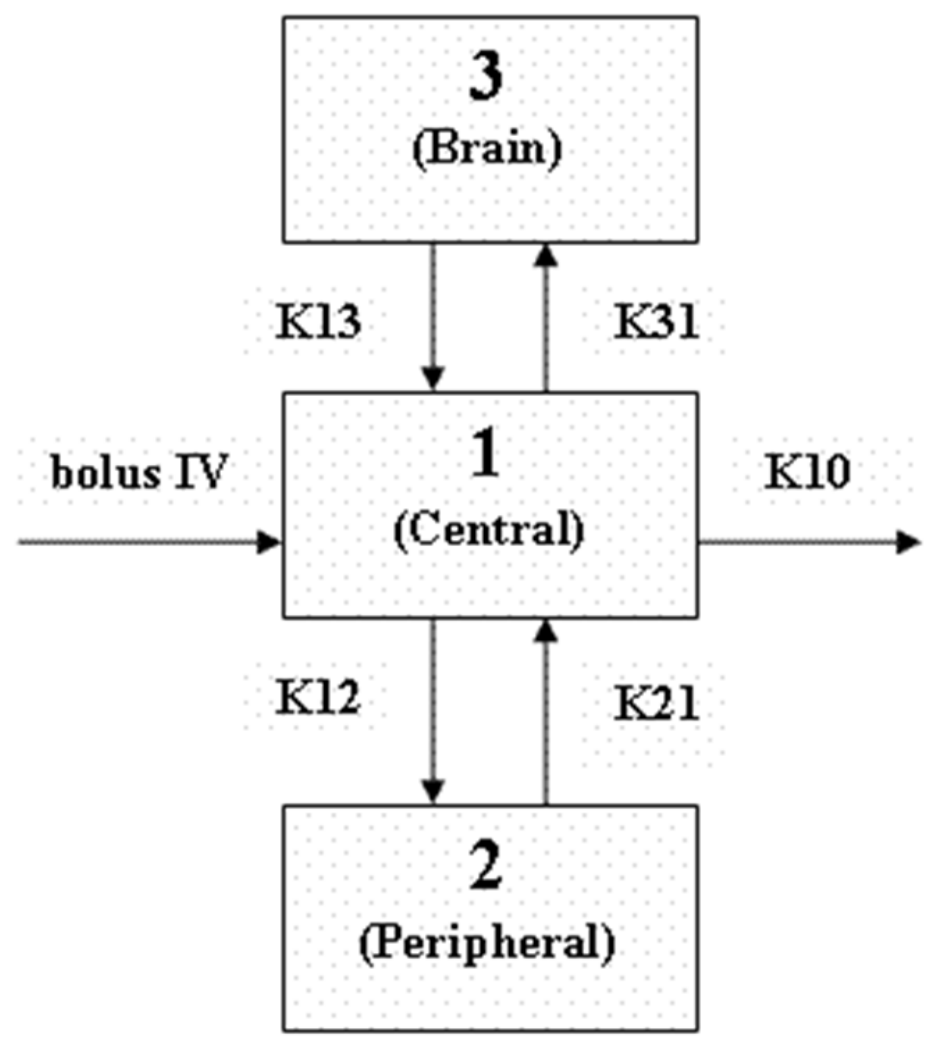

Figure 2-2. Three-compartment user-defined model for simultaneous fitting of plasma and brain concentration of EDL-291 after intravenous bolus injection

Boxes represent compartments. Arrows represent direction of mass transfer. The rate constants $(\mathrm{k} 10, \mathrm{k} 12, \mathrm{k} 21, \mathrm{k} 13$, and $\mathrm{k} 31)$ are shown beside the corresponding mass transfer arrows. 


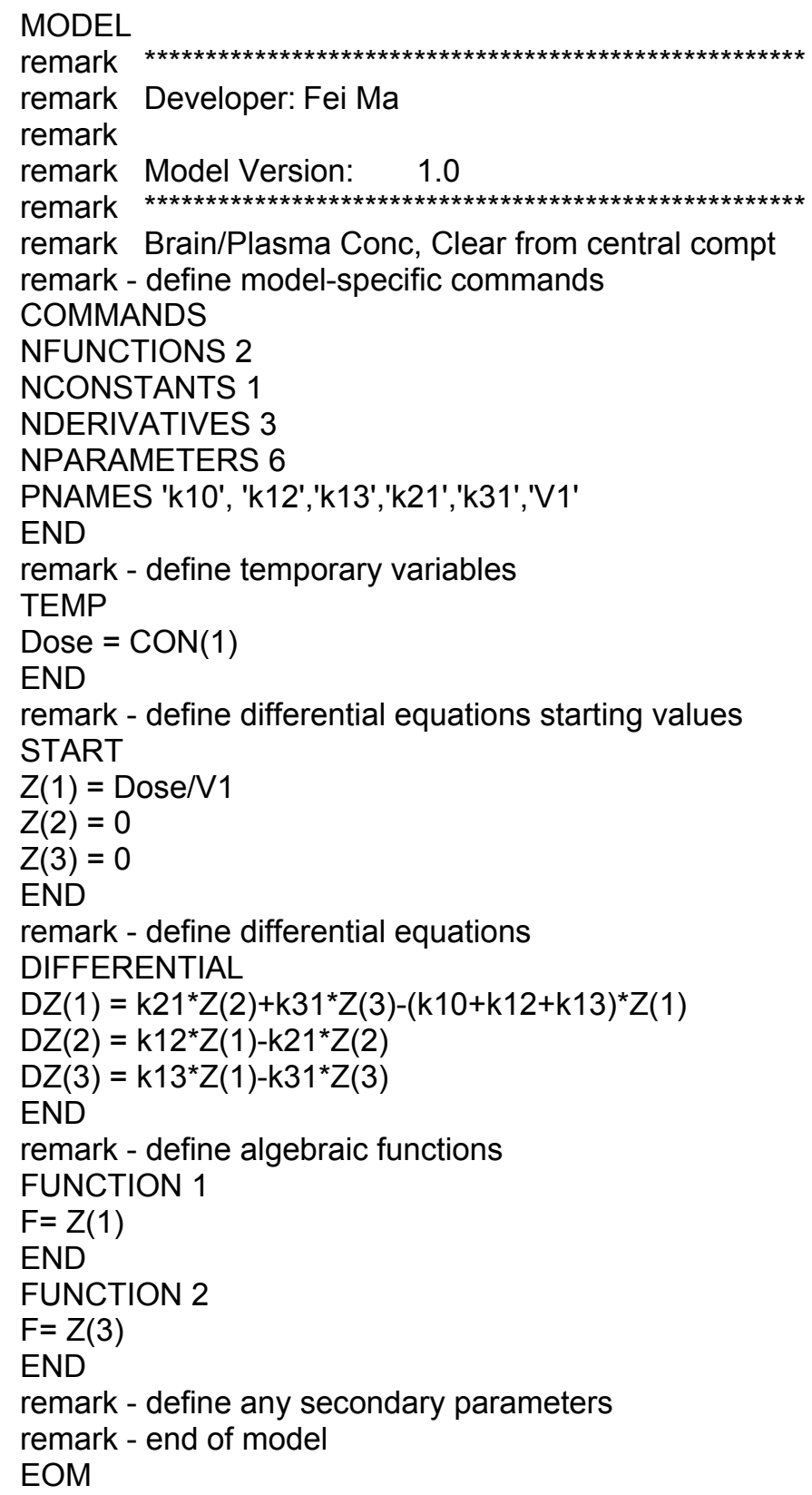

Figure 2-3. WinNonlin codes for the three-compartment user-defined model in Figure 2-2 


\subsection{Results}

\subsubsection{Plasma protein binding}

EDL-291 was extensively bound to plasma proteins with percent bound values of $60.0,54.4,56.4$, and 58.9 at concentrations of $5 \mu \mathrm{g} / \mathrm{mL}$ in rat plasma, $10 \mu \mathrm{g} / \mathrm{mL}$ in rat plasma, $5 \mu \mathrm{g} / \mathrm{mL}$ in human plasma, and $10 \mu \mathrm{g} / \mathrm{mL}$ in human plasma, respectively.

\subsubsection{Erythrocyte partitioning}

In order to understand erythrocyte accumulation of EDL-291 and EDL-155, partition coefficient $\mathrm{K}_{\mathrm{RBC} / \mathrm{PL}}$ was estimated for both compounds. The calculated $\mathrm{K}_{\mathrm{RBC} / \mathrm{PL}}$ of EDL-291 after 0, 60, and $120 \mathrm{~min}$ incubation are 0.2, 0.9, and 0.6, respectively. In contrast, the $\mathrm{K}_{\mathrm{RBC} / \mathrm{PL}}$ values of EDL-155 at same time points are 5.6, 8.6, and 1.4, respectively (Figure 2-4). Therefore, EDL-291 does not accumulate in erythrocytes at the tested concentration, while EDL-155 does.

\subsubsection{Stability in whole blood}

As shown in Figure 2-5, EDL-291 is stable in whole blood at the concentrations tested, while the last generation compound EDL-155 is not.

\subsubsection{Pulmonary metabolic stability}

As shown in Table 2-1, EDL-291 is susceptive to pulmonary microsomal metabolism. The pulmonary stability can be improved by modification of methoxy groups in the A-ring and C-ring.

\subsubsection{Peripheral pharmacokinetics}

\subsubsection{Intravenous bolus injection}

The plasma concentration versus time profile of EDL-291 (Figure 2-6) during the sampling period demonstrates rapid elimination. The clearance $(\mathrm{CL})$, volume of distribution at steady state $\left(\mathrm{Vd}_{\mathrm{ss}}\right)$, terminal half-life $\left(\mathrm{t}_{1 / 2}\right)$, and area under the curve $\left(\mathrm{AUC}_{\mathrm{iv}, 0-\infty}\right)$ were estimated by NCA Model 201 with Linear Up/Log Down setting in WinNonlin 5.2. The number of data points used for estimating terminal slope $\lambda_{z}$ was determined by Best Fit method in WinNonlin. The estimated individual pharmacokinetic parameters were then summarized by built-in descriptive statistics tool in the same software (Table 2-2). 1.2\% of the dosed EDL-291 was found in urine over $24 \mathrm{hr}$ post-dose period. The identified metabolites in plasma and feces as well as the putative 


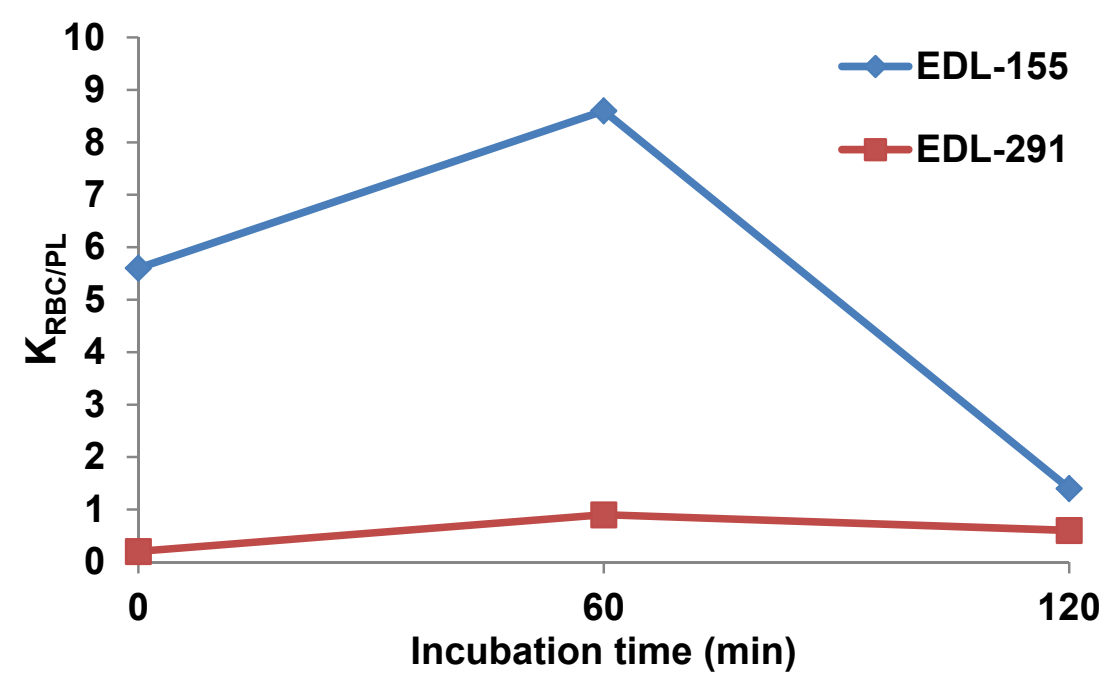

Figure 2-4. Erythrocyte partitioning of EDL-291 and EDL-155

Concentrations of EDL-291 and EDL-155 are both $500 \mathrm{nM}$. Red blood cells partition coefficient $\mathrm{K}_{\mathrm{RBC} / \mathrm{PL}}$ is the ratio of the concentration of a compound in the red blood cells to concentration of that compound in plasma.

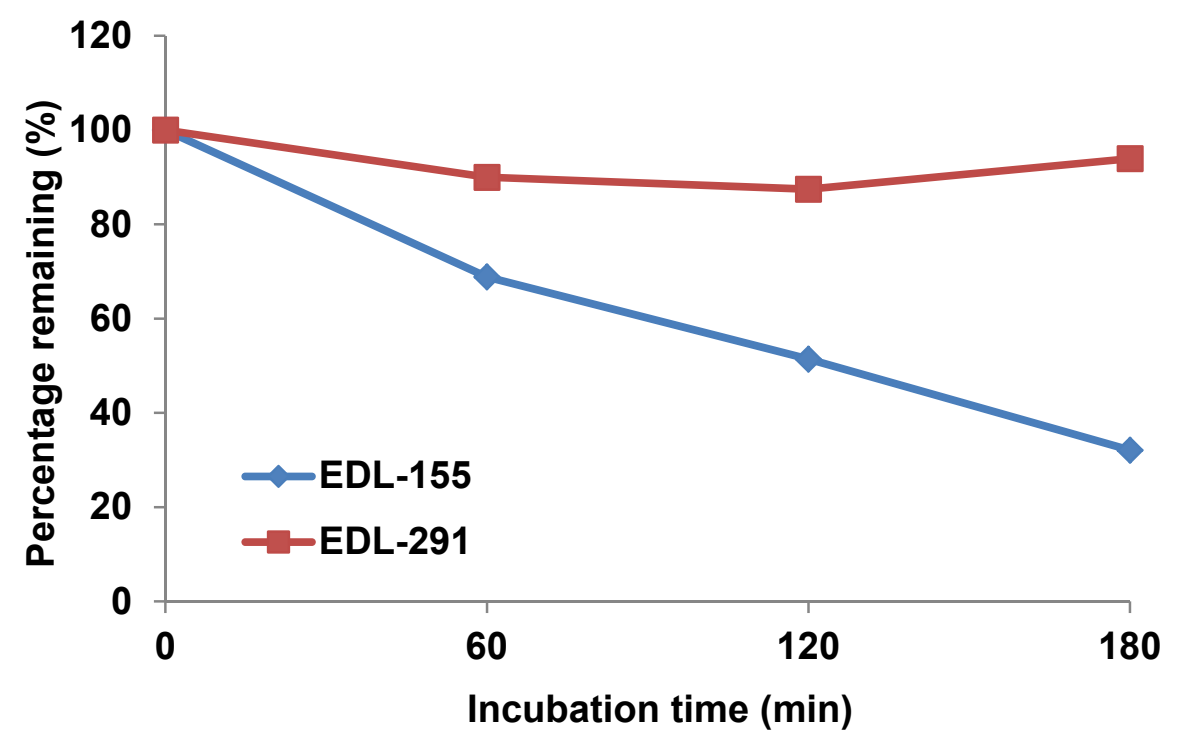

Figure 2-5. Stability of EDL-291 and EDL-155 in whole rat blood

$1 \mu \mathrm{M}$ EDL-291 or EDL-155 was spiked into fresh blood from a male SD rat and then incubated in a shaker at $37^{\circ} \mathrm{C}, 250 \mathrm{rpm}$ for up to $3 \mathrm{~h}$. 
Table 2-1. Percentage of parent compounds remaining after $2 \mathrm{hr}$ incubation with rat pulmonary microsomes

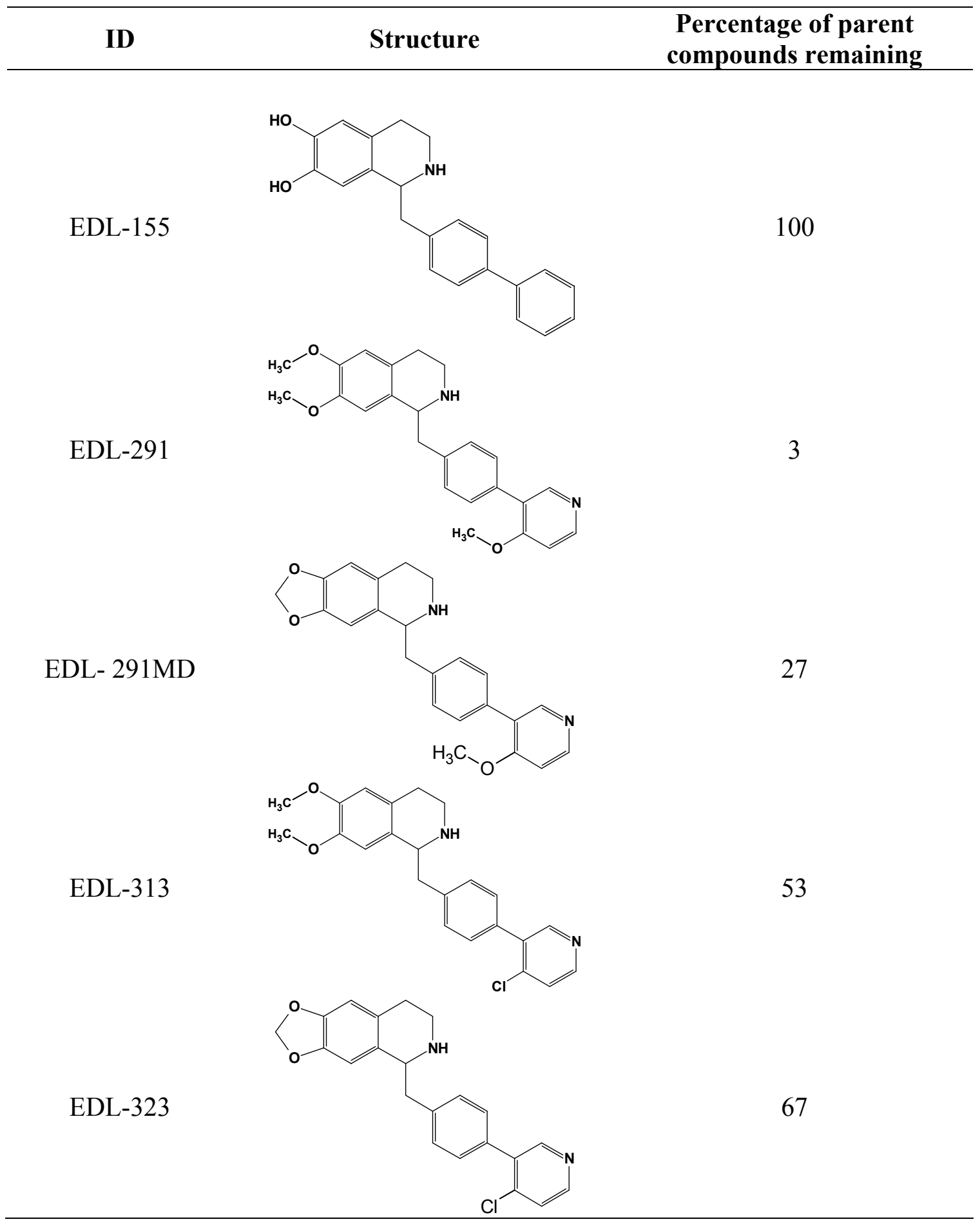




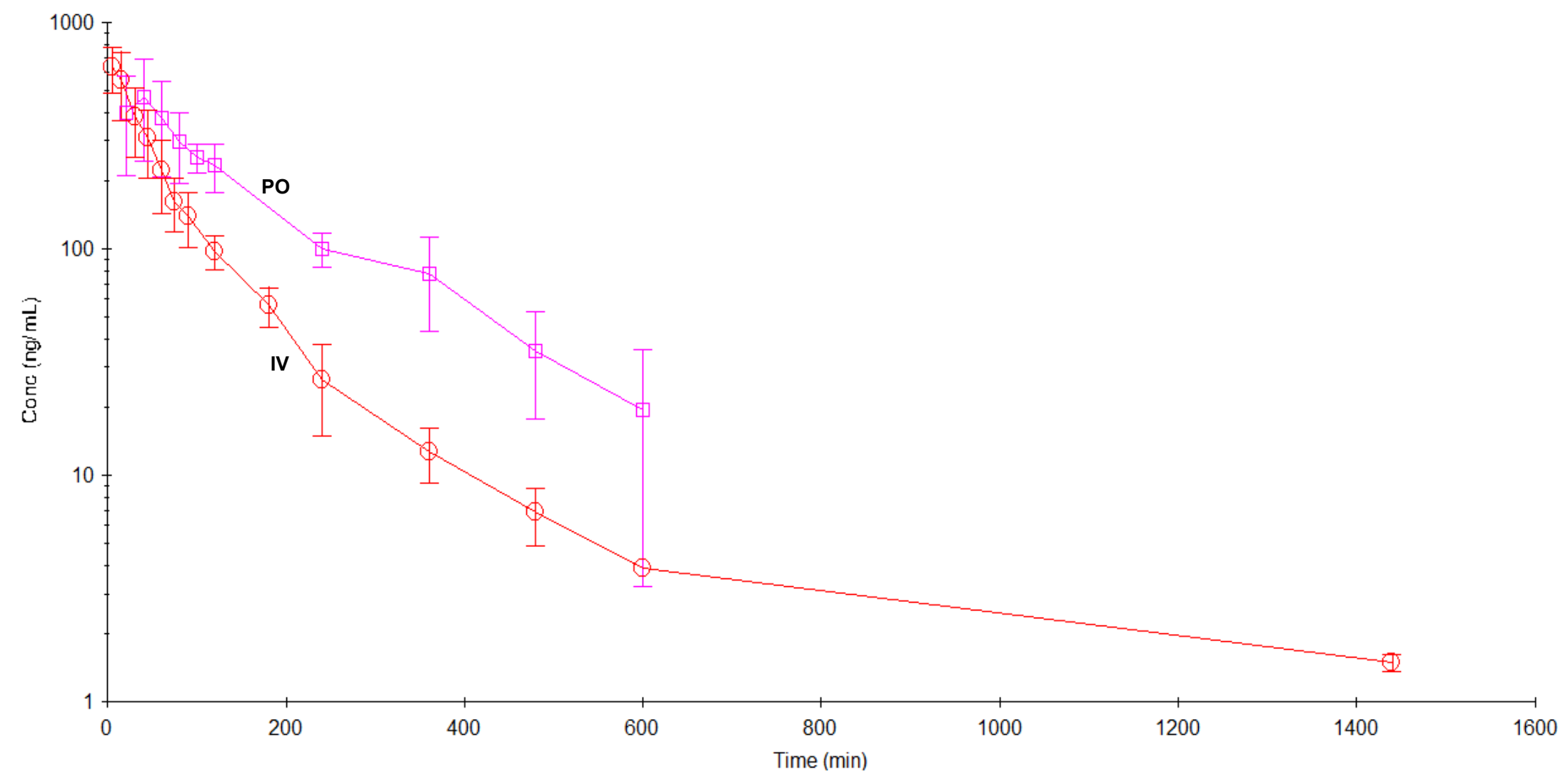

Figure 2-6. Plasma concentration-time profile in SD rats after $10 \mathrm{mg} / \mathrm{kg}$ intravenous bolus injection or $40 \mathrm{mg} / \mathrm{kg}$ oral gavage of EDL-291

Intravenous bolus (IV) injection: $\mathrm{n}=5$ at $5 \mathrm{~min}, 360 \mathrm{~min}$, and $1440 \mathrm{~min} ; \mathrm{n}=1$ at $600 \mathrm{~min} ; \mathrm{n}=6$ at all other time points. Oral gavage (PO): $\mathrm{n}=4$ at $80 \mathrm{~min}$ and $120 \mathrm{~min} ; \mathrm{n}=5$ at at all other time points. The error bars are standard deviations. 
Table 2-2. Pharmacokinetic parameters of EDL-291 in male SD rats after intravenous bolus injection

\begin{tabular}{ccccc}
\hline Subject & $\begin{array}{c}\mathbf{C L} \\
(\mathbf{m L} / \mathbf{m i n} / \mathbf{k g})\end{array}$ & $\begin{array}{c}\mathbf{V d} \mathbf{d}_{\mathbf{s s}} \\
(\mathbf{L} / \mathbf{k g})\end{array}$ & $\begin{array}{c}\text { Terminal t} \\
\mathbf{( m i n})\end{array}$ & $\begin{array}{c}\mathbf{A U C}_{\mathbf{i v}, \mathbf{0}-\infty} \\
(\mathbf{m i n} \mathbf{m g} / \mathbf{L})\end{array}$ \\
\hline No. 2 & 190 & 28.6 & 465 & 52.6 \\
No. 3 & 252 & 49.4 & 322 & 39.7 \\
No. 4 & 294 & 60.7 & 338 & 34.0 \\
No. 5 & 167 & 26.3 & 352 & 59.8 \\
No. 6 & 215 & 36.4 & 492 & 46.5 \\
No. 7 & 166 & 14.4 & 92.0 & 60.3 \\
Geometric Mean & 209 & 32.5 & 305 & 47.8 \\
CV (\%) & 23.7 & 46.6 & 41.3 & 21.9 \\
\hline
\end{tabular}


pathways are shown in Figure 2-7.

\subsubsection{Oral gavage}

The plasma concentration-time profile after oral gavage is also shown in Figure 2-6. Oral clearance $\left(\mathrm{CL}_{\text {oral }}\right)$, oral volume of distribution during terminal phase $\left(\mathrm{Vd}_{\mathrm{z} \text {, oral }}\right)$, terminal half-life $\left(\mathrm{t}_{1 / 2, \mathrm{z}}\right)$, area under the curve $\left(\mathrm{AUC}_{\mathrm{po}, 0-\infty}\right)$, maximum plasma concentration $\left(\mathrm{C}_{\max }\right)$, and time to reach maximum plasma concentration $\left(\mathrm{t}_{\max }\right)$ were estimated by NCA Model 200 with Linear Up/Log Down setting in WinNonlin 5.2. The number of data points used for estimating terminal slope $\lambda_{z}$ was determined by Best Fit method in WinNonlin. The estimated individual parameters were then summarized by built-in descriptive statistics tool in the same software (Table 2-3). The absolute bioavailability was calculated as ratio of dosed normalized geometric mean of $\mathrm{AUC}_{\mathrm{po}, 0-\infty}$ and $\mathrm{AUC}_{\mathrm{iv}, 0-\infty}$.

\subsubsection{CNS pharmacokinetics}

\subsubsection{Rat intravenous bolus injection}

The rat brain and plasma concentration profile was shown in Figure 2-8. The $\mathrm{AUC}_{\text {brain }}{ }^{20-180 \mathrm{~min}}$ was estimated at $361 \mathrm{~min} \bullet \mathrm{mg} / \mathrm{L}$ by noncompartmental analysis of the naïve pooled sparse sampling brain concentration data using WinNonlin 5.2 NCA Model 201 with Linear Interpolation setting. By using the plasma concentration data generated in peripheral pharmacokinetics experiment after intravenous bolus, $\mathrm{AUC}_{\mathrm{plasma}} 20-180 \mathrm{~min}$, the geometric mean of individual plasma EDL-291 exposure during the same time, was estimated at $23.7 \mathrm{~min} \bullet \mathrm{mg} / \mathrm{L}$. Thus the rat brain to plasma AUC ratio was estimated at 14.0 .

The averaged brain and plasma concentrations were also simultaneously fitted (Figure 2-9) into the three-compartment model shown in Figure 2-2. The final estimates of parameters for the model parameters are $\mathrm{k}_{10}=0.164 \pm 0.0246 \mathrm{~min}^{-1}$ (estimate \pm standard error), $\mathrm{k}_{12}=0.0265 \pm 0.00606 \mathrm{~min}^{-1}, \mathrm{k}_{13}=0.736 \pm 0.419 \mathrm{~min}^{-1}, \mathrm{k}_{21}=0.00199 \pm$ $0.000320 \mathrm{~min}^{-1}, \mathrm{k}_{31}=0.0817 \pm 0.0404 \mathrm{~min}^{-1}$, and $\mathrm{V}_{1}=1.08 \times 10^{3} \pm 195 \mathrm{~mL} / \mathrm{kg}$.

\subsubsection{Mouse subcutaneous injection}

The mice brain and plasma concentration profile was shown in Figure 2-10. The mice $\mathrm{AUC}_{\text {brain }}{ }^{10-180 \mathrm{~min}}$ and $\mathrm{AUC}_{\text {plasma }}{ }^{10-180 \mathrm{~min}}$ were estimated at $150 \mathrm{~min} \cdot \mathrm{mg} / \mathrm{L}$ and 36.9 $\min \cdot \mathrm{mg} / \mathrm{L}$, respectively by noncompartmental analysis of the naïve pooled sparse sampling data using WinNonlin 5.2 NCA Model 200 with Linear Interpolation setting. Thus the mice brain to plasma AUC ratio was estimated at 4.07. In addition, the mice subcutaneous clearance was estimated to be $1.16 \mathrm{~L} / \mathrm{min} / \mathrm{kg}$. 


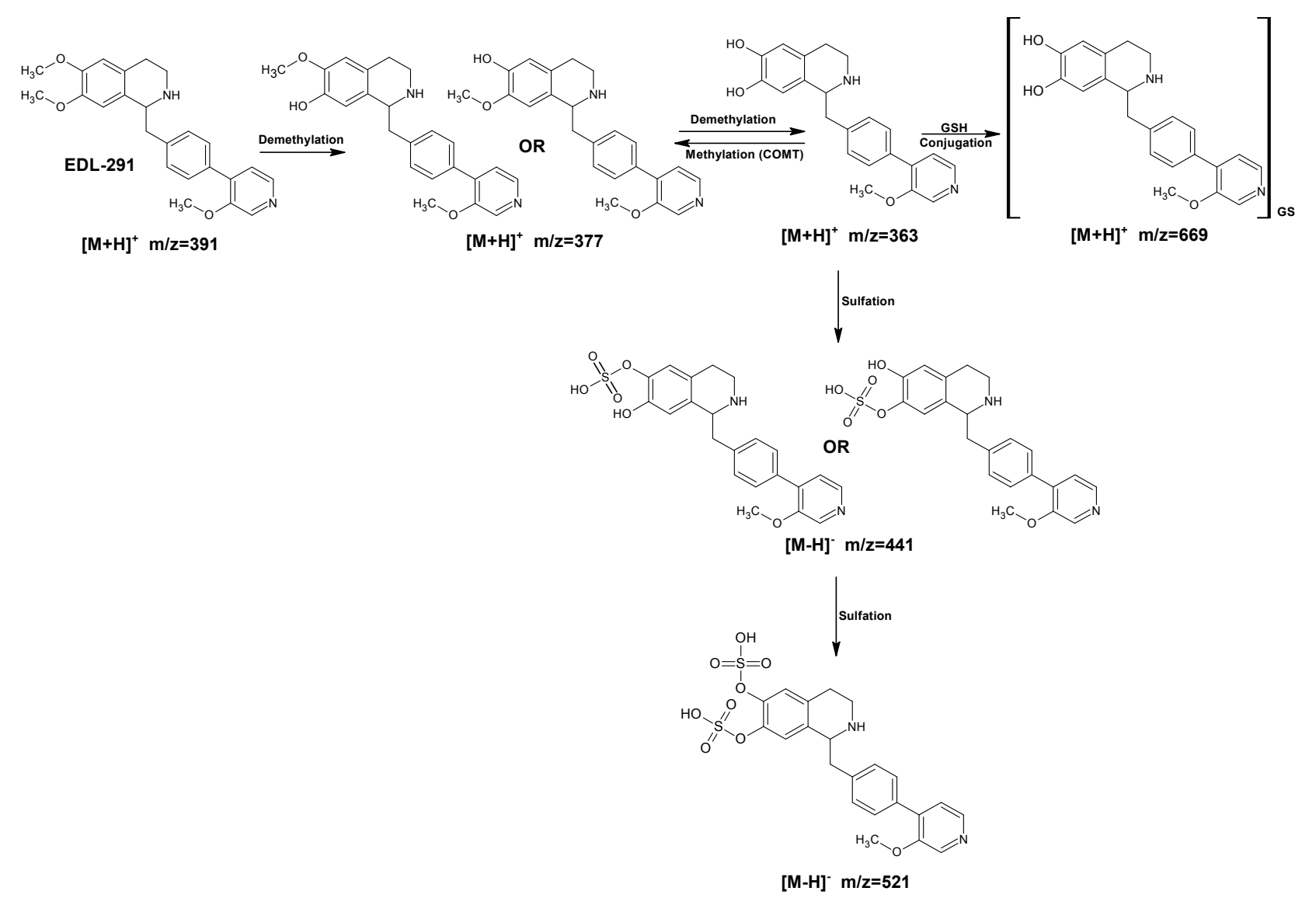

\section{Figure 2-7. Metabolites of EDL-291 in rat plasma and feces}

EDL-291 metabolites from both phase I and phase II xenobiotic metabolism are found in plasma and feces of male SD rats that received intravenous dosing. 
Table 2-3. Pharmacokinetic parameters of EDL-291 in male SD rats after oral gavage

\begin{tabular}{ccccccc}
\hline Subject & $\begin{array}{c}\mathbf{C L}_{\text {oral }} \\
(\mathbf{m L} / \mathbf{m i n} / \mathbf{k g})\end{array}$ & $\begin{array}{c}\mathbf{V d}_{\mathbf{z}, \text { oral }} \\
(\mathbf{L} / \mathbf{k g})\end{array}$ & $\begin{array}{c}\text { Terminal } \\
\mathbf{( m i n )}\end{array}$ & $\begin{array}{c}\mathbf{C}_{\mathbf{m a x}} \\
(\mathbf{n g} / \mathbf{m L} \mathbf{m})\end{array}$ & $\begin{array}{c}\mathbf{t}_{\mathbf{m a x}} \\
(\mathbf{m i n})\end{array}$ & $\begin{array}{c}\mathbf{A U} \mathbf{C}_{\mathbf{p o}, \mathbf{0}-\infty} \\
(\mathbf{m i n} \cdot \mathbf{m g} / \mathbf{L}\end{array}$ \\
\hline No. 1 & 492 & 93.6 & 132 & 504 & 40 & 81.2 \\
No. 2 & 510 & 52.4 & 71.3 & 457 & 20 & 78.5 \\
No. 2 & 740 & 65.4 & 61.3 & 239 & 100 & 54.0 \\
No. 4 & 486 & 82.6 & 118 & 599 & 40 & 82.4 \\
No. 5 & 409 & 56.9 & 96.5 & 689 & 40 & 97.8 \\
Geometric Mean & 517 & 68.5 & 91.9 & - & - & 77.4 \\
CV (\%) & 23.7 & 24.8 & 31.2 & - & - & 20.0 \\
Median & - & - & - & 504 & 40 & - \\
Range & - & - & - & 450 & 80 & - \\
\hline
\end{tabular}

Note: Bioavailablity $(\mathrm{F})=\left(\mathrm{AUC}_{\mathrm{po}, 0-\infty} / \operatorname{Dose}_{\mathrm{po}}\right) /\left(\mathrm{AUC}_{\mathrm{iv}, 0-\infty} / \mathrm{Dose}_{\mathrm{iv}}\right) \times 100 \%=(77.4 / 40) /(47.8 / 10) \times 100 \%=40.4 \%$ 


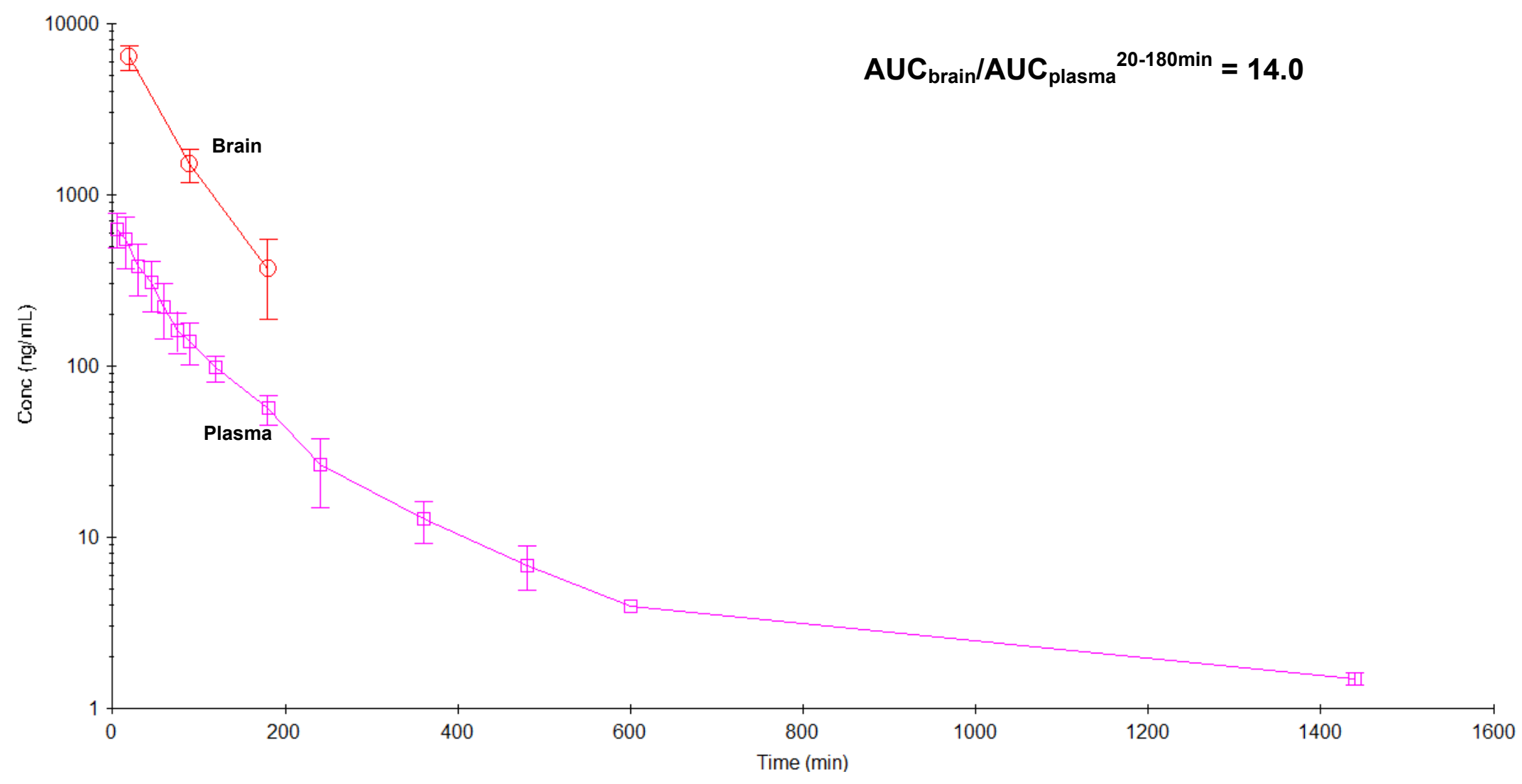

Figure 2-8. Brain and plasma concentration-time profile after $10 \mathrm{mg} / \mathrm{kg}$ intravenous bolus injection to SD rats

Plasma: $\mathrm{n}=5$ at $5 \mathrm{~min}, 360 \mathrm{~min}$, and $1440 \mathrm{~min} ; \mathrm{n}=1$ at $600 \mathrm{~min} ; \mathrm{n}=6$ at all other time points. Brain: $\mathrm{n}=5$ at 20 min, $\mathrm{n}=2$ at both 90 min and $180 \mathrm{~min}$. The error bars are standard deviations. 


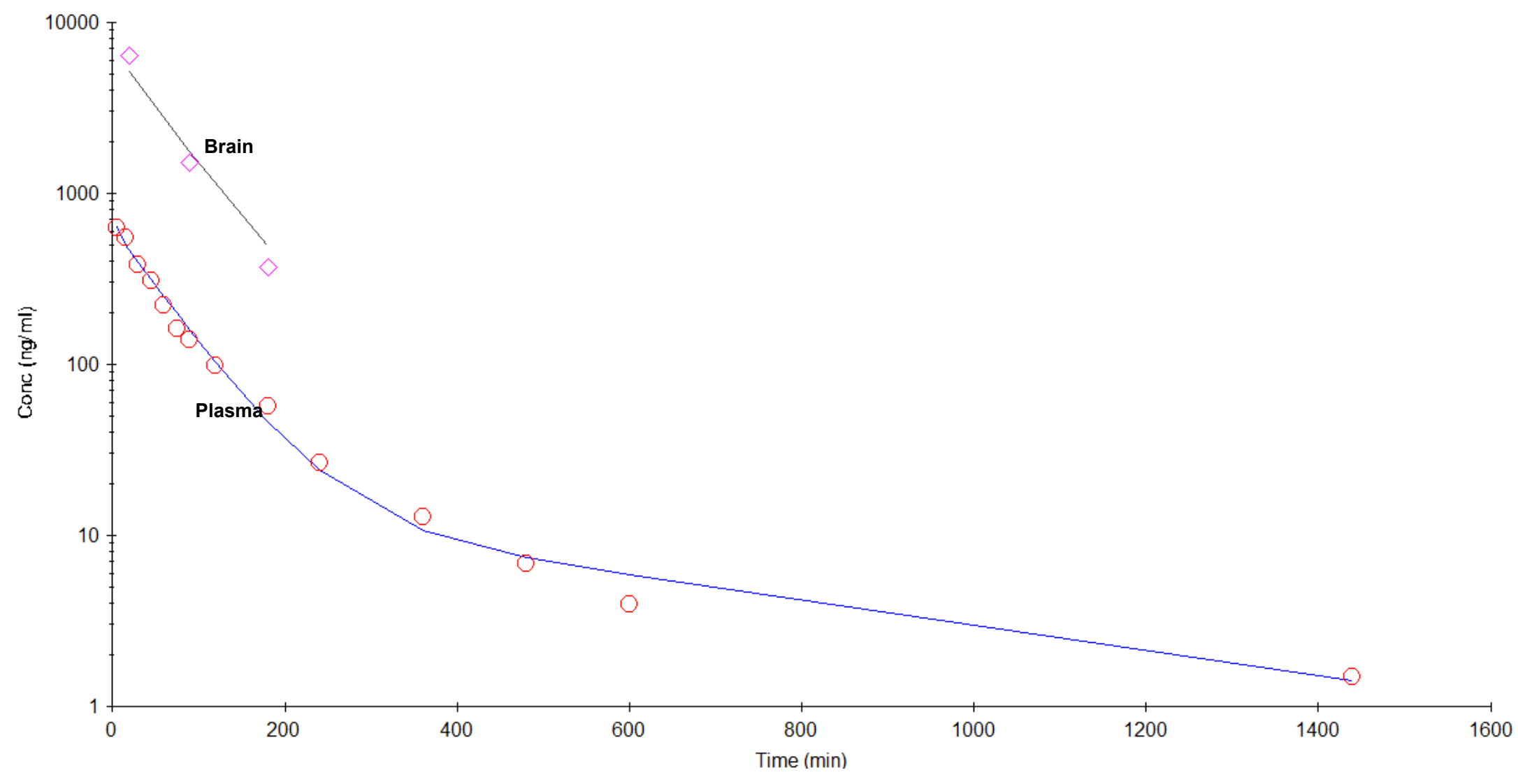

Figure 2-9. Simultaneous fitting of rat brain and plasma concentration after $10 \mathrm{mg} / \mathrm{kg}$ intravenous bolus injection to the three-compartment user-defined model 


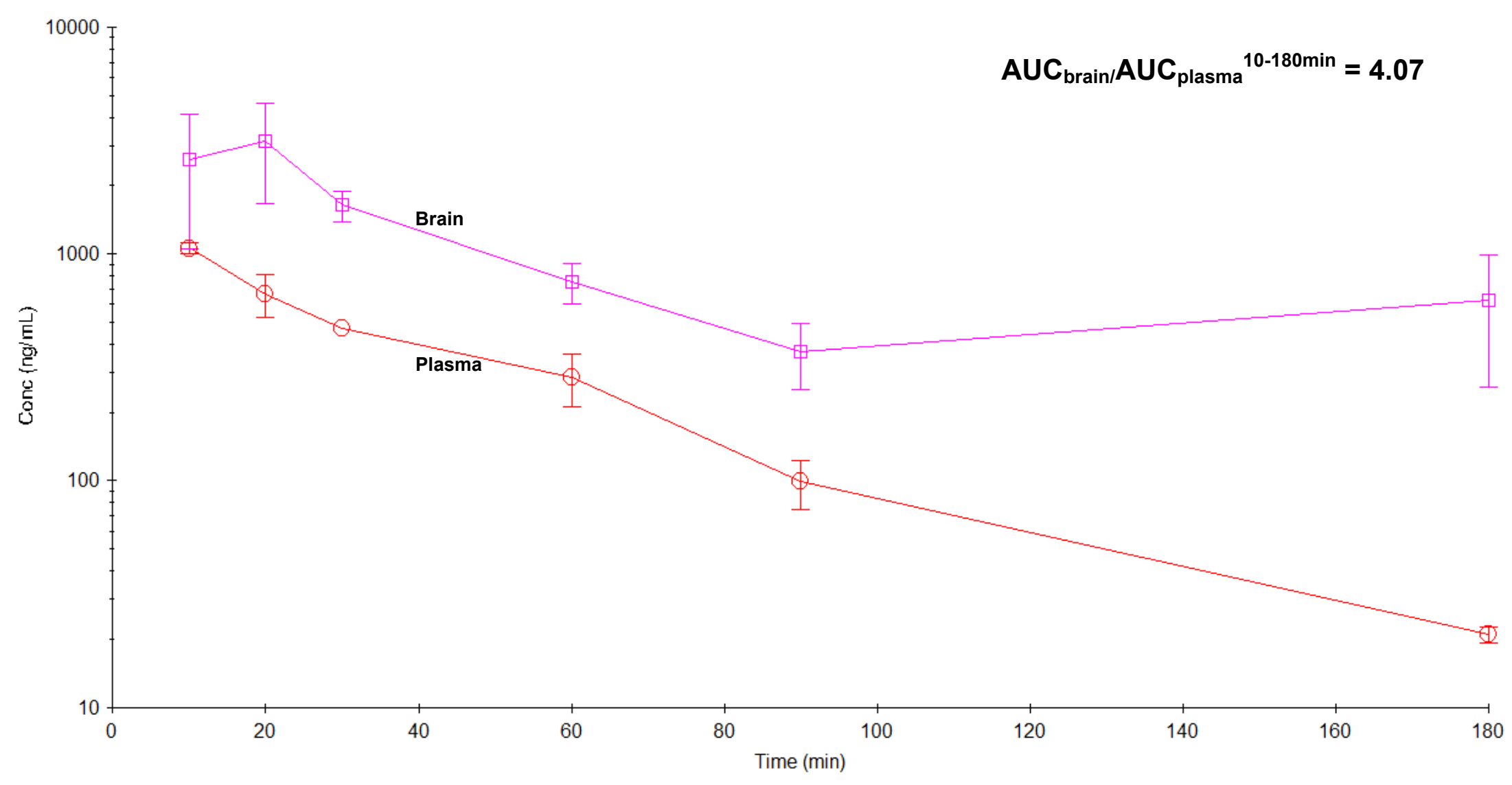

Figure 2-10. Brain and plasma concentration-time profile after $50 \mathrm{mg} / \mathrm{kg}$ subcutaneous injection to mice

Plasma: $\mathrm{n}=1$ at 30 min; $\mathrm{n}=2$ at all other time points. Brain: $\mathrm{n}=2$. The error bars are standard deviations. 


\subsection{Discussion}

Pharmacokinetic study is an integral part of the current drug development paradigm, playing an important role in various developmental stages. In the early drug development process, information obtained from pharmacokinetic study can provide valuable feedback for lead optimization and drug candidate selection [98]. The subject of the preclinical pharmacokinetics investigation presented in this chapter is the tetrahydroisoquinoline analog EDL-291, a result from DMPK-guided structure modification (i.e., blocking the metabolic hot spots and lowering cLogP) of lead compound EDL-155.

As expected, total body clearance of EDL-291 in male SD rats $(209 \mathrm{~mL} / \mathrm{min} / \mathrm{kg})$ is $39 \%$ lower than that of EDL-155 $(343 \mathrm{~mL} / \mathrm{min} / \mathrm{kg})$. However, the former value is still almost 4 times higher than rat hepatic blood flow $(55.2 \mathrm{~mL} / \mathrm{min} / \mathrm{kg})$ and approaches cardiac output $(296 \mathrm{~mL} / \mathrm{min} / \mathrm{kg}$ ) [99]. For most drugs, the liver and kidney are the two most important eliminating organs. Therefore, total clearance (CL) can usually be approximate by hepatic clearance $\left(\mathrm{CL}_{\mathrm{h}}\right)$ plus renal clearance $\left(\mathrm{CL}_{\mathrm{r}}\right)$ (Figure 2-11). The renal clearance of EDL-291 can be ignored, since the fraction excreted unchanged in urine $\left(\mathrm{f}_{\mathrm{e}}\right)$ is only 0.012 . Hepatic clearance cannot be larger than liver blood flow $\left(\mathrm{Q}_{\mathrm{h}}\right)$ since the hepatic extraction ratio $\left(\mathrm{ER}_{\mathrm{h}}\right)$ cannot be larger than 1 . So the elimination of EDL-291 far exceeds the capacity of liver. Thus, there must be either some experimental artifacts which can lead to overestimating total clearance of EDL-291 or some extrahepatic mechanisms that contribute substantially to the elimination.

The first extrahepatic mechanism deserving consideration is the pulmonary metabolism [100-102]. The lung contains various CYP450 enzymes as well as phase II drug metabolism enzymes [103-108]. It has the potential of metabolizing many foreign chemicals to a vast array of metabolites with different pharmacological and toxicological properties $[100,102,109,110]$. Intravenously dosed drugs are subject to pulmonary metabolism before entering the liver. Since lungs accept total cardiac output, which is 5 times higher than hepatic blood flow in rats, if the pulmonary extraction ratio is same as hepatic extraction ratio, the rat lung clearance could be 5 times higher than the hepatic

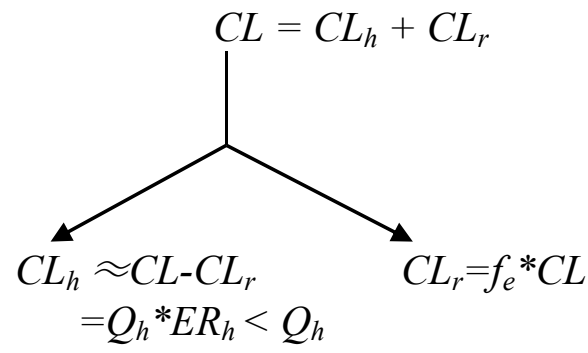

Figure 2-11. The usual relationship between total body clearance (CL), hepatic clearance $\left(C L_{h}\right)$, renal clearance $\left(C L_{r}\right)$, and liver blood flow $\left(Q_{h}\right)$ 
clearance. As evidenced by the pulmonary microsomal stability experiment, EDL-291 is susceptive to pulmonary metabolism. The hot-spots for pulmonary metabolism are the methoxy groups in A-ring and C-ring since modification of these groups can increase the stability to pulmonary microsomes.

Another important extrahepatic mechanism is metabolism or chemical degradation in the blood. Various drug metabolizing enzymes are located in either blood cells or plasma, and contribute to the elimination of dozens of structurally diverse drugs $[111,112]$. Metabolism and degradation in blood is apparently not limited by the hepatic blood flow. However, the whole blood incubation experiment demonstrated that EDL-291 is stable for $3 \mathrm{hr}$ in blood. Thus the contribution of blood metabolism/degradation to total body clearance of EDL-291 is negligible.

A well-known artifact that can cause extraordinarily high clearance value is drug accumulation in erythrocytes [113]. Clearance is defined as the volume of blood irreversibly cleared of drug per unit of time. The total clearance value can be calculated as the dose divided by AUC in blood. For most drugs, blood concentration is close to plasma concentration, and plasma is easier to handle. Thus clearance of a drug is usually calculated from plasma drug concentration data instead of the whole-blood concentration data. This common practice is also used in this study. However, if the compound is accumulated in erythrocytes, i.e., the blood concentration is higher than plasma concentration, the clearance will be overestimated. Since the result of the erythrocyte partitioning experiment showed that EDL-291 does not accumulate in erythrocytes, the high clearance is not caused by this artifact.

Therefore, the major contributor to the high clearance of EDL-291 is extensive lung metabolism. Measurement of the afferent-efferent arterial (pulmonary artery vs. aorta) concentrations in steady states during a long intravenous infusion can be used in future study to confirm this finding in vivo [100, 102]. Comparing AUC after intravenous or intra-aortic short-term infusion is more convenient method to examine effect of lung on drug disposition. However, in some case, lung tissue may act as a deep compartment, which drugs will bind to and will not be released before end of blood sampling [100, 102]. The afferent-efferent concentrations measurement can assure that the binding sites in lungs are saturated after long infusion and thus will not mistakenly count lung retention as lung clearance. The lung clearance can be calculated as $\mathrm{CL}_{\text {lung }}=\mathrm{CO}^{*} \mathrm{ER}_{\text {lung }}$ $=\mathrm{CO} *\left(\mathrm{C}_{\mathrm{pa}}-\mathrm{C}_{\mathrm{aorta}}\right) / \mathrm{C}_{\mathrm{pa}}$, where $\mathrm{CL}_{\text {lung }}, \mathrm{ER}_{\text {lung }}, \mathrm{CO}, \mathrm{C}_{\mathrm{pa}}$ and $\mathrm{C}_{\mathrm{aorta}}$ refer to lung clearance, lung extraction ratio, cardiac output, drug concentration in pulmonary artery and drug concentration in aorta in this method, respectively. The lung clearance is a well-known exception to additivity of organ clearance [102]. But the ratio $\mathrm{CL}_{\text {lung }} / \mathrm{CL}$ can still be used to express the relative contribution of lung to the total clearance.

It can be speculated that intra-arterial injection of EDL-291 will lead to higher systemic exposure by avoidance of pulmonary first-pass effect. According to principle of diffusion, brain exposure will also be increased. If EDL-291 is injected through a microcatheter [114] to the rat internal carotid artery branch that supplies blood to brain, 
its brain exposure of will be further increased since almost all the injected compound will be presented to BBB without loss due to clearance by lung, liver or kidney.

EDL-155 was included as a control in the above-mentioned pulmonary microsomal stability, whole blood stability, and erythrocyte partitioning experiments. The results suggest that blood metabolism/degradation and erythrocyte accumulation contributed to the high clearance value of that compound.

Due to the difficulties in collecting CSF and the nature of early phase brain pharmacokinetic research, brain homogenate concentrations of EDL-291were measured in this study. $\mathrm{AUC}_{\text {brain }} / \mathrm{AUC}_{\text {plasma }}$ ratio of 14.0 in rats and 4.07 in mice indicates a high brain penetration of EDL-291. A three-compartment pharmacokinetic model was successfully developed to fit EDL-291 plasma and brain homogenate concentrations simultaneously using WinNonlin software.

Plasma protein binding of EDL-291 is around $60 \%$ at $5 \mu \mathrm{g} / \mathrm{mL}$ and $10 \mu \mathrm{g} / \mathrm{mL}$ concentration levels. Lowered plasma protein binding may be one of the reasons for improved brain penetration since the fraction of free drug available for BBB diffusion is increased. The bioavailability of EDL-291 after oral gavage is $42 \%$. This indicates that oral dosing is feasible for this compound.

Both phase I and phase II metabolites of EDL-291 were found in plasma and feces. COMT, responsible for methylation of the A-ring catechol of EDL-155, might be able to convert the A-ring didemethylation metabolite of EDL-291 back to the monodemethylation metabolite. As reported before, the most abundant EDL-155 metabolite is formed by C-ring hydroxylation [65]. In EDL-291 structure modification in C-ring seems to have successfully blocked that reaction.

In conclusion, preclinical pharmacokinetic studies of EDL-291 were conducted in mice and rats following intravenous, oral, and subcutaneous administrations. EDL-291 demonstrated lower clearance and improved brain penetration compared to the last generation compound EDL-155. EDL-291 has a low fraction of renal elimination, but the total clearance is still higher than liver blood flow. The likely mechanism of this high clearance value is not the red blood cell distribution or metabolism/degradation in blood. EDL-291 is rapidly and extensively metabolized by the lung microsomes, indicating that lung metabolism may cause this phenomenon. 


\section{CHAPTER 3. PHARMACOKINETICS OF EDL-323}

\subsection{Introduction}

As shown in Chapter 2, EDL-291 was extensively metabolized by the lung microsomes, and demonstrated high clearance. For developing an antiglioma agent with better in vivo stability, EDL-323, i.e., 4-chloro-3- $(4-\{2 \mathrm{H}, 5 \mathrm{H}, 6 \mathrm{H}, 7 \mathrm{H}, 8 \mathrm{H}-[1,3]$ dioxolo [4,5-g] isoquinolin-5-ylmethylphenyl) pyridine, a derivative of EDL-291, was synthesized in Dr. Duane Miller's laboratory by modification of pulmonary metabolic "soft spots." Chemical structure and selected physiochemical properties of EDL-323 are shown in Figure 3-1.

As shown in Table 2-2, EDL-323 has higher stability to rat pulmonary microsomes when compared to EDL-291. The objective of the experiments in this chapter was to examine the in vivo pharmacokinetic properties of EDL-323 in rats following both intravenous and oral administrations, which were used to provide feedback information for further antiglioma drug development decisions.

\subsection{Materials and Methods}

\subsubsection{Materials}

Ammonium acetate (ACS), HPLC grade acetonitrile and HPLC grade water were purchased from Fisher Scientific (Fair Lawn, NJ). Compounds EDL-323 and EDL-313 (internal standard for EDL-323) were synthesized in Dr. Duane Miller's laboratory.

\subsection{2. $\mathrm{LC} / \mathrm{MS} / \mathrm{MS}$ method}

The LC/MS/MS system was composed of an Applied Biosystems Sciex (Foster City, CA) API 3000 tandem mass spectrometer, and Shimadzu (Columbia, MD) LC-10ADvp pumps with a LEAP (Carrboro, NC) HTS PAL autosampler. Data were processed using Analyst software 1.4.2. Chromatographic separation was performed using a Cadenza CD-C18 column $(100 \times 2.0 \mathrm{~mm}, 3 \mu \mathrm{m}$, purchased from Silvertone Sciences, Philadelphia, PA). The mobile phase consisting of A $\left(10 \mathrm{mM} \mathrm{NH}_{4} \mathrm{Ac}\right.$ in HPLC grade water, $\mathrm{pH} 7.4$ ) and $\mathrm{B}$ (acetonitrile) was delivered at $0.5 \mathrm{~mL} / \mathrm{min}$. The total run time was $3.5 \mathrm{~min}$. Gradient elution began at $30 \% \mathrm{~B}$ and was held for $1 \mathrm{~min}$, then increased to $70 \% \mathrm{~B}$ over $1 \mathrm{~min}$, decreased to $30 \% \mathrm{~B}$ over $1 \mathrm{~min}$, and finished at $30 \% \mathrm{~B}$ for $0.5 \mathrm{~min}$.

The mass spectrometer was operated in positive ESI mode with the following parameters: ionspray voltage (IS) $1500 \mathrm{~V}$, nebulizing gas (NEB) 14.0, curtain gas (CUR) 14.0, source temperature (TEM) $550.0^{\circ} \mathrm{C}$, collision-activated dissociation (CAD) gas 
EDL-291

EDL-323

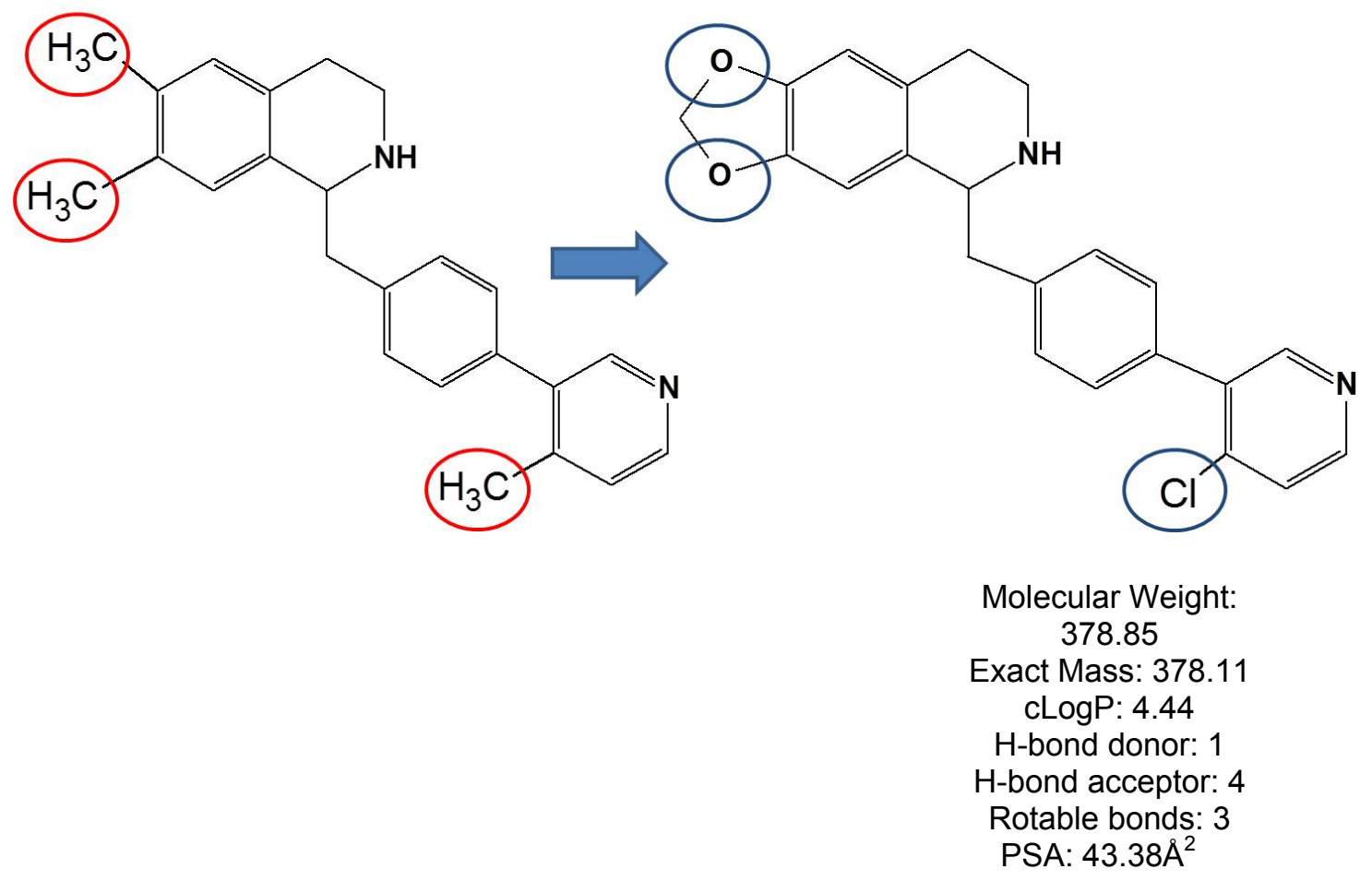

Figure 3-1. Structure and selected physiochemical properties of EDL-323

Exact mass and cLogP were calculatedd by ChemDraw Ultra 12.0 (CambridgeSoft Corporation, Cambridge, MA). All other values were calculated by Marvin Calculator Plugins (ChemAxon Kft., Hungary). 
7.0, declustering potential (DP) $76.0 \mathrm{~V}$, focusing potential (FP) $150.0 \mathrm{~V}$, entrance potential (EP) $10.0 \mathrm{~V}$, collision energy $31.0 \mathrm{~V}$, collision cell exit potential (CXP) $18.00 \mathrm{~V}$, deflector (DF) $-200 \mathrm{~V}$, channel electron multiplier (CEM) $2200 \mathrm{~V}$, and turbo gas (GS2) $7.0 \mathrm{~L} / \mathrm{min}$.

The MS/MS measurements were performed under MRM mode. The molecule ions $[\mathrm{M}+\mathrm{H}]^{+}$selected in Q1 were subjected to collision-activated dissociation by $\mathrm{N}_{2}$ in the collision cell $(\mathrm{Q} 2)$, and the product ions were monitored by scanning the third quadrupole (Q3). The monitored MRM transition values were 379.2 $\rightarrow 202.2$ for EDL-323 and $395.0 \rightarrow 202.2$ for EDL-313.

\subsubsection{Animals}

Male Sprague-Dawley rats weighing between 250 and 275 grams were purchased from Charles River Laboratories (Wilmington, MA) and maintained in the animal facility of the UTHSC. All the rats $(n=4)$ bore both jugular and femoral vein catheters. The patency of catheters was maintained every other day with heparinized glycerol solution (500 IU heparin/mL final solution in 75\% glycerol) according to vendor's instructions. Rats were fed ad libitum on normal laboratory diet and water. A $12 \mathrm{hr}$ light-dark cycle and ambient temperature of $25^{\circ} \mathrm{C}$ were maintained. Rats were individually housed in regular plastic cages.

\subsubsection{Drug solution}

EDL-323 was dissolved in sterile normal saline at $10 \mathrm{mg} / \mathrm{mL}$ concentration.

\subsubsection{Pharmacokinetic sampling and processing}

EDL-323 was administered $(10 \mathrm{mg} / \mathrm{kg})$ to SD rats $(\mathrm{n}=4)$ by intravenous bolus via the femoral vein catheter. Blood $(100 \mu \mathrm{L})$ was collected into Microtainer ${ }^{\circledR}$ tubes with lithium heparin and plasma separation gel (BD, Franklin Lakes, NJ, Catalog \# 365958) from the jugular vein catheter at timed intervals $2,5,15,30,45,60,75,90,120,180$, $240,360,480,600,960$, and $1440 \mathrm{~min}$. Samples were centrifuged at 10,000 g, $4{ }^{\circ} \mathrm{C}$ for 2 min. Plasma was stored at $-80{ }^{\circ} \mathrm{C}$ until analysis.

$200 \mu \mathrm{L}$ of ice-cold acetonitrile and $20 \mu \mathrm{L}$ of IS (internal standard solution) were added to each of $50 \mu \mathrm{L}$ plasma samples. The resulting mixture was vortexed and centrifuged at $10,000 \mathrm{~g}, 4{ }^{\circ} \mathrm{C}$ for $10 \mathrm{~min} .10 \mu \mathrm{L}$ of the supernatant was injected for $\mathrm{LC} / \mathrm{MS} / \mathrm{MS}$ analysis. 


\subsubsection{Pharmacokinetics data analysis}

The clearance $(\mathrm{CL})$, volume of distribution at steady state $\left(\mathrm{Vd}_{\mathrm{ss}}\right)$, terminal half-life $\left(\mathrm{t}_{1 / 2}\right)$, and area under the curve $\left(\mathrm{AUC}_{\mathrm{iv}, 0-\infty}\right)$ were estimated by NCA Model 201 with Linear Up/Log Down setting in WinNonlin 5.2. The last 3 data points with available concentrations were used for estimating terminal slope $\lambda_{\mathrm{z}}$. The estimated individual pharmacokinetic parameters were then summarized by the built-in descriptive statistics tool in WinNonlin.

\subsection{Results}

The plasma concentration versus time profile of EDL-323 (Figure 3-2) during the sampling period demonstrated rapid elimination. The secondary peak around $600 \mathrm{~min}$ after dosing could be a sign of enterohepatic recirculation. The pharmacokinetic parameters are shown in Table 3-1.

\subsection{Discussion}

As expected, total body clearance of EDL-323 is $38 \%$ lower than that of EDL-291. However a pilot study showed that the brain penetration is dramatically reduced. Therefore, other structure modifications should be tried to obtain lower clearance but maintain the high brain penetration.

A newer derivative EDL-355 showed higher brain penetration and in vitro efficacy in another pilot study. Thus EDL-355 will be the next candidate to be used in future pharmacokinetics investigation. 


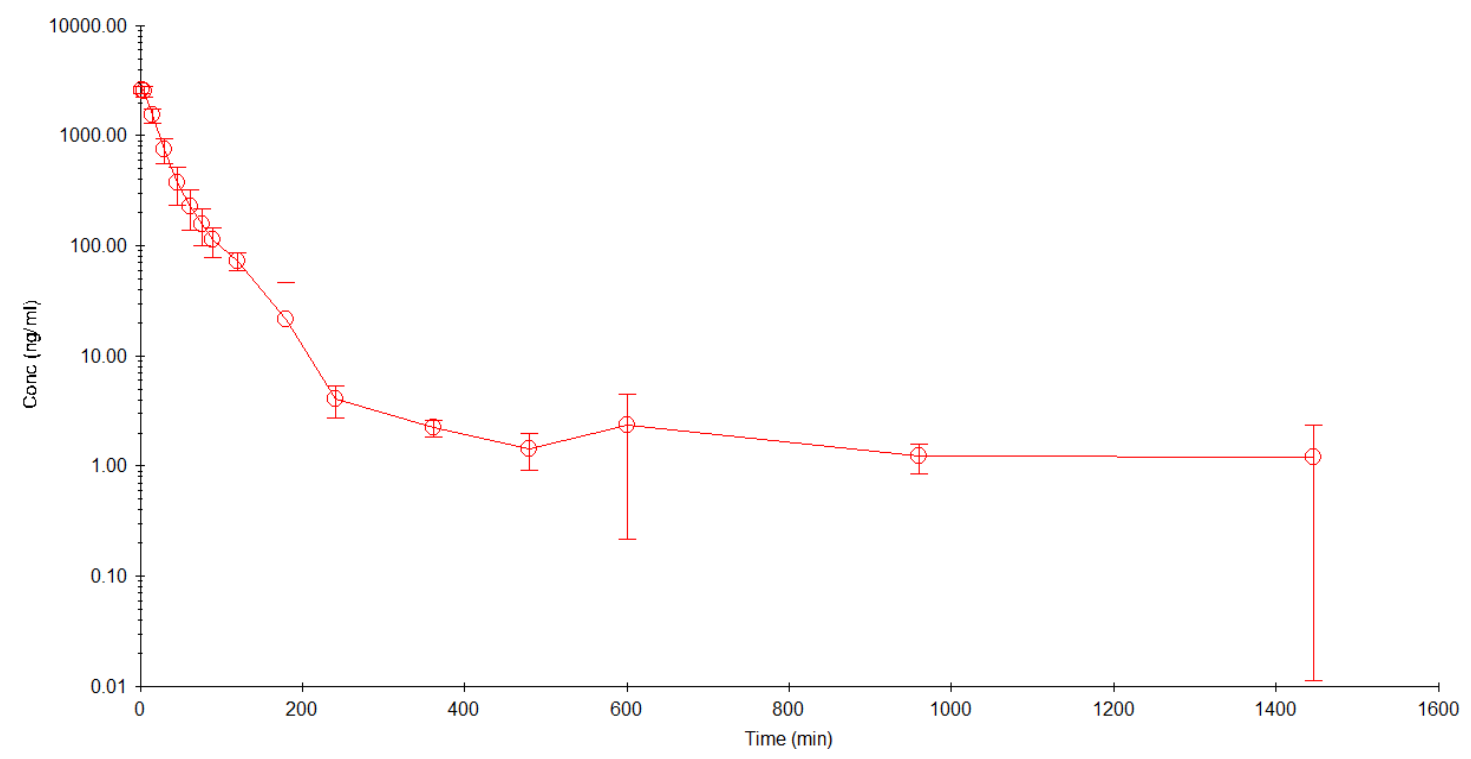

Figure 3-2. Plasma concentration-time profile after $10 \mathrm{mg} / \mathrm{kg}$ intravenous bolus injection of EDL-323

$\mathrm{N}=3$ at $2 \min ; \mathrm{n}=4$ at all the other data points. The error bars are standard deviations.

Table 3-1. Pharmacokinetic parameters of EDL-323 in male SD rats after intravenous bolus injection

\begin{tabular}{ccccc}
\hline Subject & $\begin{array}{c}\mathbf{C L} \\
(\mathbf{m L} / \mathbf{m i n} / \mathbf{k g})\end{array}$ & $\begin{array}{c}\mathbf{V d}_{\mathbf{s s}} \\
(\mathbf{L} / \mathbf{k g})\end{array}$ & $\begin{array}{c}\text { Terminal t/2 }_{\mathbf{2}} \\
(\mathbf{m i n})\end{array}$ & $\begin{array}{c}\mathbf{A U C}_{\mathbf{i v}, \mathbf{0}-\infty} \\
(\mathbf{m i n} \cdot \mathbf{m g} / \mathbf{L})\end{array}$ \\
\hline No. 1 & 114 & 9.00 & $1.07 \times 10^{3}$ & 87.5 \\
No. 2 & 136 & 19.8 & 834 & 73.6 \\
No. 3 & 127 & 9.07 & 776 & 78.5 \\
No. 4 & 155 & 7.48 & 373 & 64.6 \\
Geometric Mean & 132 & 10.5 & 713 & 75.6 \\
CV (\%) & 12.7 & 50.3 & 38.0 & 12.5 \\
\hline
\end{tabular}




\section{CHAPTER 4. MECHANISM OF ACTION STUDY OF EDL-291}

\subsection{Introduction}

Many EDL series of novel tetrahydroisoquinoline analogs show antiproliferative activity on glioma cells. Since they were discovered by serendipity, the mechanism of action was unknown for these compounds before the start of this dissertation research project. Currently, a drug candidate with unknown mechanism is not likely to get FDA approval [68]. Therefore, a preliminary mechanism of action study was included in this project. EDL-291 was selected as a model compound for this study.

There are five major modes of cell death induced by chemotherapy: apoptosis, autophagic cell death, necrosis, mitotic catastrophe, and senescence [74]. Among these, apoptosis is the most well-known way of cell death after anticancer drug treatment. Therefore, the role of apoptosis machinery on the activity of EDL-291 was the focus of this study.

\subsection{Materials and Methods}

\subsubsection{Cell cultures}

Human glioma cell line U-87MG was purchased from American Type Culture Collection (ATCC, Manassas, VA). Culture medium for this cell line was Basal Medium Eagle with Earle's salts (BME, Mediatech, Manassas, VA) supplemented by $10 \%$ fetal bovine serum (FBS, Sigma, St. Louis, MO), $2.2 \mathrm{mg} / \mathrm{mL}$ sodium bicarbonate (Sigma, St. Louis, MO), $50 \mathrm{IU} / \mathrm{mL}$ penicillin (Invitrogen, Carlsbad, CA), $50 \mu \mathrm{g} / \mathrm{mL}$ streptomycin (Invitrogen, Carlsbad, CA), and $50 \mu \mathrm{g} / \mathrm{mL}$ streptomycin (Invitrogen, Carlsbad, CA). Human glioma cell line U251 was obtained from the National Cancer Institute (NCI, Frederick, MD). Culture medium for this cell line was RPMI 1640 (Invitrogen, Carlsbad, CA) supplemented by $10 \%$ fetal bovine serum, $100 \mathrm{IU} / \mathrm{mL}$ penicillin, and $100 \mu \mathrm{g} / \mathrm{mL}$ streptomycin. These cell lines were maintained in $75 \mathrm{~cm}^{2}$ culture flasks (Corning Life Science, Lowell, MA) in a $37^{\circ} \mathrm{C}$ incubator (NuAire, Plymouth, MN) containing a humid $5 \% \mathrm{CO}_{2}$ atmosphere and passaged in 1:4 ratio after being washed by Dulbecco's phosphate-buffered saline without calcium and magnesium (D-PBS, Invitrogen, Carlsbad, CA) and dislodged by $0.25 \%$ trysin-EDTA (Mediatech, Manassas, VA) once they reached $80 \%$ confluence.

\subsubsection{Cell proliferation assay with caspase inhibitors or mitochondrial permeability transition (MPT) inhibitors}

EDL-291 was synthesized in the laboratory of Dr. Duane Miller. CellTiter $96^{\circledR}$ $\mathrm{AQ}_{\text {ueous }}$ Non-Radioactive Cell Proliferation (MTS) assay kit was purchased from 
Promega (Madison, WI). Pan-caspase inhibitor Z-VAD-fmk was purchased from Enzo Life Sciences (Plymouth Meeting, PA). Caspase-3/7 inhibitor Z-DEVD-fmk was purchased from R\&D Systems (Minneapolis, MN). Caspase-8 inhibitor Z-IETD-fmk and caspase-9 inhibitor Z-LEHD-fmk were purchased from Tocris (Ellisville, MO). MPT inhibitor decylubiquinone (dUb) was purchased from Enzo Life Sciences.

The antiproliferative effect of EDL-291 with or without inhibitors was determined by using MTS assay according to manufacturer's direction. In brief, U-87MG and U251 cells were seeded at $5 \times 10^{3}$ cells/well in 96-well flat-bottomed plates (Corning Life Science, Lowell, MA) and grown overnight in $200 \mu \mathrm{L}$ aforementioned medium with 10\% FBS in a $37{ }^{\circ} \mathrm{C}$ incubator containing a humid $5 \% \mathrm{CO}_{2}$ atmosphere. EDL-291 was dissolved in sterile normal saline to get a $50 \mathrm{mM}$ stock solution, while caspase inhibitors and dUb were dissolved in DMSO (Sigma, St. Louis, MO) to make stock solutions. These stock solutions were spiked into the aforementioned medium with $2 \%$ FBS to get drug-containing media. The DMSO concentrations were kept at less than $0.25 \%$. Control media were made by spiking DMSO to final concentrations that matched those in the drug-containing media. Then the medium in the 96 -well plate was replaced by 200 $\mu \mathrm{L} /$ well drug-containing medium or control medium. After the cells were incubated for $96 \mathrm{hr}$ in $37^{\circ} \mathrm{C}, 5 \% \mathrm{CO}_{2}$, the consumed media were replaced by $100 \mu \mathrm{L} /$ well fresh media with $2 \%$ FBS. Then $20 \mu \mathrm{L} /$ well MTS [3- (4, 5-dimethylthiazol-2-yl) -5- (3carboxymethoxyphenyl) -2- (4-sulfophenyl) -2H-tetrazolium] - PMS (phenazine methosulfate) mixtures were added. After $1 \mathrm{hr}$ incubation in $37^{\circ} \mathrm{C}, 5 \% \mathrm{CO}_{2}$, the absorbance at $450 \mathrm{~nm}$ was measured using a DTX 880 multimode detector (Beckman Coulter, Fullerton, CA). The absorbance of medium-only wells was subtracted from reading of control or treated wells. The viability of control cells was considered to be $100 \%$.

\subsubsection{Caspase $3 / 7$ activity assay}

U-87MG and U251 cells were seeded at $5 \times 10^{3}$ cells/well in 96-well flat-bottomed plates and grown overnight in $200 \mu \mathrm{L}$ of the aforementioned medium with $10 \% \mathrm{FBS}$ in a $37{ }^{\circ} \mathrm{C}$ incubator containing a humid $5 \% \mathrm{CO}_{2}$ atmosphere. Then the medium in the 96 -well plate was replaced by $200 \mu \mathrm{L} /$ well $2 \%$ FBS medium containing $10 \mu \mathrm{M}$ EDL-291 with or without dUb or control medium. After the cells were incubated for $60 \mathrm{hr}$ in $37^{\circ} \mathrm{C}, 5 \% \mathrm{CO}_{2}$, the consumed media were replaced by $100 \mu \mathrm{L} /$ well fresh media with $2 \%$ FBS. The luminogenic substrate and luciferase-containing buffer from the Capase 3/7 Glo kit were mixed to prepare the reagent right before use. $100 \mu \mathrm{L}$ prewarmed reagent was added to each well, and then the plate was put on a plate shaker for $30 \mathrm{~min}$. After $60 \mathrm{~min}$ incubation in room temperature, the luminescence was measured by DTX 880 multimode detector. The luminescence of medium only wells was subtracted from reading of the control or treated wells. The blank subtracted luminescence readings (RLU) were further normalized by absorbance at $450 \mathrm{~nm}$, which was obtained from the aforementioned MTS assay of duplicate wells. 


\subsubsection{Luminex assay of activated caspase-3 and poly (ADP-ribose) polymerase (PARP)}

Human apoptosis 3-plex Luminex kit, MultiScreen ${ }_{\text {HTS }}$ BV filter plates, and vacuum manifold were purchased from Millipore (Billerica, MA). Complete Mini ${ }^{\mathrm{TM}}$ protease inhibitor cocktail tablets were purchased from Roche Diagnostics (Indianapolis, IN). Phosphate-buffered saline (PBS) was purchased from Invitrogen (Carlsbad, CA). $\mathrm{U}-87 \mathrm{MG}$ and U251 cells were cultured in a $200 \mu \mathrm{L} /$ well $2 \%$ FBS medium containing $10 \mu \mathrm{M}$ EDL-291 or control medium, the same as described from the caspase 3/7 activity assay. After the cells were incubated for $72 \mathrm{hr}$ or $96 \mathrm{hr}$, the consumed media were aspirated. $1 / 4$ tablet of Complete Mini $^{\mathrm{TM}}$ protease inhibitor was added to the ice-cold Beadlyte cell signaling universal lysis buffer in the Luminex kit right before use. Then 30 $\mu \mathrm{L} /$ well lysis buffer was added, and the plates were shaken for $20 \mathrm{~min}$ at $4{ }^{\circ} \mathrm{C}$. The lysate was transferred to a pre-wetted MultiScreen HTS BV filter plate, and then was filtered by centrifugation at $500 \mathrm{~g}$ for $5 \mathrm{~min}$. The filtrate from the wells of the same treatment group was combined and diluted by equal volume of PBS. $25 \mu \mathrm{L} /$ well $1 \times 3$-plex [human glyceraldehyde 3-phosphate dehydrogenase (GAPDH), activated caspase-3, and PARP] bead suspension and $25 \mu \mathrm{L} /$ well diluted filtrate were added into a new MultiScreen HTS BV filter plate pre-wetted by using vacuum manifold. The filter plate was incubated on a plate shaker overnight at $4{ }^{\circ} \mathrm{C}$ while protected from light; then the liquid was removed and beads were washed by using vacuum manifold. $25 \mu \mathrm{L} /$ well of $1 \times$ Beadlyte biotinylated reporter was added to beads, and then the filter plate was incubated on a plate shaker for $1 \mathrm{hr}$ at room temperature. After removal of the liquid by vacuum, $25 \mu \mathrm{L}$ 1:25 diluted Strep-PE was added to each well; then the filter plate was incubated on a plate shaker for $30 \mathrm{~min}$ at room temperature. The liquid was removed again by vacuum. The beads were resuspended by $100 \mu 1$ assay buffer and then analyzed on Luminex 200 system (Luminex, Austin, TX).The raw data was processed by Millipore Beadview multiplex data analysis software, and the activated caspase-3 and PARP level were normalized to GAPDH level.

\subsubsection{Phase contrast and fluorescence microscopy}

U-87MG and U251 cells were seeded at $5 \times 10^{3}$ cells/well in 96-well flatbottomed plates and grown overnight in $200 \mu \mathrm{L}$ of the aforementioned medium with $10 \%$ FBS in a $37{ }^{\circ} \mathrm{C}$ incubator containing a humid $5 \% \mathrm{CO}_{2}$ atmosphere. Then the medium in the 96 -well plate was replaced by $200 \mu \mathrm{L} /$ well $2 \%$ FBS medium containing $10 \mu \mathrm{M}$ EDL-291 or control medium. After the cells were incubated for $60 \mathrm{hr}$ in $37^{\circ} \mathrm{C}, 5 \% \mathrm{CO}_{2}$, and pictures were taken under a phase contrast microscope. Following this, the cells were washed by PBS, fixed by $1 \%$ paraformaldehyde for $10 \mathrm{~min}$, and then stained with Hoechst 33342 for $20 \mathrm{~min}$ at room temperature before pictures were taken under an Eclipse 80i fluorescence microscope (Nikon, Melville, NY). 


\subsubsection{Terminal deoxynucleotidyl transferase dUTP nick end labeling (TUNEL) assay}

TUNEL assay was performed using a BD Pharmingen APO-BRDU kit (BD Biosciences, San Jose, CA) according to manufacturer's direction. Briefly, $2.34 \times 10^{6}$ U-87MG or U251 cells were seeded in $150 \mathrm{~cm}^{2}$ culture flasks (Corning Life Science, Lowell, MA) using the aforementioned 10\% FBS media. After overnight incubation in 37 ${ }^{\circ} \mathrm{C}, 5 \% \mathrm{CO}_{2}$ incubator, the consumed media were changed to drug-containing or control $2 \%$ FBS media. After $60 \mathrm{hr}$ treatment, the floating cells and trypsinized adherent cells from the same treatment were collected together. These cells were washed by PBS, fixed by $1 \%$ paraformaldehyde, and permeabilized by $70 \%$ ethanol. Then the DNA breaks were labeled by terminal deoxynucleotidyltransferase $(\mathrm{TdT})$ catalyzed addition of bromolated deoxyuridine triphosphates (Br-dUTP), followed by staining with fluorescein isothiocyanate (FITC) conjugated BrdU antibody. The samples were loaded to a LSR II flow cytometer (BD Biosciences) using $488 \mathrm{~nm}$ laser, and the data were processed by FACSDiva software.

\subsection{Results}

\subsubsection{Effect of caspase inhibitor}

As shown in Figure 4-1, antiproliferative effect of EDL-291 can be partially reversed by pan-caspase inhibitor Z-VAD-fmk and caspase-3/7 inhibitor Z-DEVD-fmk. However, caspase-8 inhibitor Z-IETD-fmk and caspase-9 inhibitor Z-LEHD-fmk cannot reverse the effect of EDL-291.

\subsubsection{Effector caspase activation}

As shown in Figure 4-2, $60 \mathrm{hr} 10 \mu \mathrm{M}$ EDL-291 treatment can increase the activity of caspase-3/7 in U-87MG and U251 cells. In Luminex assay, the activated caspase-3 protein as well as its product cleaved PARP are increased after $72 \mathrm{hr}$ EDL-291 treatment (Figure 4-3).

\subsubsection{Cell and nucleus morphology}

No change in cell morphology was found in U-87MG and U251 cells treated by $10 \mu \mathrm{M}$ EDL-291 for $60 \mathrm{hr}$ (Figure 4-4). No nucleus change was found by Hoescht 33342 staining at the same time point (Figure 4-5). 
Figure 4-1. Antiproliferative effect of EDL-291 can be partially reversed by pan-caspase inhibitor (panel $A$ ) and caspase-3/7 inhibitor (panel B), but not by caspase-8 and 9 inhibitors (panel $\mathrm{C}$ )

U-87MG and U251 human glioma cells were treated by $10 \mu \mathrm{M}$ EDL-291 with or without caspase inhibitor for $96 \mathrm{hr}$. The cell viability was measured by MTS assay using Promega CellTiter AQueous 96 kit. The absorbance of medium-only wells was subtracted from reading of control or treated wells. The viability of control cells was considered to be $100 \%$. The data shown here are representative results of 3 independent experiments. The error bars are standard deviation of 3 replicates in the same treatment condition. 


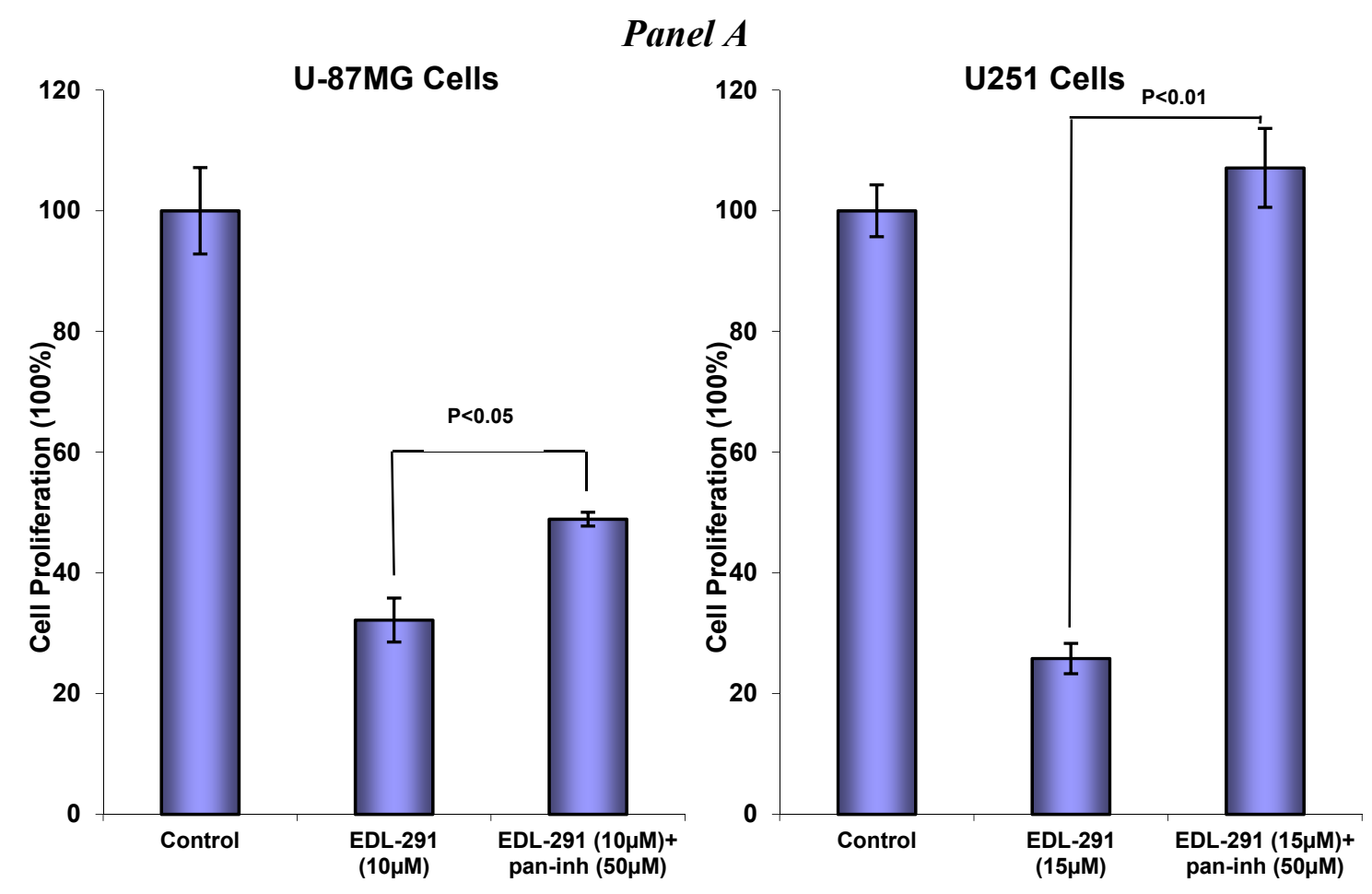

Panel B
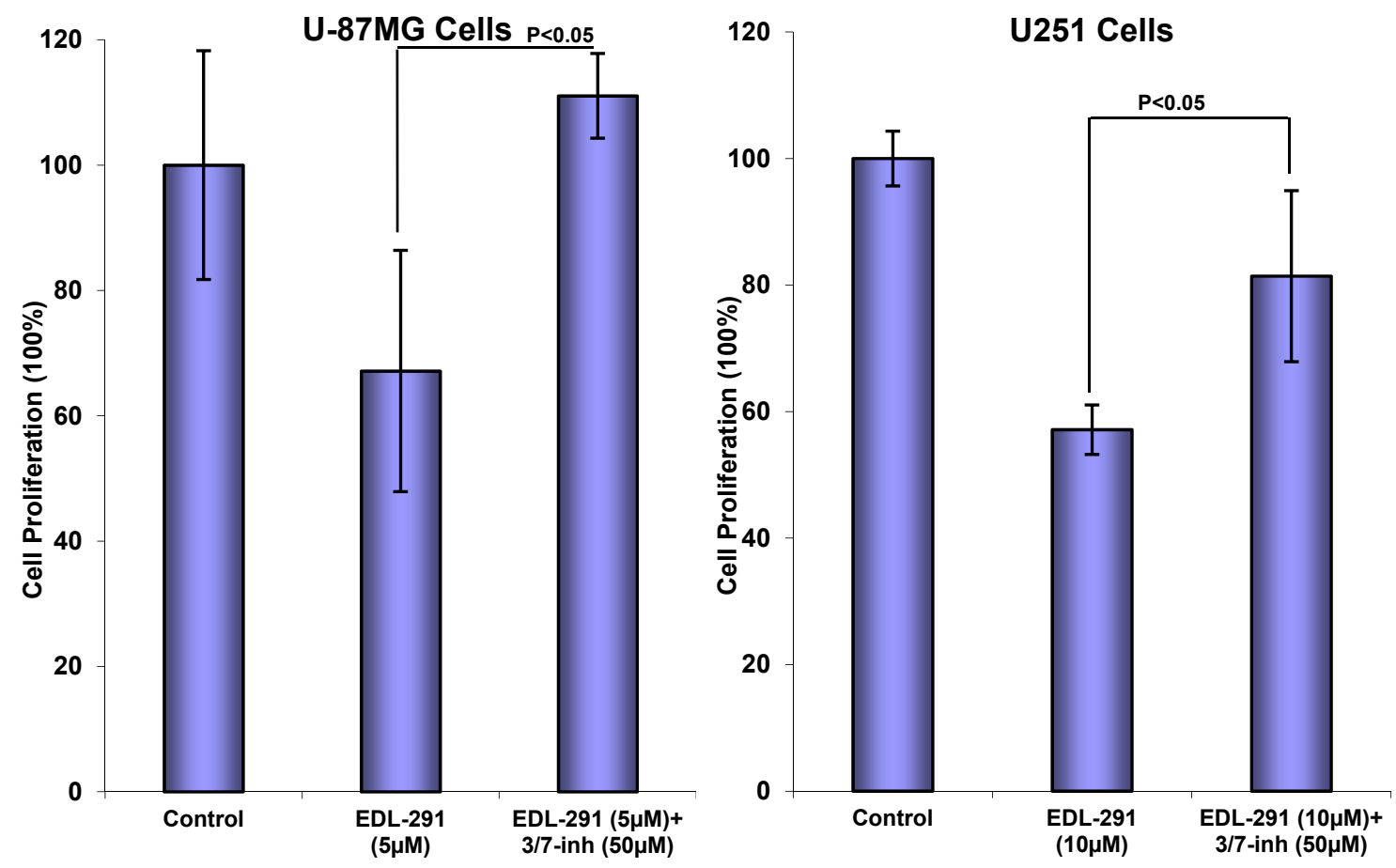

\section{(Continued)}




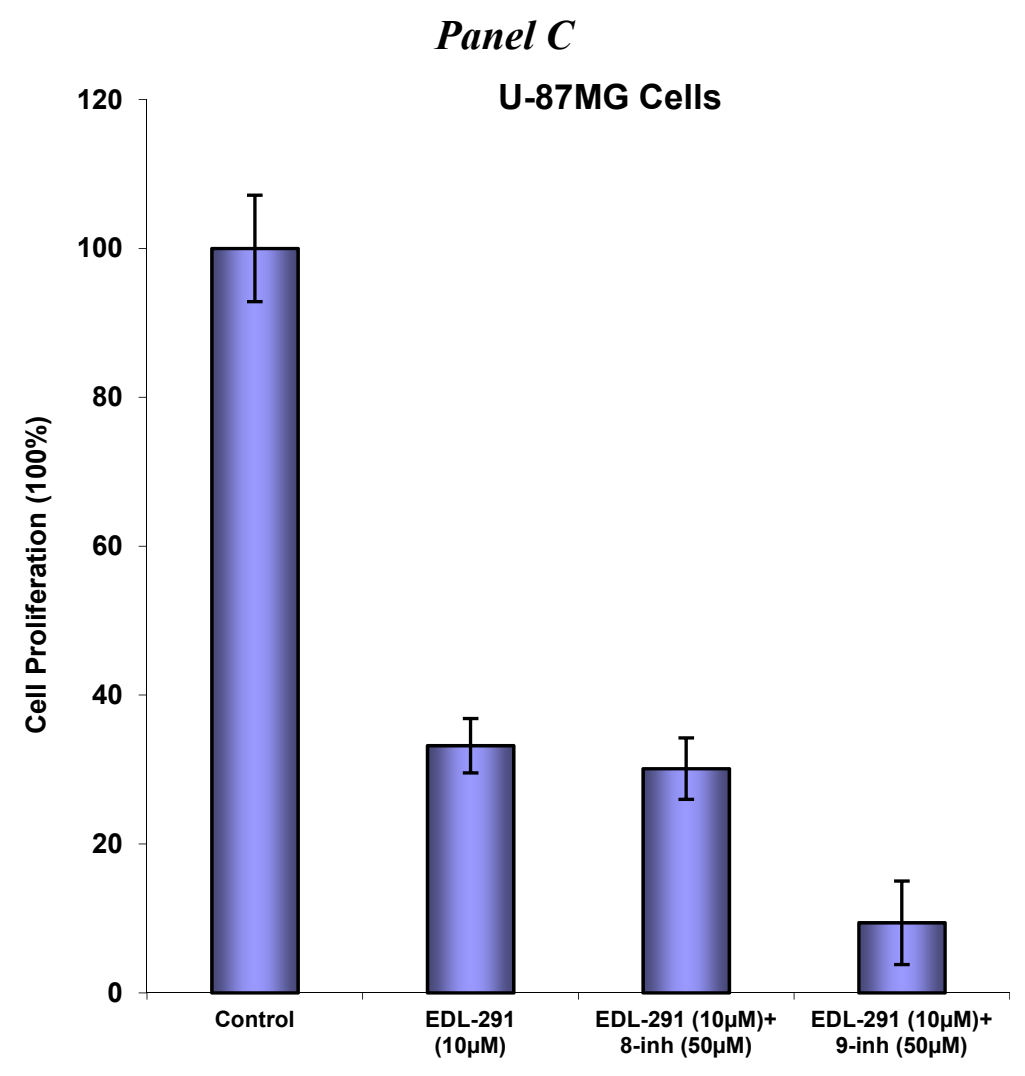

Figure 4-1. (Continued) 

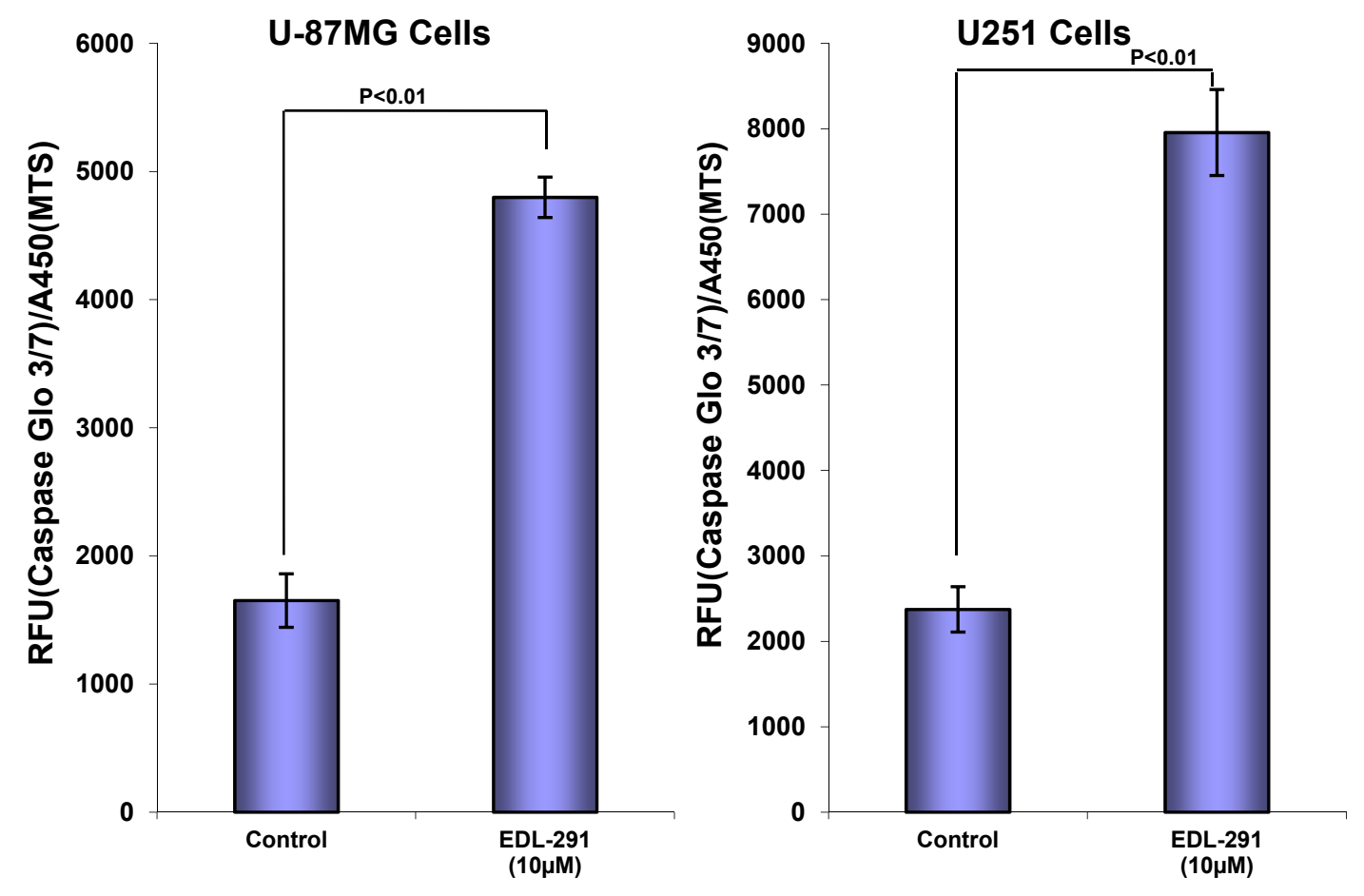

Figure 4-2. EDL-291 can increase caspase-3/7 activity in human glioblastoma cells

U-87MG and U251 human glioma cells treated by $10 \mu \mathrm{M}$ EDL-291 for $60 \mathrm{hr}$ were subjected to caspase-3/7 activity assay using Promega Caspase-Glo 3/7 kit. The data shown here are representative results of 3 independent experiments. The error bars are standard deviation of 3 replicates under the same treatment condition. 

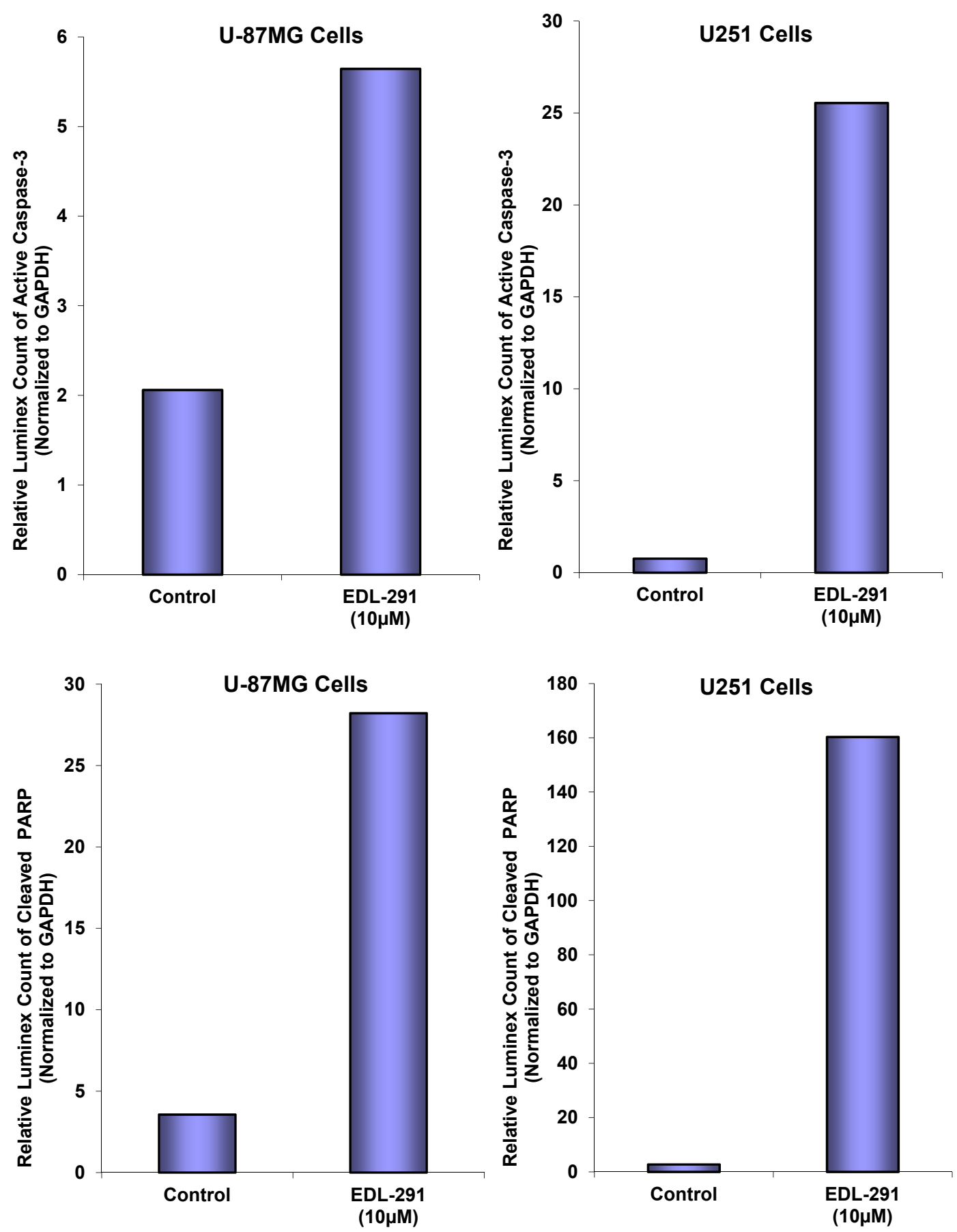

Figure 4-3. Increase of activated caspase-3 and its product, cleaved poly (ADP-ribose) polymerase (PARP) after EDL-291 treatment as measured by Luminex multiplex immunoassay

U-87MG and U251 human glioma cells were treated by EDL-291 for $72 \mathrm{hr}$. The cell lysate was analyzed using Millipore Human Apoptosis 3-Plex kit and Luminex 200 instrument. 


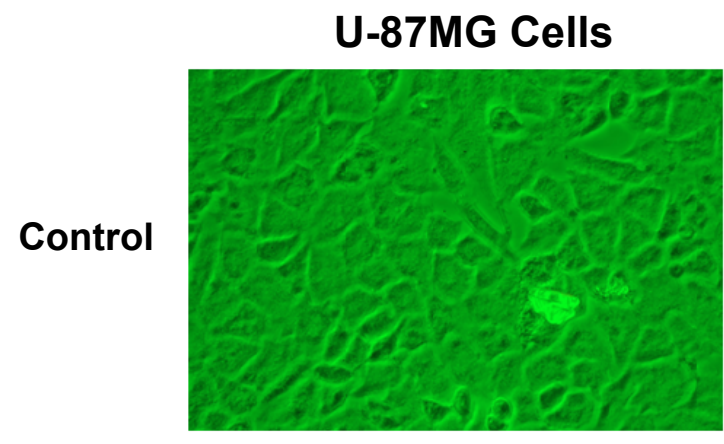

U251 Cells

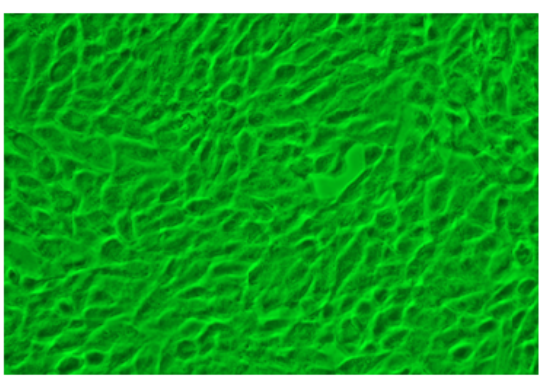

EDL-291

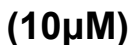
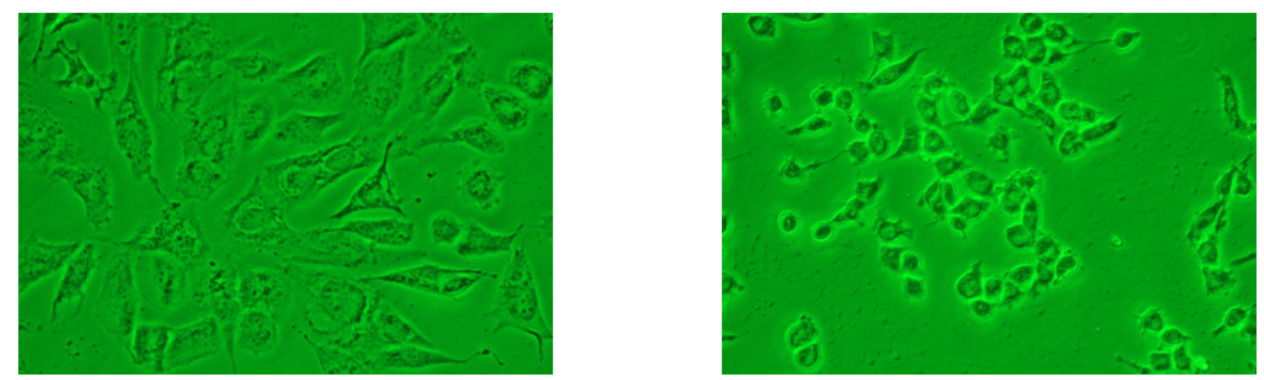

Figure 4-4. Cell morphology checked by phase contrast microscopy

U-87MG and U251 human glioma cells treated by $10 \mu \mathrm{M}$ EDL-291 for $60 \mathrm{hr}$ were pictured under a phase contrast microscope. 

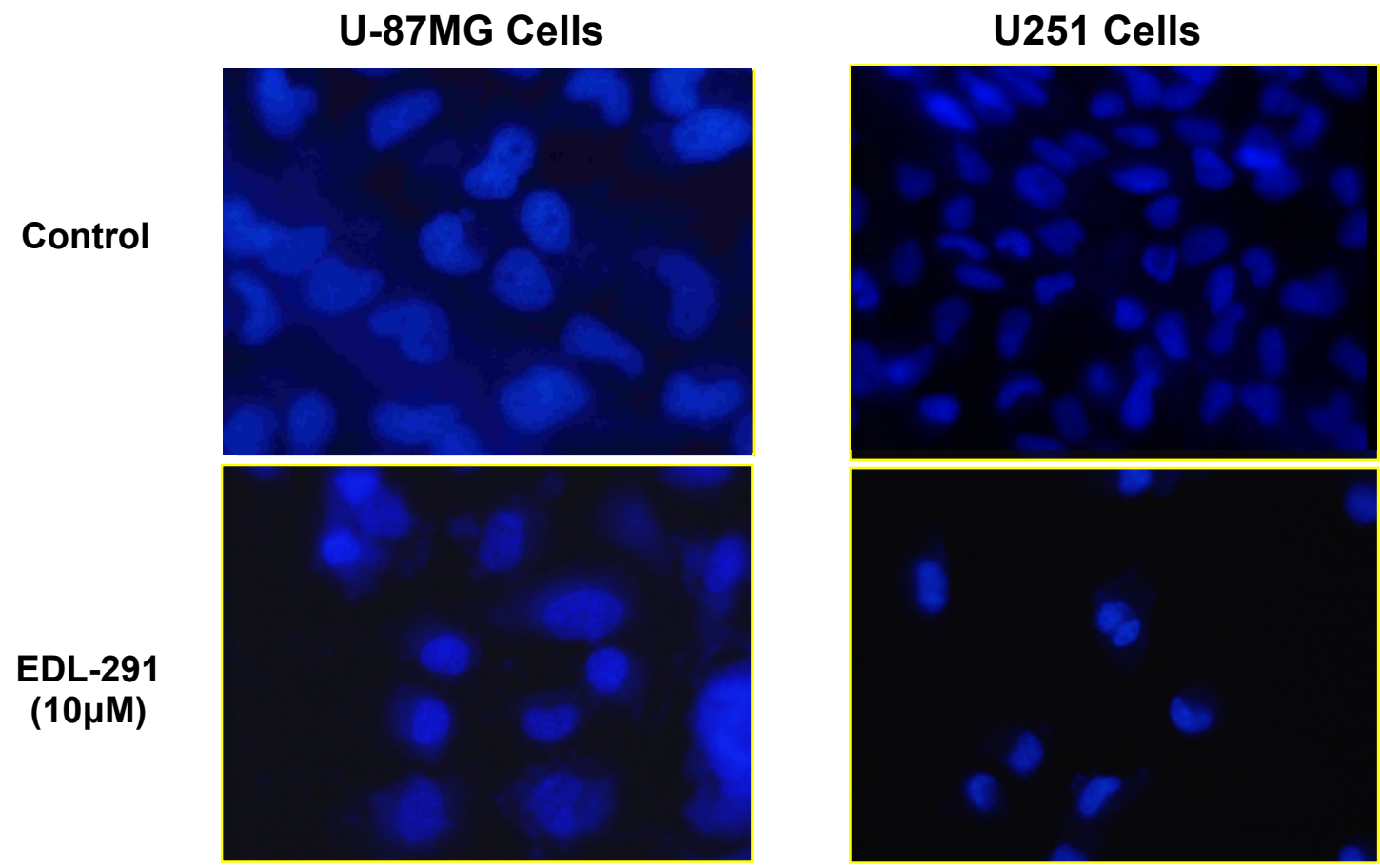

Figure 4-5. Nucleus morphology checked by florescent microscopy after Hoescht staining

U-87MG and U251 human glioma cells treated by $10 \mu \mathrm{M}$ EDL-291 for $60 \mathrm{hr}$ were stained with Hoechst 33342 and pictured under Eclipse 80i fluorescence microscope. 


\subsubsection{DNA fragmentation}

Increase of DNA fragmentation was found in U251 cells after $60 \mathrm{hr}$ EDL-291 treatment as indicated by the TUNEL result, while change of DNA fragmentation in $\mathrm{U}-87 \mathrm{MG}$ cells under same condition is minor (Figure 4-6).

\subsubsection{Effect of MPT inhibitors}

As shown in Figure 4-7, the antiproliferative effect of EDL-291 can be enhanced rather than reversed by MPT inhibitor dUb. The caspase-3/7 activation after EDL-291 treatment also can be enhanced by dUb.

\subsection{Discussion}

Since antigloma activity of the EDL series of compounds was an unexpected output in a HCV drug screening project [72]. Efforts were made by molecular docking and various ligand binding assays to "fish" the putative molecular target directly but with no success. Therefore, a less ambitious approach was taken, which was to first investigate their effect of EDL series of compounds on cell death pathways. A preliminary evaluation of the effect of EDL-291 on human glioma cell apoptosis machinery was performed in our laboratory.

The investigation was begun with caspase inhibitor assay. The pan caspase inhibitor can significantly reverse the effect of EDL-291 on both U-87MG and U251 human glioma cell lines, which indicates that caspases contribute to the effect of EDL-291. Since pan caspase inhibitor also can also inhibit caspases not related to apoptosis, a further assay with a specific inhibitor of apoptosis effector caspases-3/7 was performed, and then followed by direct measurement of caspases-3/7 activity by luminogenic substrate. The results confirmed activation of these effector caspases and their involvement in the antiproliferative effect of EDL-291. An additional Luminex assay also supported this finding.

Caspases-3/7 activation is a biochemical hallmark of apoptosis [115]. Cell and nucleus morphology, as well as DNA fragmentation, were evaluated after $60 \mathrm{hr}$ of EDL-291 treatment, the same time point used in the caspases-3/7 activity assays. However, no morphology change of cell or nucleus was found, and the increase of DNA fragmentation was minor in U-87MG. The explanation could be that there is some time delay between caspase activation and those downstream events.

As described in 1.3.3.1., effector caspases activation is catalyzed by initiator caspases. Caspase- 8 and -9 are the initiator caspases for the extrinsic and intrinsic pathways of apoptosis, respectively (Figure 4-8). Thus specific caspase-8 and -9 inhibitors assay was performed to identify the route of apoptosis. But none of these inhibitors could reverse the effect of EDL-291 under the condition used. 

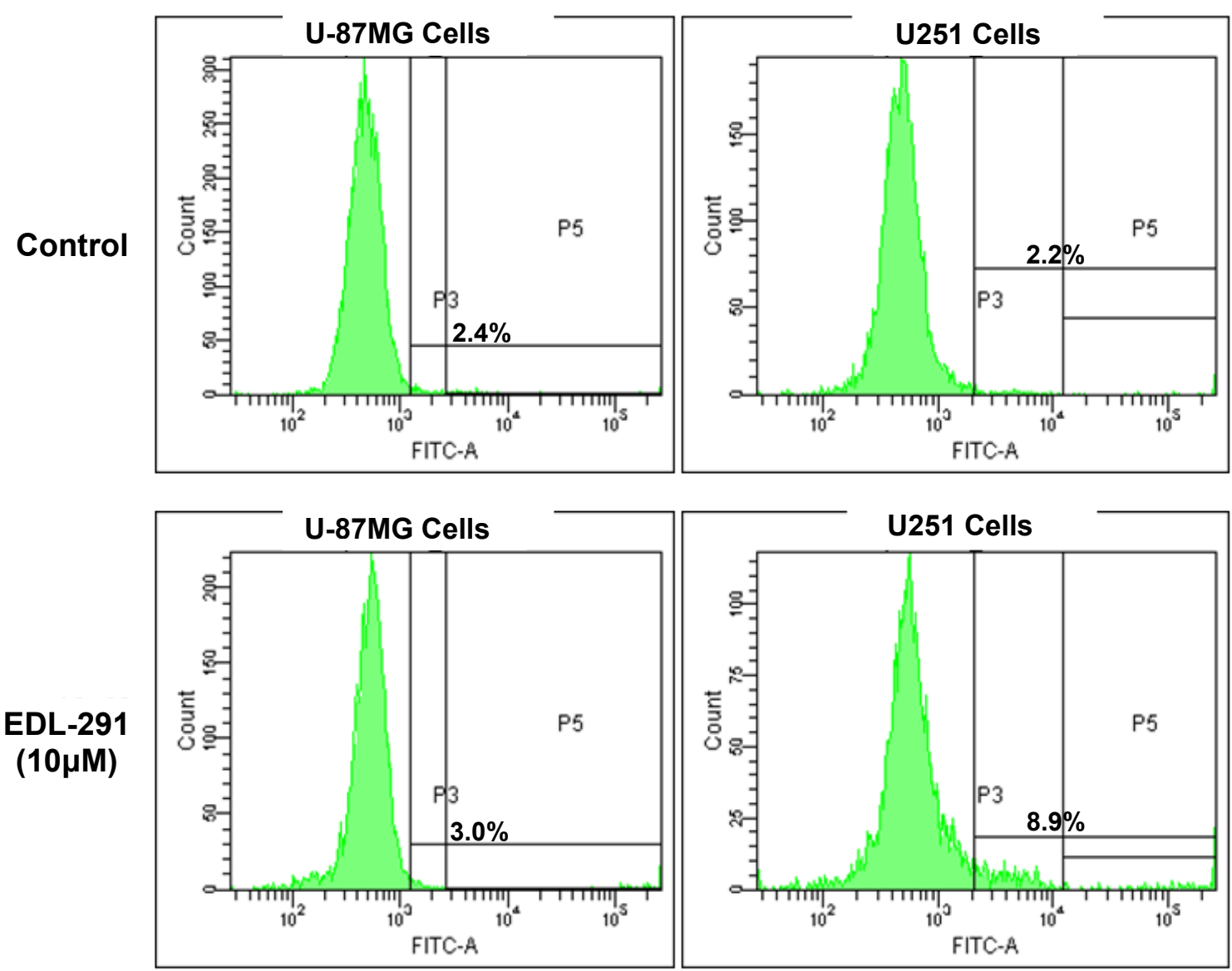

Figure 4-6. DNA fragmentation assay results from flow cytometric TUNEL

U-87MG or U251 cells treated by $10 \mu \mathrm{M}$ EDL-291 for $60 \mathrm{hr}$ were labeled by Br-dUTP, then stained with FITC-conjugated BrdU antibody. X-axis is the cell count and Y-axis is the intensity of FITC fluorescence $(520 \mathrm{~nm})$ that is proportional to amount of Br-dUTP incorporation. The apoptotic cells incorporate more Br-dUTP because of existence of abundant 3'-OH DNA ends. As shown in the figure, the percentages of apoptotic cells are quantified as percentages of cells at the right side of P3 gate. The main peaks correspond to the non-apoptotic cell population. The samples were measured by BD LSR II flow cytometer using $488 \mathrm{~nm}$ laser, and the data was processed by FACSDiva software. 

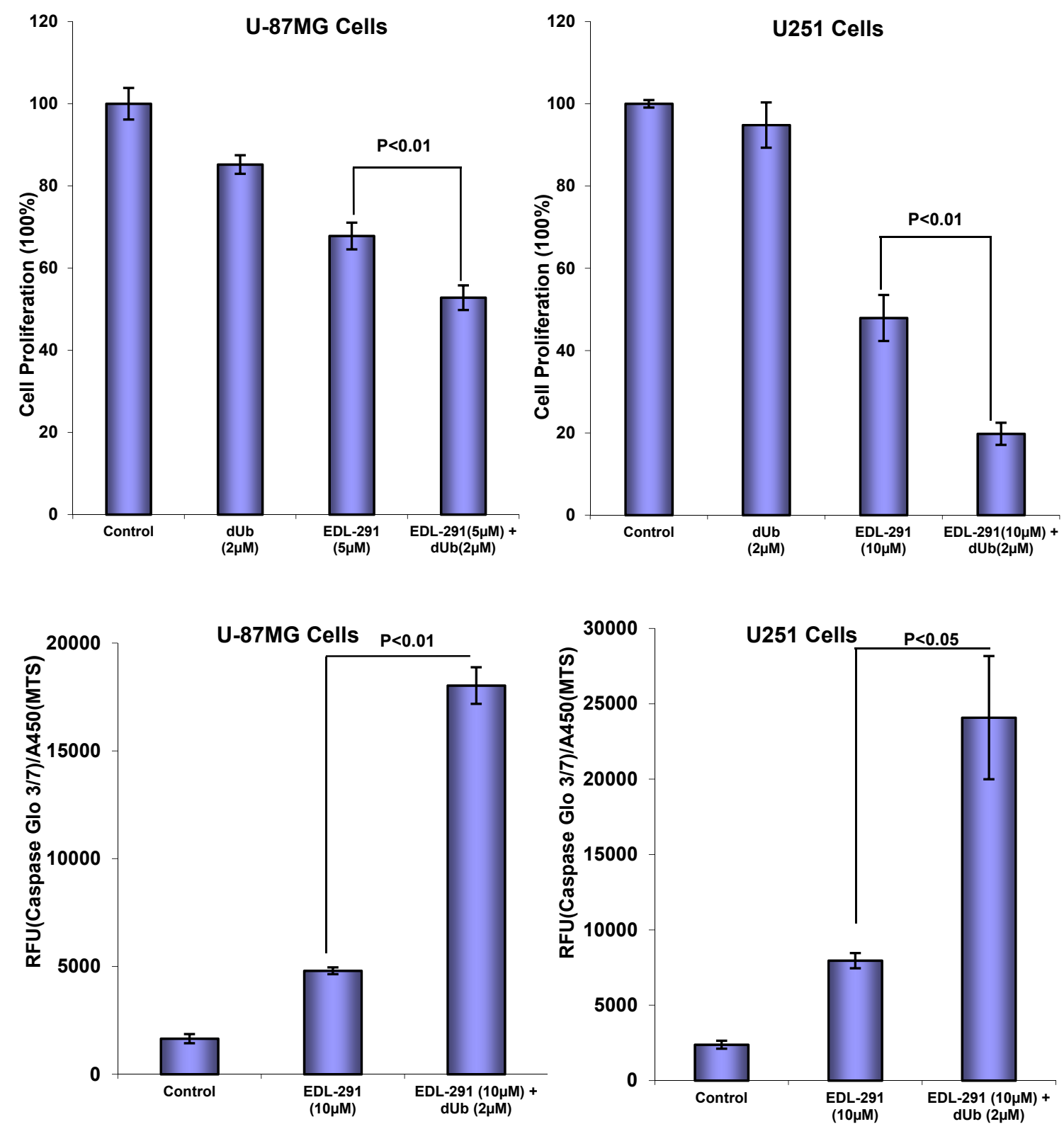

Figure 4-7. Antiproliferative effect of EDL-291 and caspase 3/7 activation can be enhanced, rather than reversed by decylubiquinone (dUb)

Upper panel: U-87MG and U251 human glioma cells were treated by EDL-291 with or without $2 \mu \mathrm{M} \mathrm{dUb}$ for $96 \mathrm{hr}$. The viable cell number was measured by MTS assay using Promega CellTiter AQueous 96 kit. The reading was subtracted by media blank and then normalized by the control. Lower panel: U-87MG and U251 human glioma cells treated by EDL-291 with or without $2 \mu \mathrm{M}$ dUb for $60 \mathrm{hr}$ were subjected to caspase-3/7 activity assay using Promega Caspase-Glo 3/7 kit. The data shown here are representative results of 3 independent experiments. The error bars are standard deviation of 3 replicates under the same treatment condition. 


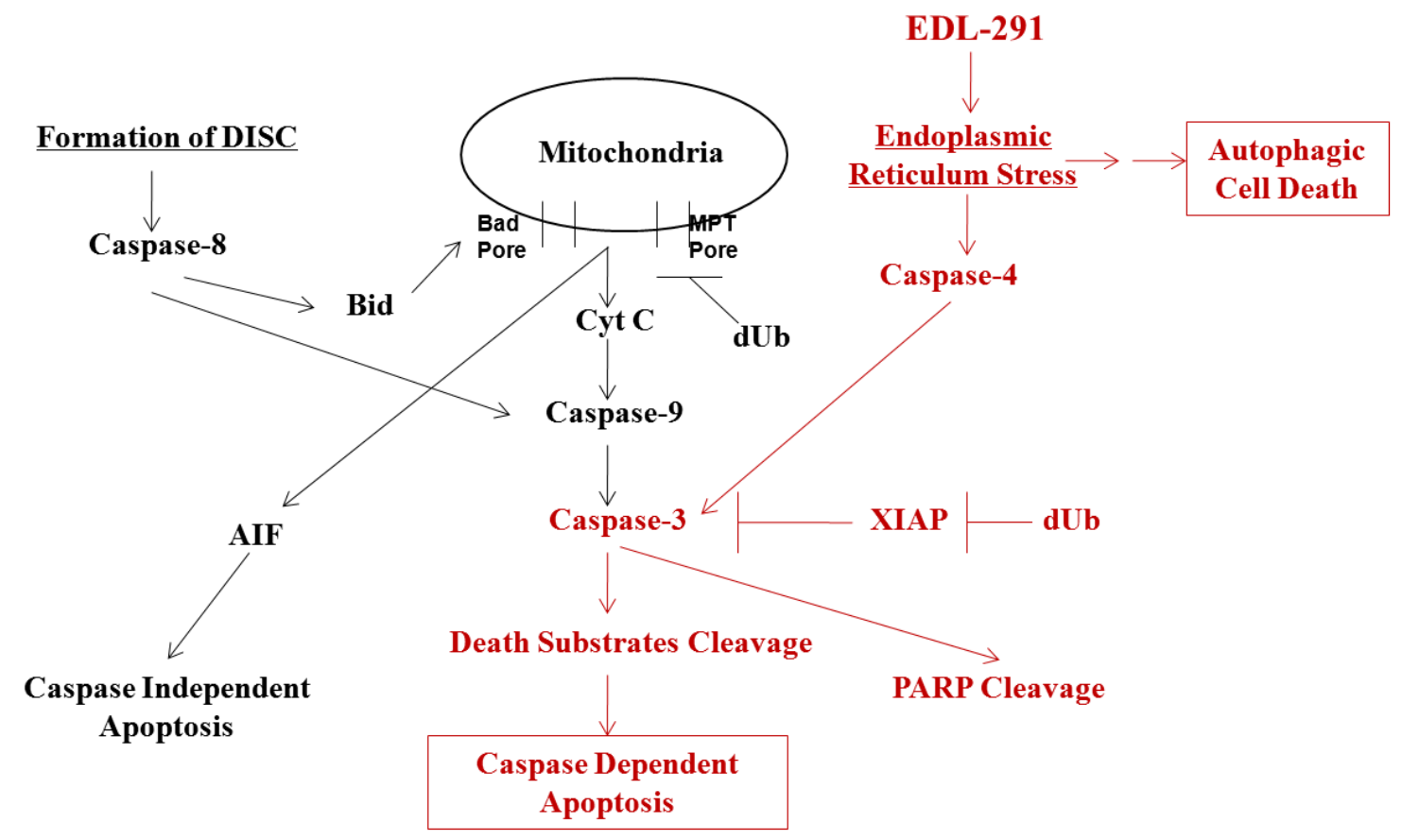

Figure 4-8. Apoptosis pathways and proposed model of EDL-291's effect in glioma cells

The extrinsic, intrinsic, caspase-independent and endoplasmic reticulum stress-induced apoptosis pathways are all shown in this figure. The proposed model of EDL-291's effect in glioma cells are shown in red color. 
Since most chemotherapeutic drugs induce apoptosis via intrinsic route $[75,76]$, and opening of mitochondrial permeability transition (MPT) pore could be an upstream event in this route [116], the MPT pore inhibitor decylubiquinone (dUb) was used to investigate if MPT is involved in the effect of EDL-291. This led to a surprising finding: dUb enhances, instead of reverses, EDL-291's effect on human glioma cells. Further evaluation by effector caspase activity assay suggests that this effect is related to enhancement of caspase-3/7 activation.

A recent publication about antiglioma activity of XIAP inhibitor embelin provides a potential explanation of this finding [117]. Chemical structure of dUb is similar with that of embelin (Figure 4-9). Therefore, dUb may also be a XIAP inhibitor and is capable of de-inhibiting caspases. Further investigation by ligand binding assay is necessary to test this hypothesis.

The upstream apoptotic pathway that leads to effector caspase-3/7 activation was not successfully identified by the caspase- $8 / 9$ inhibitor assay in this study. A direct caspase- $8 / 9$ activity assay by either luminogenic substrate or Luminex assay may be helpful to solving this problem.

It is also possible that capsase-4 (counterpart of murine caspase-12), an uncommon initiator caspase activated after ER stress [86], is responsible for the caspase-3 activation after EDL-291 treatment(Figure 4-8). When ER homeostasis is disrupted by various stimuli, unfolded proteins are accumulated in the ER, which initiate ER stress response to enhance protein folding capabilities, reduce new protein synthesis, and clear malformed proteins. But when this response is prolonged, it will lead to cell death. During ER stress, ER associated procaspase-4 was released from GRP78. The prolonged stress will also cause ER to release its calcium storage and thus increase cytosolic $\mathrm{Ca}^{2+}$ concentration. These events enable cleavage of procaspse- 4 by $\mathrm{Ca}^{2+}$ dependent cysteine proteases calpain [79, 118]. Procapase- 3 then can be activated by caspase-4 directly [87]. Multiple reports already showed that caspase-4 was activated during ER stress in malignant human glioma [79]. Examples of drugs inducing apoptosis via the ER stress pathway in glioma or other cancer cells include, sarco/endoplasmic reticulum ATPase inhibitors (celecoxib, curcumin and THAP), flavonoids, N-linked glycosylation inhibitors (tunicamycin), Golgi disruptors (brefeldin A), and proteasome inhibitors (bortezomib) [79].

There is an unusual $60 \mathrm{hr}$ time delay between beginning of EDL-291 treatment and peaking of caspase-3 activity. This delayed apoptosis has also been observed after radiation-induced mitotic catastrophe [119]. However, lack of nucleus morphology change in the Figure 4-5 indicates that mitotic catastrophe did not happen. The hypothesis that a prolonged ER stress response precedes the onset of apoptosis caused by EDL-291 can therefore also help explain that time delay.

ER stress can lead to both apoptosis and autophagy [77]. The decrease of cell density in treated wells in Figure 4-4 also suggests that other cell death pathways, such as autophagy, may already have taken place before the culmination of apoptosis, which 

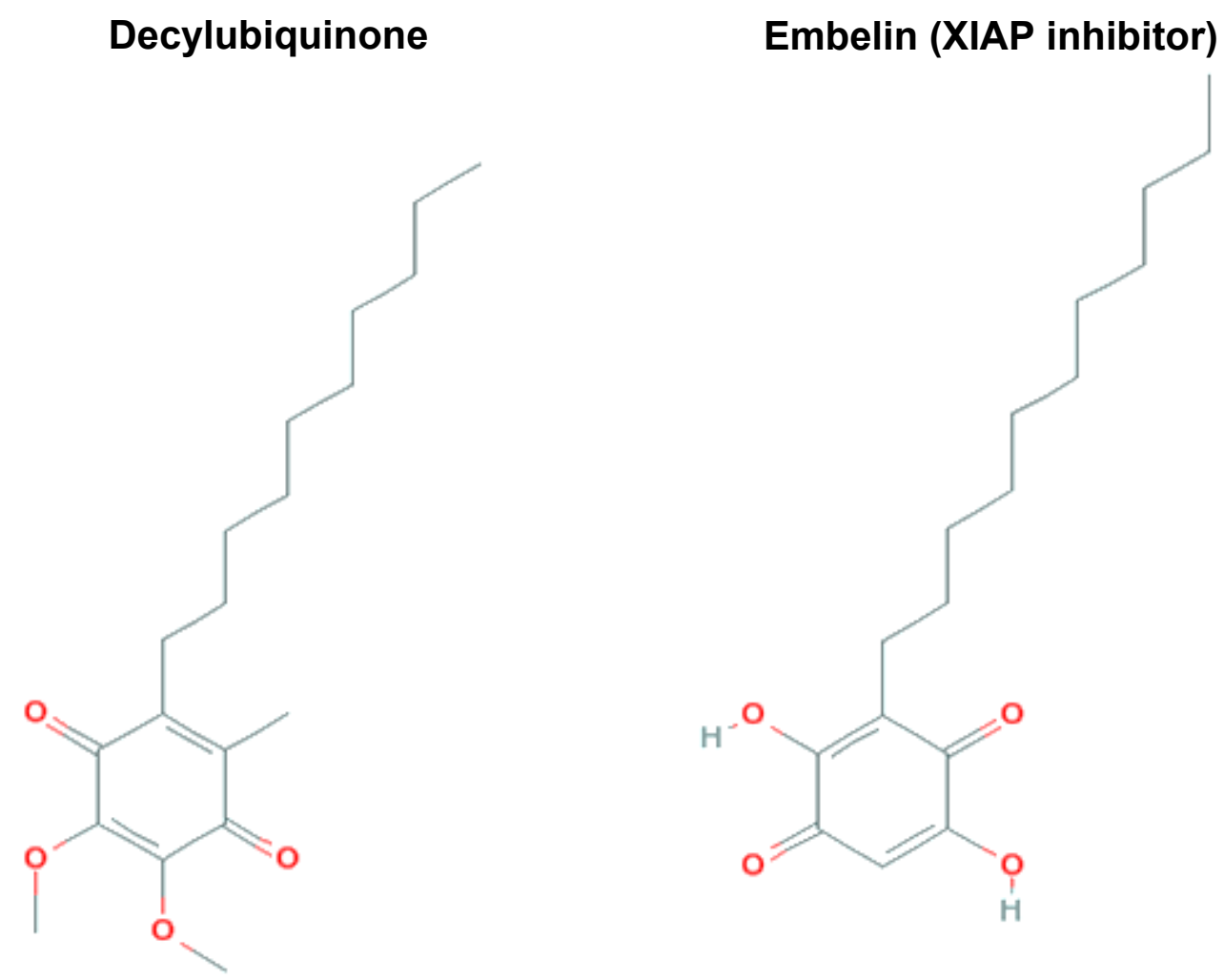

Figure 4-9. Chemical structures of decylubiquinone and embelin 
should happen after that $60 \mathrm{hr}$ caspase-3 peak time. Our collaborating laboratory has recently reported that EDL-155 can cause autophagy in Y79 retinoblastoma cells [120]. And after EDL-155 treatment, autophagosome-like double-membrane-bound large vacuoles in cytoplasm were found in rat $\mathrm{C} 6$ glioma cells but not in rat normal astrocytes [66]. As indicated by green fluorescence mitochondrial stain, the mitochondrial membranes have coalesced into those large vacuoles in EDL-155 treated C6 cells [66], suggesting mitophagy, i.e., specific autophagic elimination of mitochondria may have occurred [121]. A pilot study in our laboratory shows autophagy inhibitor 3-methyladenine can partially reverse the effect of EDL-291 on human glioma cells. Therefore, EDL-291 may cause ER stress, and the latter leads to both apoptosis and autophagic cell death. A putative model of the effect of EDL-291 as well as relevant apoptosis pathways are shown in Figure 4-7. Further investigation using ER stress inhibitor, caspase-4 inhibitor and calpain inhibitor is needed to check the validity of this model.

In order to find clue about the target of EDL series of compounds, a literature search on mechanisms of action of other isoquinoline derivatives with antiglioma activity was conducted. Tetrahydropapaveroline, the structure of which is very similar to that of EDL-155, can cause oxidative DNA damage and JNK/MAPK mediated cell death in rat C6 glioma cells [122]. However, this mechanism depends on the catechol moieties in the structure of tetrahydropapaveroline. The catechol moiety can be found in structure of EDL-155 but not in the structure of EDL-291. The fact that EDL-291 has lower EC50 than EDL-155 is apparently against this oxidative damage mechanism.

Papaverine can also inhibit growth of rat C6 glioma cells [123]. There are two possible mechanisms: increase of intracellular cAMP concentration by inhibiting phosphodiesterase (PDE) 3 and $4[124,125]$, and inhibition of mitochondria respiration [126]. Increased cAMP level is a proapoptotic signal in multiple cancer cell lines and may promote differentiation of astrocyte, while low levels of cAMP promote glioma formation in neurofibromatosis-1 (NF1) genetically engineered mice [127]. Another PDE4 inhibitor rolipram also promotes differentiation and apoptosis in A-172 human glioma cell line [128]. However, tetrahydropapaverine and tetrahydropapaveroline, structures of which closely mimic those of EDL-291 and EDL-155, respectively, have very low PDE inhibitor activity [125]. Papaverine, tetrahydropapaverine and tetrahydropapaveroline are all inhibitors of mitochondrial electron transport chain complex I $[129,130]$. In the other hand, dUb, as a substrate of complex I, can attenuated the inhibition caused by the potent complex I inhibitor rotenone [131]. Therefore, at least for EDL-291, the complex I inhibition could not be plausible mechanism, because that mechanism is contradict to the observation in this study that dUb can enhance EDL-291's effect.

Another opium derived tetrohydroisoquinoline drug noscapine has antiglioma effect both in vitro [132] and in vivo [133]. As a microtubule-interfering agent, noscapine induces mitotic catastrophe followed by apoptosis [132]. But since no multinucleated glioma cells were found after EDL-291 and EDL-155 treatment, microtubule-interfering is not a plausible mechanism of the EDL series of compounds. 
In addition, tetrahydroisoquinoline alkaloid trabectedin also has antiglioma activity in vitro [134]. Its antitumor mechanism is not fully understood. It is believed to be able to bind the minor groove of DNA through the two fused tetrahydroisoquinoline rings [135], which is absent in the structures of EDL series of antiglioma tetrahydroisoquinoline derivatives.

Many other tetrahydroisoquinolines with various mechanisms of action show activities against other types of cancer cells [136]. Tarby et al. reported a 4-phenyl-tetrahydroisoquinoline lead series has antiproliferative effect on human ovarian cancer cells. They may act as inhibitor of human mitotic kinesin Eg5 [137]. Again, the lack of multinucleated glioma cell after treatment ruled out this mitotic related mechanism as the antiglioma mechanism of the EDL compounds. A series of tetrahydroisoquinoline-based hydroxamic acid derivatives was discovered by Zhang et al. as HDAC inhibitor with in vivo antitumor potency in a human breast carcinoma xenograft model [138]. The carboxamide group is part of the pharmacophore [139], but this group is not presented in the structures of EDL-291 and EDL-155. A series of tetrahydroisoquinoline amide substituted phenyl pyrazoles are reported to be selective Bcl-2 inhibitors [140]. However, no evidence of direct interaction between EDL-291 and Bcl-2/Bcl-XL was found in a pilot study in our laboratory using Luminex and fluorescence polarization techniques.

In conclusion, EDL-291 activates caspase-3/7 and PARP cleavage. The upstream event before caspase-3 activation could be ER stress. The molecular target of EDL-291 is still unknown. As an enhancer of EDL-291 caused capase-3/7 activation, dUb could be a candidate as a companion drug of EDL-291 analogs in combination therapy of glioma. 


\section{CHAPTER 5. SUMMARY}

Malignant glioma is a relative uncommon but extremely deadly disease. Each year, more than 18,000 people are diagnosed with malignant glioma in the USA. Despite advances in brain tumor diagnosis and treatment in the last decades, patients with malignant gliomas, especially glioblastoma, still have a poor prognosis. Novel antiglioma drugs are urgently needed, as chemotherapy has been established as part of standard care for these dreadful diseases.

A novel series of tetrahydroisoquinoline derivatives with potent antiproliferative activity against human glioma cells was identified in The University of Tennessee Health Science Center by our collaborating laboratories as a result of scientific serendipity. Further investigations were performed in the effort to develop a latest addition to the current antiglioma arsenal from these compounds. Pharmacokinetics plays an important role in the current drug discovery and development paradigm. EDL-291, a result from DMPK-guided structure modification of last generation antiglioma tetrahydroisoquinoline derivative lead compound EDL-155, is the subject of preclinical pharmacokinetic characterization in this dissertation project.

In male Sprague Daley rats, after $10 \mathrm{mg} / \mathrm{kg}$ intravenous injection, total body clearance (CL) and apparent volume of distribution at steady state $\left(\mathrm{Vd}_{\mathrm{ss}}\right)$ of EDL-291 were $209 \mathrm{~mL} / \mathrm{min} / \mathrm{kg}$ (CV 23.7\%) and $32.5 \mathrm{~L} / \mathrm{kg}$ (CV 46.6\%), respectively. $1.2 \%$ of dosed EDL-291 was found in urine $\left(\mathrm{f}_{\mathrm{e}}\right)$ over the $24 \mathrm{hr}$ post-dose period. Plasma protein binding of EDL-291 at $5 \mu \mathrm{g} / \mathrm{mL}$ and $10 \mu \mathrm{g} / \mathrm{mL}$ concentration levels was $60.0 \%$ and $54.4 \%$, respectively, in the rat plasma. The bioavailability $(\mathrm{F})$ after oral gavage was $40.4 \%$, which indicates this compound is orally available.

The ratio of the EDL-291 brain area under concentration curve (AUC) to plasma AUC between 20-180 min after intravenous injection in SD rats was 14.0. The brain/plasma AUC ratio at 10 - $180 \mathrm{~min}$ after $50 \mathrm{mg} / \mathrm{kg}$ subcutaneous injection to C57BL/6J mice was estimated at 4.07. Thus EDL-291 has high brain penetration in both rats and mice. The rat plasma and brain concentration of EDL-291 can be fitted simultaneously into a three-compartment model consisting of one brain compartment and two peripheral compartments by using WinNonlin ${ }^{\circledR}$ software version 5.2.

CL of EDL-291 was 39\% lower than that of EDL-155 but was still almost 4 times higher than rat hepatic blood flow, while the small $f_{e}$ value indicates that renal CL was minimal. Three possible causes were examined to decipher this phenomenon. EDL-291 is stable in whole blood, thus metabolism or chemical degradation in blood is not a reason. EDL-291 is also not accumulated in red blood cells, thus the high CL is not an artifact caused by plasma sampling. On the other hand, this compound is susceptible to pulmonary microsomal metabolism. Considering that lungs accept total cardiac output, the major contributor to the high CL of EDL-291 is extensive lung metabolism.

EDL-323, an analog of EDL-291 with higher stability to pulmonary microsomes, 
was selected as the subject of an in vivo pharmacokinetic study. As expected, CL of EDL-323 was 38\% lower than that of EDL-291. However, a pilot study showed that the brain penetration is dramatically reduced. Thus, further structural modifications are required to achieve both reduced clearance and enhanced brain penetration.

Since antigloma activity of EDL compounds was an unexpected discovery in a $\mathrm{HCV}$ drug screening project at our collaborating groups, their mechanism of action was unknown. The last part of this dissertation is focused on a preliminary evaluation of the effect of EDL-291 on human glioma cell apoptosis machinery.

Capase 3/7 activation is one of the biochemical hallmarks of apoptosis. After EDL-291 treatment, activity of caspase-3/7 and the amount of cleaved PARP, a product of activated caspase-3, were increased in human glioma cell lines. The antiproliferative effect of EDL-291 was partially reversed by the caspase-3/7 inhibitor, which confirmed the involvement of effector caspase activation in the action of EDL-291. However, neither the inhibitor of caspase-8 (initiator caspase for extrinsic apoptosis pathway) nor the inhibitor of caspase-9 (initiator caspase for intrinsic pathway) reversed the apoptotic effect of EDL-291. Therefore, the initiator caspase could be caspase-4, the initiator caspase for the newly discovered endoplasmic reticulum (ER) stress-induced apoptosis pathway.

Surprisingly, the antiproliferative effect of EDL-291 can be enhanced, rather than reversed, by mitochondrial permeability transition (MPT) inhibitor decylubiquinone (dUb). The caspase-3/7 activation after EDL-291 treatment also can be enhanced by dUb. $\mathrm{dUb}$ shares structure similarity to X-linked inhibitor of apoptosis protein (XIAP) inhibitor embelin; thus, it may also inhibit XIAP and de-inhibit caspases. Therefore, dUb could be a candidate companion drug of EDL-291 analogs in treating glioma, which provides a potential direction for building a mechanism-based combination chemotherapy strategy. 


\section{LIST OF REFERENCES}

1. Ferlay J, et al., GLOBOCAN 2008 v2.0, cancer incidence and mortality worldwide: IARC CancerBase No. 10 [Internet]. Lyon (France): International Agency for Research on Cancer, 2010. Available from: http://globocan.iarc.fr [accessed Janary 1, 2012].

2. Howlader N, et al., SEER cancer statistics review, 1975-2008 [Internet]. Bethesda (MD): National Cancer Institute (US), 2011. Available from: http://seer.cancer.gov/csr/1975_2008/ [accessed Janary 1, 2012].

3. CBTRUS, CBTRUS statistical report: primary brain and central nervous system tumors diagnosed in the United States in 2004-2008 [Internet]. Hinsdale (IL): Central Brain Tumor Registry of the United States. Available from: http://www.cbtrus.org/reports/reports.html [accessed March 12, 2012].

4. Van Meir EG, et al., Exciting new advances in neuro-oncology: the avenue to a cure for malignant glioma. CA Cancer J Clin, 2010. 60(3): p. 166-193.

5. Sathornsumetee S, et al., Molecularly targeted therapy for malignant glioma. Cancer, 2007. 110(1): p. 13-24.

6. Ohgaki H, Epidemiology of brain tumors. Methods Mol Biol, 2009. 472: p. 323-342.

7. Bondy ML, et al., Brain tumor epidemiology: consensus from the Brain Tumor Epidemiology Consortium. Cancer, 2008. 113(S7): p. 1953-1968.

8. Kohler BA, et al., Annual report to the nation on the status of cancer, 1975-2007, featuring tumors of the brain and other nervous system. J Natl Cancer Inst, 2011. 103(9): p. 714-736.

9. Salvati M, et al., Radiation-induced gliomas: report of 10 cases and review of the literature. Surg Neurol, 2003. 60(1): p. 60-67.

10. Lu-Emerson C, et al., Epidemiology and risk factors, In Primary central nervous system tumors: Pathogenesis and Therapy, Norden MD, et al., editors, Springer: New York. 2011. p. 4-13.

11. Neglia JP, et al., New primary neoplasms of the central nervous system in survivors of childhood cancer: a report from the childhood cancer survivor study. J Natl Cancer Inst, 2006. 98(21): p. 1528-1537.

12. Ron E, et al., Tumors of the brain and nervous system after radiotherapy in Childhood. N Engl J Med, 1988. 319(16): p. 1033-1039. 
13. Preston DL, et al., Tumors of the nervous system and pituitary gland associated with atomic bomb radiation exposure. J Natl Cancer Inst, 2002. 94(20): p. 1555-1563.

14. Baan R, et al., Carcinogenicity of radiofrequency electromagnetic fields. Lancet Oncol, 2011. 12(7): p. 624-626.

15. The INTERPHONE Study Group, Brain tumour risk in relation to mobile telephone use: results of the INTERPHONE international case-control study. Int J Epidemiol, 2010. 39(3): p. 675-694.

16. Brandes AA, et al., Glioblastoma in adults. Crit Rev Oncol Hematol, 2008. 67(2): p. 139-152.

17. Chen W, Clinical applications of PET in brain tumors. J Nucl Med, 2007. 48(9): p. 1468-1481.

18. Stummer W, et al., Fluorescence-guided surgery with 5-aminolevulinic acid for resection of malignant glioma: a randomised controlled multicentre phase III trial. Lancet Oncol, 2006. 7(5): p. 392-401.

19. Cappabianca, P., et al., Application of neuroendoscopy to intraventricular lesions. Neurosurgery, 2008. 62(Suppl 2): p. 575-597.

20. Adamson C, et al., Glioblastoma multiforme: a review of where we have been and where we are going. Expert Opin Investig Drugs, 2009. 18(8): p. 1061-1083.

21. Ashby LS, et al., Management of malignant glioma: steady progress with multimodal approaches. Neurosurg Focus, 2006. 20(4): p. E3.

22. Laperriere $\mathrm{N}$, et al., Radiotherapy for newly diagnosed malignant glioma in adults: a systematic review. Radiother Oncol, 2002. 64(3): p. 259-273.

23. Cohen MH, et al., FDA drug approval summary: bevacizumab (Avastin $\AA)$ as treatment of recurrent glioblastoma multiforme. Oncologist, 2009. 14(11): p. 1131-1138.

24. Schor NF, Pharmacotherapy for adults with tumors of the central nervous system. Pharmacol Ther, 2009. 121(3): p. 253-264.

25. Donawho CK, et al., ABT-888, an orally active poly(ADP-ribose) polymerase inhibitor that potentiates DNA-damaging agents in preclinical tumor models. Clin Cancer Res, 2007. 13(9): p. 2728-2737.

26. Yamanaka R, et al., Molecularly targeted therapies for glioma. Ann Neurol, 2009. 66(6): p. 717-729. 
27. Kanu OO, et al., Glioblastoma multiforme: a review of therapeutic targets. Expert Opin Ther Targets, 2009. 13(6): p. 701-718.

28. Thaker NG, et al., Molecularly targeted therapies for malignant glioma: rationale for combinatorial strategies. Expert Rev Neurother, 2009. 9(12): p. 1815-1836.

29. Beal K, et al., Antiangiogenic agents in the treatment of recurrent or newly diagnosed glioblastoma: Analysis of single-agent and combined modality approaches. Radiat Oncol, 2011. 6(1): p. 2.

30. Chamberlain MC, Bevacizumab for the treatment of recurrent glioblastoma. Clin Med Insights Oncol, 2011. 5: p. 117-129.

31. Chamberlain MC, Emerging clinical principles on the use of bevacizumab for the treatment of malignant gliomas. Cancer, 2010. 116(17): p. 3988-3999.

32. Vredenburgh JJ, et al., Experience with irinotecan for the treatment of malignant glioma. Neuro Oncol, 2009. 11(1): p. 80-91.

33. Easaw JC, et al., Canadian recommendations for the treatment of recurrent or progressive glioblastoma multiforme. Curr Oncol. 2011.18(3): p. e126-e136.

34. Olson JJ, et al., Management of newly diagnosed glioblastoma: guidelines development, value and application. J Neurooncol, 2009. 93(1): p. 1-23.

35. DiMasi JA, et al., The cost of biopharmaceutical R\&D: is biotech different? Managerial Dec. Econ., 2007. 28(4-5): p. 469-479.

36. DiMasi JA, et al., Trends in risks associated with new drug development: success rates for investigational drugs. Clin Pharmacol Ther, 2010. 87(3): p. 272-277.

37. Kennedy T, Managing the drug discovery/development interface. Drug Discov Today, 1997. 2(10): p. 436-444.

38. Kola I, et al., Can the pharmaceutical industry reduce attrition rates? Nat Rev Drug Discov, 2004. 3(8): p. 711-715.

39. Pardridge WM, The blood-brain barrier: bottleneck in brain drug development. NeuroRx, 2005. 2(1): p. 3-14.

40. Abbott NJ, et al., Structure and function of the blood-brain barrier. Neurobiol Dis, 2010. 37(1): p. 13-25.

41. Jeffrey P, et al., Assessment of the blood-brain barrier in CNS drug discovery. Neurobiol Dis, 2010. 37(1): p. 33-37.

42. Urquhart BL, et al., Blood-brain barrier transporters and response to CNS-active drugs. Eur J Clin Pharmacol, 2009. 65(11): p. 1063-1070. 
43. Gabathuler R, Approaches to transport therapeutic drugs across the blood-brain barrier to treat brain diseases. Neurobiol Dis, 2010. 37(1): p. 48-57.

44. Herve F, et al., CNS delivery via adsorptive transcytosis. AAPS J, 2008. 10(3): p. 455-472.

45. Vajkoczy P, et al., Vascular microenvironment in gliomas. Cancer Treat Res, 2004. 117: p. 249-262.

46. Laquintana V, et al., New strategies to deliver anticancer drugs to brain tumors. Expert Opin Drug Deliv, 2009. 6(10): p. 1017-1032.

47. Sarin H, Recent progress towards development of effective systemic chemotherapy for the treatment of malignant brain tumors. J Transl Med, 2009. 7(9): p. 77.

48. Stukel JM, et al., Targeted drug delivery for treatment and imaging of glioblastoma multiforme. Expert Opin Drug Deliv, 2009. 6(7): p. 705-718.

49. Beduneau A, et al., Active targeting of brain tumors using nanocarriers. Biomaterials, 2007. 28(33): p. 4947-4967.

50. Black KL, et al., Modulation of brain tumor capillaries for enhanced drug delivery selectively to brain tumor. Cancer Control, 2004. 11(3): p. 165-173.

51. Geoff W, Ayub Khan Ommaya. Lancet, 2008. 372(9649): p. 1540.

52. Bidros DS, et al., Novel drug delivery strategies in neuro-oncology. Neurotherapeutics, 2009. 6(3): p. 539-546.

53. Badruddoja MA, et al., Improving the delivery of therapeutic agents to CNS neoplasms: a clinical review. Front Biosci, 2006. 11: p. 1466-1478.

54. Dauchy S, et al., ABC transporters, cytochromes P450 and their main transcription factors: expression at the human blood-brain barrier. J Neurochem, 2008. 107(6): p. 1518-1528.

55. Batrakova EV, et al., Pluronic block copolymers: evolution of drug delivery concept from inert nanocarriers to biological response modifiers. J Control Release, 2008. 130(2): p. 98-106.

56. Tsuji A, Small molecular drug transfer across the blood-brain barrier via carrier-mediated transport systems. NeuroRx, 2005. 2(1): p. 54-62.

57. Blasi P, et al., Solid lipid nanoparticles for targeted brain drug delivery. Adv Drug Deliv Rev, 2007. 59(6): p. 454-477.

58. Kreuter J, Nanoparticulate systems for brain delivery of drugs. Adv Drug Deliv Rev, 2001. 47(1): p. 65-81. 
59. Takada Y, et al., Rapid high-affinity transport of a chemotherapeutic amino acid across the blood-brain barrier. Cancer Res, 1992. 52(8): p. 2191-2196.

60. Mehdipour AR, et al., Brain drug targeting: a computational approach for overcoming blood-brain barrier. Drug Discov Today, 2009. 14(21-22): p. 1030-1036.

61. Pajouhesh H, et al., Medicinal chemical properties of successful central nervous system drugs. NeuroRx, 2005. 2(4): p. 541-553.

62. Mandula $\mathrm{H}$, et al., Role of site-specific binding to plasma albumin in drug availability to brain. J Pharmacol Exp Ther, 2006. 317(2): p. 667-675.

63. Song P, Pharmacokinetic studies for drug developability assessment of novel isoquinoline derivatives targeting gliomas [dissertation]. Memphis (TN): University of Tennessee; 2005.136 p.

64. Mohler ML, et al., Discovery of antiglioma activity of biaryl 1,2,3,4-tetrahydroisoquinoline derivatives and conformationally flexible analogues. J Med Chem, 2006. 49(19): p. 5845-5848.

65. Song $\mathrm{P}$, et al., Plasma and cerebrospinal fluid pharmacokinetics of the novel tetrahydroisoquinoline EDL-155 in rats. Cancer Chemother Pharmacol, 2008. 61(6): p. 1037-1044.

66. Kang GS, et al., Effects, in an in-vivo model system, of 1,2,3,4-tetrahydroisoquinoline on glioma. Anticancer Drugs, 2008. 19(9): p. 859-870.

67. Hart CP, Finding the target after screening the phenotype. Drug Discov Today, 2005. 10(7): p. 513-519.

68. Ross-Macdonald P, Drug discovery without a molecular target: the road less traveled. Expert Rev Mol Diagn, 2007. 7(1): p. 1-4.

69. Butcher EC, Can cell systems biology rescue drug discovery? Nat Rev Drug Discov, 2005. 4(6): p. 461-467.

70. Williams M, Productivity shortfalls in drug discovery: contributions from qualititative, consensus- dependent, technology-driven preclinical science? J Pharmacol Exp Ther, 2011.336(1): p. 3-8.

71. Terstappen GC, et al., Target deconvolution strategies in drug discovery. Nat Rev Drug Discov, 2007. 6(11): p. 891-903.

72. Shepard S, Spotlight on Memphis. NWA WorldTraveler, 2007. 2007(8): p. 111-112. 
73. Wagner CE, et al., Synthesis of 1-boraadamantaneamine derivatives with selective astrocyte vs C6 glioma antiproliferative activity. A novel class of anti-hepatitis C agents with potential to bind CD81. J Med Chem, 2003. 46(14): p. 2823-2833.

74. de Bruin EC, et al., Apoptosis and non-apoptotic deaths in cancer development and treatment response. Cancer Treat Rev, 2008. 34(8): p. 737-749.

75. Ricci MS, et al., Chemotherapeutic approaches for targeting cell death pathways. Oncologist, 2006. 11(4): p. 342-357.

76. Tan ML, et al., Programmed cell death pathways and current antitumor targets. Pharm Res, 2009. 26(7): p. 1547-60.

77. Heath-Engel HM, et al., The endoplasmic reticulum in apoptosis and autophagy: role of the BCL-2 protein family. Oncogene, 2008. 27(50): p. 6419-6433.

78. Verfaillie T, et al., Targeting ER stress induced apoptosis and inflammation in cancer. Cancer Lett [internet], 2010. Available from: http://dx.doi.org/10.1016/ j.canlet.2010.07.016 [accessed March 14, 2012].

79. Johnson GG, et al., Stressed to death: targeting endoplasmic reticulum stress response induced apoptosis in gliomas. Curr Pharm Des, 2011. 17(3): p. 284-292.

80. Healy SJ, et al., Targeting the endoplasmic reticulum-stress response as an anticancer strategy. Eur J Pharmacol, 2009. 625(1-3): p. 234-246.

81. Kardosh A, et al., Aggravated endoplasmic reticulum stress as a basis for enhanced glioblastoma cell killing by bortezomib in combination with celecoxib or its non-coxib analogue, 2,5-dimethyl-celecoxib. Cancer Res, 2008. 68(3): p. 843-851.

82. Kim I, et al., Cell death and endoplasmic reticulum stress: disease relevance and therapeutic opportunities. Nat Rev Drug Discov, 2008. 7(12): p. 1013-1030.

83. Szegezdi E, et al., Mediators of endoplasmic reticulum stress-induced apoptosis. EMBO Rep, 2006. 7(9): p. 880-885.

84. Wlodkowic D, et al., ER-Golgi network--a future target for anti-cancer therapy. Leuk Res, 2009. 33(11): p. 1440-1447.

85. Hitomi J, et al., Apoptosis induced by endoplasmic reticulum stress depends on activation of caspase-3 via caspase-12. Neuroscience Letters, 2004. 357(2): $\mathrm{p}$. 127-130.

86. Hitomi J, et al., Involvement of caspase-4 in endoplasmic reticulum stress-induced apoptosis and AB-induced cell death. The Journal of Cell Biology, 2004. 165(3): p. 347-356. 
87. Kamada S, et al., Involvement of caspase-4(-like) protease in Fas-mediated apoptotic pathway. Oncogene, 1997. 15(3): p. 285-290.

88. Martinet W, et al., Autophagy in disease: a double-edged sword with therapeutic potential. Clin Sci (Lond), 2009. 116(9): p. 697-712.

89. Lefranc F, et al., Proautophagic drugs: a novel means to combat apoptosis-resistant cancers, with a special emphasis on glioblastomas. Oncologist, 2007. 12(12): p. 1395-1403.

90. Aoki H, et al., Evidence that curcumin suppresses the growth of malignant gliomas in vitro and in vivo through induction of autophagy: role of Akt and extracellular signal-regulated kinase signaling pathways. Mol Pharmacol, 2007. 72(1): p. 29-39.

91. Edinger AL, et al., Death by design: apoptosis, necrosis and autophagy. Curr Opin Cell Biol, 2004. 16(6): p. 663-669.

92. Portugal J, et al., Cell death pathways in response to antitumor therapy. Tumori, 2009. 95(4): p. 409-421.

93. Vakifahmetoglu H, et al., Death through a tragedy: mitotic catastrophe. Cell Death Differ, 2008. 15(7): p. 1153-1162.

94. Collado M, et al., Senescence in tumours: evidence from mice and humans. Nat Rev Cancer, 2010. 10(1): p. 51-57.

95. Patil R, et al., inventors; Univeristy of Tennessee Research Foundation, assignee. Therapeutic tetrahydroisoquinoline-based compositions for cancer therapy. United States patent application US 2008/0146597 A1, 2008. June 19

96. Yu S, et al., A novel liquid chromatography/tandem mass spectrometry based depletion method for measuring red blood cell partitioning of pharmaceutical compounds in drug discovery. Rapid Commun Mass Spectrom, 2005. 19(2): p. 250-254.

97. Rai A, et al., Disposition of morphine in plasma and cerebrospinal fluid varies during neonatal development in pigs. J Pharm Pharmacol, 2005. 57(8): p. 981-986.

98. Tsaioun $\mathrm{K}$, et al., ADDME--avoiding drug development mistakes early: central nervous system drug discovery perspective. BMC Neurol, 2009. 9(Suppl 1): p. S1.

99. Davies B, et al., Physiological parameters in laboratory animals and humans. Pharm Res, 1993. 10(7): p. 1093-1095.

100. Boer F, Drug handling by the lungs. Br J Anaesth, 2003. 91(1): p. 50-60. 
101. Collins JM, et al., Contribution of lungs to total body clearance: linear and nonlinear effects. J Pharm Sci, 1982. 71(1): p. 66-70.

102. Upton RN, et al., Kinetic aspects of drug disposition in the lungs. Clin Exp Pharmacol Physiol, 1999. 26(5-6): p. 381-391.

103. Bernauer U, et al., Characterisation of the xenobiotic-metabolizing Cytochrome P450 expression pattern in human lung tissue by immunochemical and activity determination. Toxicol Lett, 2006. 164(3): p. 278-288.

104. Carlson GP, Critical appraisal of the expression of cytochrome P450 enzymes in human lung and evaluation of the possibility that such expression provides evidence of potential styrene tumorigenicity in humans. Toxicology, 2008. 254(1-2): p. 1-10.

105. Hukkanen J, Xenobiotic-metabolizing cytochrome P450 enzymes in human lung [dissertation]. Oulu (Finland): University of Oulu; 2001.69 p.

106. Hukkanen J, et al., Expression and regulation of xenobiotic-metabolizing cytochrome P450 (CYP) enzymes in human lung. Crit Rev Toxicol, 2002. 32(5): p. 391-411.

107. Hukkanen J, et al., Expression of xenobiotic-metabolizing enzymes in human pulmonary tissue: possible role in susceptibility for ILD. Eur Respir J, 2001. 18(Suppl 32): p. 122s-126s.

108. Zhang JY, et al., Xenobiotic-metabolizing enzymes in human lung. Curr Drug Metab, 2006. 7(8): p. 939-48.

109. Castell JV, et al., Metabolism and bioactivation of toxicants in the lung. The in vitro cellular approach. Exp Toxicol Pathol, 2005. 57 (Suppl 1): p. 189-204.

110. Cohen GM, Pulmonary metabolism of foreign compounds: its role in metabolic activation. Environ Health Perspect, 1990. 85: p. 31-41.

111. Cossum PA, Role of the red blood cell in drug metabolism. Biopharm Drug Dispos, 1988. 9(4): p. 321-336.

112. Siest $\mathrm{G}$, et al., Transcription factor and drug-metabolizing enzyme gene expression in lymphocytes from healthy human subjects. Drug Metab Dispos, 2008. 36(1): p. 182-189.

113. Hinderling PH, Red blood cells: a neglected compartment in pharmacokinetics and pharmacodynamics. Pharmacol Rev, 1997. 49(3): p. 279-295.

114. Zink WE, et al., Novel microcatheters for selective intra-arterial injection of fluid in the rat brain. AJNR Am J Neuroradiol, 2009. 30(6): p. 1190-1196. 
115. Saraste A, et al., Morphologic and biochemical hallmarks of apoptosis.

Cardiovasc Res, 2000. 45(3): p. 528-537.

116. Kroemer G, et al., Mitochondrial membrane permeabilization in cell death. Physiol Rev, 2007. 87(1): p. 99-163.

117. Siegelin MD, et al., The XIAP inhibitor embelin enhances TRAIL-mediated apoptosis in malignant glioma cells by down-regulation of the short isoform of FLIP. Neurochem Int, 2009. 55(6): p. 423-430.

118. Matsuzaki S, et al., Caspase-4 is partially cleaved by calpain via the impairment of $\mathrm{Ca}^{2+}$ homeostasis under the ER stress. Neurochem Int, 2010. 56(2): p. 352-356.

119. Firat E, et al., Delayed cell death associated with mitotic catastrophe in gamma-irradiated stem-like glioma cells. Radiat Oncol, 2011. 6(1): p. 71.

120. Nassr M, et al., Treating retinoblastoma in tissue culture and in a rat model with a novel isoquinoline derivative. Invest Ophthalmol Vis Sci, 2010. 51(7): p. 3813-3819.

121. Youle RJ, et al., Mechanisms of mitophagy. Nat Rev Mol Cell Biol, 2011. 12(1): p. 9-14.

122. Soh Y, et al., Oxidative DNA damage and glioma cell death induced by tetrahydropapaveroline. Mutat Res, 2003. 544(2-3): p. 129-142.

123. Friedman SJ, et al., Membrane-active drugs potentiate the killing of tumor cells by D-glucosamine. Proc Natl Acad Sci U S A, 1980. 77(2): p. 1172-1176.

124. Chelmicka-Schorr E, et al., C-6 Glioma growth in rats: suppression with a $\beta$-adrenergic agonist and a phosphodiesterase inhibitor. Ann Neurol, 1980. 8(4): p. 447-449.

125. Chulia $\mathrm{S}$, et al., Relationships between structure and vascular activity in a series of benzylisoquinolines. Br J Pharmacol, 1997. 122(3): p. 409-416.

126. Browning ET, et al., Papaverine, a potent inhibitor of respiration in C-6 astrocytoma cells. Mol Pharmacol, 1974. 10(1): p. 175-181.

127. Warrington NM, et al., Cyclic AMP suppression is sufficient to induce gliomagenesis in a mouse model of neurofibromatosis-1. Cancer Res, 2010. 70(14): p. 5717-5727.

128. Chen TC, et al., The type IV phosphodiesterase inhibitor rolipram induces expression inhibitors p21Cip1 and p27Kip1, resulting in growth inhibition, increased differentiation, and subsequent apoptosis of malignant A-172 glioma cells. Cancer Biol Ther, 2002. 1(3): p. 262-263. 
129. Suzuki K, et al., Inhibition of mitochondrial respiration by 1,2,3,4-tetrahydroisoquinoline-like endogenous alkaloids in mouse brain. Neurochem Res, 1990. 15(7): p. 705-710.

130. Morikawa N, et al., Effect of dopamine, dimethoxyphenylethylamine, papaverine, and related compounds on mitochondrial respiration and complex I activity. $\mathrm{J}$ Neurochem, 1996. 66(3): p. 1174-1181.

131. Telford JE, et al., Decylubiquinone increases mitochondrial function in synaptosomes. J Biol Chem, 2010. 285(12): p. 8639-8645.

132. Newcomb EW, et al., Noscapine induces apoptosis in human glioma cells by an apoptosis-inducing factor-dependent pathway. Anticancer Drugs, 2008. 19(6): p. 553-563

133. Landen JW, et al., Noscapine crosses the blood-brain barrier and inhibits glioblastoma growth. Clin Cancer Res, 2004. 10(15): p. 5187-5201.

134. Poindessous V, et al., Marked activity of irofulven toward human carcinoma cells. Clin Cancer Res, 2003. 9(7): p. 2817-2825.

135. D'Incalci M, et al., A review of trabectedin (ET-743): a unique mechanism of action. Mol Cancer Ther, 2010. 9(8): p. 2157-2163.

136. Liu CJ, et al., Bioactivity diversity and functional mechanism of tetrahydroisoquinoline alkaloids. Yao Xue Xue Bao, 2010. 45(1): p. 9-16. Chinese.

137. Tarby CM, et al., Inhibitors of human mitotic kinesin Eg5: characterization of the 4-phenyl-tetrahydroisoquinoline lead series. Bioorg Med Chem Lett, 2006. 16(8): p. 2095-2100.

138. Zhang Y, et al., Development of tetrahydroisoquinoline-based hydroxamic acid derivatives: potent histone deacetylase inhibitors with marked in vitro and in vivo antitumor activities. J Med Chem, 2011. 54(8): p. 2823-2838.

139. Zhang Y, et al., Discovery of a tetrahydroisoquinoline-based hydroxamic acid derivative $(Z Y J-34 c)$ as histone deacetylase inhibitor with potent oral antitumor activities. J Med Chem, 2011. 54(15): p. 5532-5539.

140. Porter J, et al., Tetrahydroisoquinoline amide substituted phenyl pyrazoles as selective Bcl-2 inhibitors. Bioorg Med Chem Lett, 2009. 19(1): p. 230-233. 


\section{VITA}

Fei Ma was born in China in 1977. Fei enrolled in China Pharmaceutical University in Nanjing, China, in September 1994 and received the Bachelor of Engineering degree in Biopharmaceutical Engineering. In 2001, Fei received the Master of Science degree in Biopharmaceutical Science from the same university. In 2004, he was admitted in the Department of Pharmaceutical Sciences at the University of Tennessee Health Science Center and will receive a Ph.D. degree in Pharmaceutics in May 2012. 